OPEN ACCESS

Edited by:

Daniela Tropea

Trinity College, Dublin, Ireland

Reviewed by:

Alla B. Salmina,

Krasnoyarsk State Medical University,

Russia

Gunnar Naulaers,

KU Leuven, Belgium

*Correspondence:

Lancelot J. Millar

lancelot.millar@univ.ox.ac.uk

Received: 31 October 2016 Accepted: 07 March 2017

Published: 08 May 2017

Citation:

Millar LJ, Shi L,

Hoerder-Suabedissen A and Molnár Z (2017) Neonatal Hypoxia Ischaemia: Mechanisms, Models, and Therapeutic Challenges. Front. Cell. Neurosci. 11:78. doi: 10.3389/fncel.2017.00078

\section{Neonatal Hypoxia Ischaemia: Mechanisms, Models, and Therapeutic Challenges}

\author{
Lancelot J. Millar ${ }^{1 *}$, Lei Shi ${ }^{1,2}$, Anna Hoerder-Suabedissen ${ }^{1}$ and Zoltán Molnár ${ }^{1}$ \\ ${ }^{1}$ Molnár Group, Department of Physiology, Anatomy and Genetics, University of Oxford, Oxford, UK, ${ }^{2}$ JNU-HKUST Joint \\ Laboratory for Neuroscience and Innovative Drug Research, College of Pharmacy, Jinan University, Guangzhou, China
}

Neonatal hypoxia-ischaemia $(\mathrm{HI})$ is the most common cause of death and disability in human neonates, and is often associated with persistent motor, sensory, and cognitive impairment. Improved intensive care technology has increased survival without preventing neurological disorder, increasing morbidity throughout the adult population. Early preventative or neuroprotective interventions have the potential to rescue brain development in neonates, yet only one therapeutic intervention is currently licensed for use in developed countries. Recent investigations of the transient cortical layer known as subplate, especially regarding subplate's secretory role, opens up a novel set of potential molecular modulators of neonatal $\mathrm{HI}$ injury. This review examines the biological mechanisms of human neonatal $\mathrm{HI}$, discusses evidence for the relevance of subplate-secreted molecules to this condition, and evaluates available animal models. Neuroserpin, a neuronally released neuroprotective factor, is discussed as a case study for developing new potential pharmacological interventions for use post-ischaemic injury.

Keywords: neonatal, hypoxia-ischemia, encephalopathy, subplate, neurodevelopment, neuroserpin, neuroprotection

\section{INTRODUCTION: GLOBAL CLINICAL IMPACT OF NEONATAL HYPOXIA ISCHAEMIA}

The clinical definition of neonatal HI injury is "asphyxia of the umbilical blood supply to the human fetus occurring at 36 gestational weeks or later" (Perlman, 1997, 2006; Volpe, 2001, 2012; Shah P.S. et al., 2006). Neonatal HI is synonymous with hypoxic-ischaemic encephalopathy (HIE) occurring in the term infant, where term is defined as 36 gestational weeks or later. This review addresses neonatal HI or HIE, any results concerning perinatal hypoxic-ischaemia injury will be clearly indicated in the text. This disorder encompasses a large range of physiological origins

\footnotetext{
Abbreviations: AMPA, alpha-amino-3-hydroxy-5-methyl-4-isoxazole propionic acid; BBB, blood brain barrier; CPR, cardiopulmonary resuscitation; CNS, central nervous system; CSF, cortico-spinal fluid; CSPG, chondroitin sulfate proteoglycan; CTGF, connective tissue growth factor; E(18), embryonic day (18); EM, electron microscopy; GABA, $\gamma$-aminobutyric acid; HI, hypoxia-ischaemia; HIF-1, hypoxia inducible factor 1; IL-1ß, interleukin-1ß; IL-6, interleukin-6; IL-9, interleukin-9; LPS, lipopolysaccharide; MRI, magnetic resonance imaging; MRS, magnetic resonance spectroscopy; NMDA, $N$-methyl-D-aspartate; OGD, oxygen glucose deprivation; $\mathrm{P}(8)$, postnatal day (8); poly(I:C), polyinosinicpolycytidylic acid; rER, rough endoplasmic reticulum; TNF- $\alpha$, tumour-necrosis factor- $\alpha$; tPA, tissue plasminogen activator; VEGF, vascular endothelial growth factor.
} 
and clinical outcomes (Volpe, 1995). The diagnostic criteria for neonatal HI are based on a set of markers demonstrated to correlate with clinical outcome (Finer et al., 1981; Perlman, 1997; Richer et al., 2001). These include: 5-min Apgar score of less than 5 (Levene et al., 1986; Ruth and Raivio, 1988; Laptook et al., 2009); need for delivery room intubation or CPR (Richardson B.S. et al., 1996; Salhab et al., 2004a; Shalak and Perlman, 2004; Kattwinkel et al., 2010); umbilical cord arterial pH less than 7.00 (Ruth and Raivio, 1988; Perlman and Risser, 1993; Robertson N.J. et al., 2002; Salhab et al., 2004b); and abnormal neurological signs, such as hypotonic muscles or lack of sucking reflex (Levene et al., 1986; Robertson et al., 1989; Richer et al., 2001). Electroencephalography (EEG) has also proved helpful as a predictor of clinical outcome (reviewed in Walsh et al., 2011; van Laerhoven et al., 2013). Amplitude-integrated EEG (aEEG) in particular, a filtered time-compressed continuous one- or two-channel read-out, has been demonstrated a reliable predictor in meta-analyses up to 5 years after birth (al Naqeeb et al., 1999; Sinclair et al., 1999; Toet et al., 1999; Biagioni et al., 2001; Shah D.K. et al., 2006; Nash et al., 2011; Murray et al., 2016; Weeke et al., 2016), however, some report that aEEG remains less reliable than MRI, especially following hypothermia treatment (Doyle et al., 2010; Weeke et al., 2016). The Thompson score, an EEG measure of predictive neurodevelopment, is likely to remain useful to clinicians (Thompson et al., 1997; Horn et al., 2016). This is by no means an exhaustive list of risk factors and signs of clinical concern that can occur during the early postnatal period (Shalak and Perlman, 2004; Hagberg et al., 2015).

Neonatal $\mathrm{HI}$ is the most common cause of death and disability in human neonates (Grow and Barks, 2002; Ferriero, 2004; Shalak and Perlman, 2004), accounting for $23 \%$ of infant mortality worldwide, and affecting 0.7-1.2 million infants annually (Lawn et al., 2005; see Figure 1). In developed countries, incidence of HI injury has not decreased in the past two decades (Himmelmann et al., 2005; Vincer et al., 2006), remaining a significant cause of fatality and disability. The frequency of motor and cognitive disorders linked to perinatal and early postnatal brain injury actually increased during the 1990s, and currently remains stable (Vincer et al., 2006; Robertson and Iwata, 2007; Wilson-Costello et al., 2007). Progress in assisted respiratory and intensive care technology has led to greater than $90 \%$ survival of infants born after gestational week 23 (Larroque et al., 2004; Fellman et al., 2010), perhaps accounting for the increased burden of disability within the population as mortality rates have decreased substantially.

Amongst those who survive the initial injury, rates of disability remain high throughout life. Of patients surviving neonatal $\mathrm{HI}$, $5-10 \%$ of infants demonstrate persistent motor deficits, and 20$50 \%$ display sensory or cognitive abnormalities that persist to adolescence (Hack et al., 1992; Vohr et al., 2000; Volpe, 2001, 2012; Lee et al., 2013). A meta-analysis of seven studies including 386 infant patients investigated the average incidence of mortality and morbidity: $5.9 \%$ of all patients across all studies died, 16.3\% suffered neonatal seizures, and $17.2 \%$ experienced neurological deficits, with $14.2 \%$ qualifying for a diagnosis of cerebral palsy (Graham et al., 2008). Long-term outcomes in neonatal asphyxia infants have also been investigated. One meta-analysis found that
$1-18 \%$ of patients were identified as having severe sensorimotor or learning disorders by the age of $2-5$ years, with only $50-60 \%$ of patients reported as developmentally normal (Dilenge et al., 2001). This study covered a wide range of injury severities and follow-up ages. Disorders included seizures, hearing and vision loss (Robertson and Finer, 1985), language disorders, microcephaly, and muscle spasticity (Shankaran et al., 1991, 2012). Studies also report more severe neurological signs in patients suffering severe HI compared to those with milder HI injury (Robertson and Finer, 1985). Yet, many individuals who showed abnormal neurological signs at birth were normal at 2year follow-up (De Souza and Richards, 1978). Clinical features and outcomes of neonatal HI are summarized in Figure 1.

Despite the high disability burden associated with surviving neonatal HI patients, there are very few preventative or protective treatments available for infants suspected to have suffered an HI event. The only licensed treatment currently available is hypothermia. This treatment involves subjecting either the infant's whole body or head-only to temperatures of around $33^{\circ} \mathrm{C}$ (Choi et al., 2012; Tagin et al., 2012). Hypothermia was first demonstrated to improve survival in cases of cardiac arrest (Bernard et al., 2002; Nikolov and Cunningham, 2003), and has since been applied as a neuroprotective treatment in acute neonatal HI injury patients (Gunn et al., 1997, 2005; Gunn and Gunn, 1998; Shankaran et al., 2002, 2005; Eicher et al., 2005; Gluckman et al., 2005; Jacobs et al., 2005, 2013; Shah et al., 2007; Azzopardi et al., 2009; Shah, 2010). A recent meta-analysis found that hypothermia carried out in over 1,200 infants reduced the rate of death and neurological handicaps at 18 months followup across all severity categories of neonatal HI injury (Tagin et al., 2012). However, hypothermia alone is not sufficient to prevent all brain injury or neurological symptoms, highlighting the need for additional therapies to use in conjunction. Xenon gas administration is currently being trialed as an additive therapy alongside hypothermia (Hobbs et al., 2008; Thoresen et al., 2009; Johnston et al., 2011). There are currently no other licensed treatments available for neonatal HI.

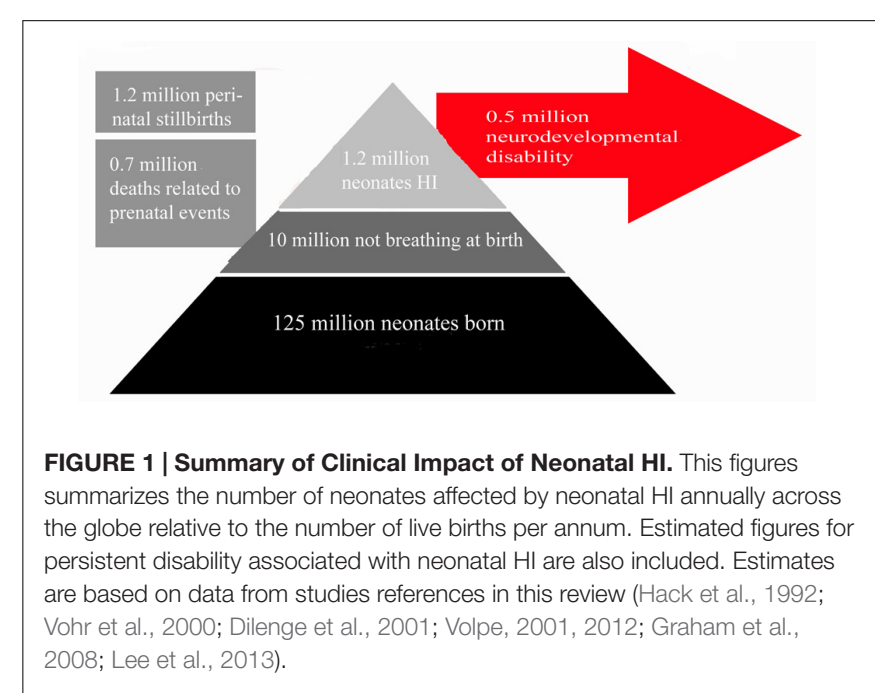


Despite the efficiency of hypothermia (Tagin et al., 2012; Jacobs et al., 2013; Pauliah et al., 2013; Srinivasakumar et al., 2013; Kracer et al., 2014; Kali et al., 2015), death and disability remain a common feature of neonatal HI prognosis. Observations concerning global prevalence and poor long-term outcome reiterate the urgency of finding novel neuroprotective treatments for use during and directly following HI injury. This review examines the neuropathology resulting from neonatal HI injury in humans. The review then examines currently available animal models of neonatal $\mathrm{HI}$ and summarizes the strengths and weakness of such models for research into this complex human condition. Finally, the review will detail a potential approach toward identifying new pharmacological targets for neonatal $\mathrm{HI}$ therapies, focusing on the protein neuroserpin.

\section{NEUROBIOLOGY OF NEONATAL HYPOXIA ISCHAEMIA IN HUMANS}

There is ample evidence that brain damage occurs in human neonatal HI patients with poor clinical outcomes, documented in both imaging and histopathological studies (Mortola, 1999; Volpe, 2008, 2012; Northington et al., 2011). Neuropathology has been characterized in human post-mortem studies, concluding that most areas of the brain are vulnerable to some extent to neonatal HI injury (Miller et al., 2005; Triulzi et al., 2006; Billiards et al., 2008; Cohen and Scheimberg, 2008; de Vries and Groenendaal, 2010; Volpe, 2012). Gray and white matter lesions have been described at term after HI (Eken et al., 1994; Marin-Padilla, 1996, 1997, 1999). Localization and extent of neuropathology has been shown to be associated with neurodevelopmental symptoms, giving insights into the nature of disability the patients may present with.

\section{Neuroanatomy: Structural Imaging}

Infants who survive the initial HI insult display cerebral damage visible with structural imaging. Magnetic resonance imagining (MRI) studies of term infants with neurological signs and combinations of fetal distress, cord acidemia, and depressed Apgar scores have been carried out in over 1,000 infants (reviewed in Volpe, 2012). These studies report great variation in the anatomical areas involved between individual patients, yet most samples described either patients demonstrating predominant or substantial injury to cerebral cortex (Barkovich et al., 1995; Rutherford et al., 2004; Miller et al., 2005; Chau et al., 2008, 2012, 2013; Li et al., 2009), or basal ganglia and thalamus (Barkovich et al., 1995; Rutherford et al., 1998, 2004; Cowan et al., 2003; Kaufman et al., 2003; Miller et al., 2005; Chau et al., 2008) in partially overlapping subpopulations. These two patterns of injury are shown in Figure 2. Cerebral white matter has been described as selectively sensitive to term HI injury (Inder et al., 1999; Craig et al., 2003). Although less common, severe selective involvement of subcortical white matter has been documented (Neil et al., 2002; Vermeulen et al., 2003). One review described the literature concerning structural MRI scans in the acute phase (within 2 weeks after birth): approximately $15-30 \%$ of scans were normal, lesions in basal ganglia and thalamus are present in 40$80 \%$ of cases, with abnormalities of watershed white matter and cortex present in $40-60 \%$ of patients (Volpe, 2012). MRI anatomy has been shown to agree well with post-mortem studies (Cowan et al., 2003). Therefore, no single area of the brain is specifically damaged following neonatal HI. Any future treatments should take this diversity into account and provide neuroprotection to neurons throughout the brain.

The MRI scan is currently the method of choice for investigation of neonatal anatomy in both clinical and experimental circumstances (Perrin et al., 1997; Ment et al., 2002; Li et al., 2009). Diffusion-weighted MRI imaging has greatly improved identification of the time of onset of brain lesions (L'Abee et al., 2005; Chau et al., 2009). A reduced diffusion coefficient can be calculated, showing restricted diffusion during the first few days after the insult, with pseudonormalization by the end of the first week (McKinstry et al., 2002; Malik et al., 2006; Liauw et al., 2009). Sequential imaging has shown that lesions in the basal ganglia may increase in size during the first week after birth (Soul et al., 2001; Barkovich et al., 2006), and asymmetric diffusion within white matter has been correlated with clinical severity of hemiparesis (Glenn et al., 2007). Cranial ultrasound also remains a valuable clinical tool (Daneman et al., 2006). Another technique promising to add to understanding of neonatal $\mathrm{HI}$ is magnetic resonance spectroscopy (MRS), which allows brain metabolism to be imaged in real time (Kemp and Radda, 1994; Soares and Law, 2009). Full-term neonates with perinatal asphyxia have been studied, indicating that brain metabolism becomes abnormal after 6 to $12 \mathrm{~h}$ only to decrease even further after $24 \mathrm{~h}$ (Wyatt et al., 1989; Moorcraft et al., 1991; Roth et al., 1992). This coincided with clinical deterioration such as development of seizures. The concept of a delayed metabolic abnormality or 'secondary energy failure' has been elaborated in animal models (Lorek et al., 1994; Penrice et al., 1997; Groenendaal et al., 2006). Using MRS in these animal models, neuroprotective strategies could be tested. By using MRS data as real-time measurements of decreased brain metabolism in brain injury. ${ }^{1} \mathrm{H}$-MRS and ${ }^{31} \mathrm{P}$-MRS studied have demonstrated metabolic abnormalities following HI insult, which may persist for weeks (Groenendaal et al., 1994; Robertson et al., 1999). Unfortunately, with the magnetic field strength of current clinical systems, only large brain areas can be examined, limiting the use of this technique. Infants who have suffered neonatal HI often exhibit abnormal EEG activity (reviewed in Walsh et al., 2011; van Laerhoven et al., 2013). A range of abnormalities have been described, including: low voltage in isoelectric EEG (Finer et al., 1983; Legido et al., 1991), mild voltage depression (Watanabe et al., 1980; Toet et al., 2002; Murray et al., 2010), and asymmetry of trace (Aso et al., 1989; Zeinstra et al., 2001; Murray et al., 2009), although all of these criteria have been differently defined by different analysts (Rennie et al., 2004; Shellhaas et al., 2007). However, imaging techniques are constantly improving.

Lesions occur in many clinical patients, yet the effect on cognitive function is as diverse as the neuroanatomy. The area of cortex and basal ganglia damaged during the initial HI injury is directly predictive of language and motor outcome in childhood (Steinman et al., 2009; Martinez-Biarge et al., 2011). Examination 


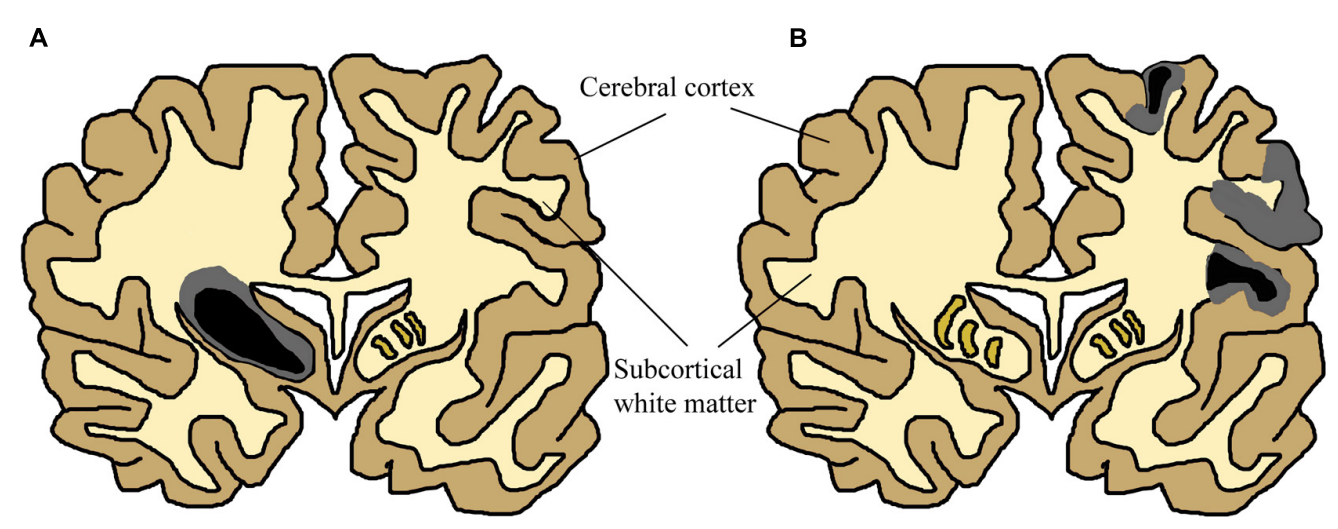

FIGURE 2 | Simplified Schematic of Brain Damage in Neonatal HI, approximately at the level of primary somatosensory and motor cortex. The two main patterns of injury, partially overlapping in patients, are shown separately for this schematic (adapted from Budday et al., 2014). Two colours have been used to show that many neonatal $\mathrm{HI}$ injuries consist of a centre of necrosis (black) and a penumbra of less acutely damaged tissue (gray). The exact location of these sites will vary depending on the nature of the injury. Black/gray areas represent the potential site of lesions, although those shown in this schematic are severe yet unilateral. (A) Primary basal-ganglia and thalamus injury pattern. (B) Primary watershed cortex and underlying white matter injury. Injury can primarily occur either to cortical gray matter or subcortical white matter depending on the nature of the injury. Severity also varies substantially between patients and within the brain of individuals. These have been documented in many human structural imaging studies (Barkovich et al., 1995; Cowan et al., 2003; Kaufman et al., 2003; Rutherford et al., 2004; Miller et al., 2005; Chau et al., 2008, 2012, 2013; Li et al., 2009).

of diffusion-tensor imaging of neonates was predictive of survival and motor outcome (Hunt et al., 2004; Ward et al., 2006). Children with basal-ganglia-thalamus pattern of injury tend to be severely disabled due to dyskinetic cerebral palsy and epilepsy (Himmelmann et al., 2007). Infants with predominant watershed white matter and cortex lesions have more prominent cognitive than motor deficits (Miller et al., 2005; Gonzalez and Miller, 2006; Steinman et al., 2009). Severe motor impairment is uncommon, and this group is often considered to have a normal outcome when seen at 12-18 months, although suboptimal head growth, behavioral problems, epilepsy, and a delay in language emerge during late childhood (Mercuri et al., 2000; Miller et al., 2002; Oguni et al., 2008; Sato et al., 2008; Steinman et al., 2009). Therefore, cortical damage appears to be relevant to functional outcome in surviving neonatal HI patients. This information could be used to predict future susceptibility to disability before it manifests, allowing social and educational supports to be put in place early.

\section{Molecular Mechanisms of Cell Death}

Anatomical studies describe loss of brain volume following moderate and severe neonatal HI. However, the underlying molecular mechanisms responsible for cell death are debated (McLean and Ferriero, 2004; Fatemi et al., 2009; Northington et al., 2011; Baburamani et al., 2012). Many pathways have been implicated in $\mathrm{HI}$ injury in the term brain, primarily: excitotoxicity, oxidative stress, and inflammation. Molecular studies have drawn attention to a fact essential for the development of successful new therapies that the neonatal brain and its injury is fundamentally different from that seen in adult HI stroke injury (McLean and Ferriero, 2004; Johnston et al., 2011; Baburamani et al., 2012; Semple et al., 2013).

There are many important differences between neonatal HI and adult ischaemic stroke. For example, severe HI events in the infant brain can lead to liquifactive disintegration, not seen after adult stroke (Larroche, 1977; Rorke, 1992). Newly formed blood vessels are fragile and prone to rupture (Trommer et al., 1987; Volpe, 1989; Ment et al., 1991; Jones et al., 2002), and surrounded by fewer astrocyte end-feet (El-Khoury et al., 2006). Another key site of difference is the BBB. Studies in rodents indicate that the $\mathrm{BBB}$ is compromised as a result of neonatal HI (Muramatsu et al., 1997; Svedin et al., 2007; Ferrari et al., 2010; Tu et al., 2011; Yang et al., 2012). Yet the common belief that the neonate $\mathrm{BBB}$ is less effective has recently come under revision (Saunders et al., 1999, 2012, 2014; McLean and Ferriero, 2004; Baburamani et al., 2012; Stolp et al., 2016). Tight junctions, the occlusive element of the $\mathrm{BBB}$, are present as soon as embryonic vessels invade the brain (Schulze and Firth, 1992; Bauer et al., 1993; Stewart and Hayakawa, 1994; Kniesel et al., 1996), and are functional (Ek et al., 2003, 2006; Daneman et al., 2010). In a model of hypoxia in newborn piglet, BBB integrity was maintained (Stonestreet et al., 1992), yet other experiments have demonstrated damage to the BBB following neonatal $\mathrm{HI}$ (Alvarez-Diaz et al., 2007; Leonardo and Pennypacker, 2009).

Cerebrovascular autoregulation is another factor which must be considered in neonates. The concept that preterm infants have a 'pressure passive' cerebral circulation is widely accepted. However, sick term infants demonstrate impaired autoregulation (Pryds et al., 1990; Hardy et al., 1999; Boylan et al., 2000) and the range of blood pressure over which cerebrovascular autoregulation functions expands with maturity (Tuor and Grewal, 1994; Verma et al., 2000). Also, the concentrations and actions of various signaling molecules is different in the developing brain including; caspase-3 (Cheng et al., 1998), VEGF (Carmeliet and Storkebaum, 2002), and HIF-1 (Iyer et al., 1998), among others (reviewed in Baburamani et al., 2012).

One surprising difference is sexual dimorphism in response to neonatal HI. Male babies are at higher risk of cerebral 
palsy than females (Jarvis et al., 2005). Cognitive and motor outcomes are worse in male than in female low birth weight infants (Johnston and Hagberg, 2007). Quantitative imaging shows that male premature infants are more vulnerable to white matter injury, whereas females are more vulnerable to gray matter injury (Thompson et al., 2007). This sex difference has also been replicated in rodent in vitro models of hypoxic cell death (Zhu et al., 2006; Nijboer et al., 2007; Du et al., 2009). Although many molecular mechanisms are currently under investigation, this sexual dimorphism remains largely unexplained (Hill and Fitch, 2012; Chavez-Valdez et al., 2014; Demarest et al., 2016a,b; Waddell et al., 2016). Therefore, the unique state of the developmental brain should always be at the forefront of the researcher's minds.

Neonatal HI injury evolves over time (McLean and Ferriero, 2004). Injuries seen with MRI scans within the first few hours after asphyxia are subtle, restricted diffusion typically starting as small lesions in the putamen and thalami, progressing over the next 3 to 4 days to involve more extensive areas of the brain (Takeoka et al., 2002). Within the first few hours, regionally specific fluctuations in blood flow trigger excitotoxicity, free radical generation, and edema (Wigglesworth and Pape, 1978; Bennet et al., 1998; Jensen et al., 1999; Shalak and Perlman, 2004; Ferrari et al., 2010). A secondary phase of injury occurs during the following hours and days, resulting in neuroinflammation, mitochondrial permeabilization, and loss of cerebral autoregulation (Inder and Volpe, 2000; Hamrick and Ferriero, 2003; Scheepens et al., 2003; Hagberg et al., 2009; Leonardo and Pennypacker, 2009). A tertiary phase of brain injury has been proposed, which may exacerbate injury through persistent inflammation (Fleiss and Gressens, 2012).

The balance between molecular cell-death processes which cause this damage in neonatal HI remains debated. Early evidence indicates that the majority of cell death in neonatal $\mathrm{HI}$ is necrotic, however, all regions also undergo increased apoptotic death (Edwards and Mehmet, 1996; Edwards et al., 1997; Northington et al., 2001). Some studies suggest a more prominent role for apoptosis (Hill et al., 1995; Sidhu et al., 1997; Pulera et al., 1998; Hu et al., 2000; McLean and Ferriero, 2004). Immature neurons in vitro are more susceptible to apoptotic death than mature neurons (McDonald et al., 1997). Others report that necrosis is the major cellular pathology in humans and animals (Adamsons and Myers, 1973; Myers, 1975; Towfighi et al., 1995; Northington et al., 2001, 2005, 2011; Folkerth, 2005; Carloni et al., 2007; Stridh et al., 2013). Yet others recognize that both occur. Some report that necrosis predominates in severe cases, whereas apoptosis occurs in milder injury (Stroemer and Rothwell, 1998; Daval and Vert, 2004; Fatemi et al., 2009). Neurons often display morphologic features along an apoptosis-necrosis continuum (Portera-Cailliau et al., 1997a,b; Nakajima et al., 2000; Northington et al., 2007, 2011). In addition to apoptosis and necrosis, some neurons in the neonatal HI brain undergo autophagy (reviewed in Klionsky and Emr, 2000; Northington et al., 2011; Balduini et al., 2012). Neuronal autophagy occurs in rodent neonatal HI models (Lockshin and Zakeri, 1994; Carloni et al., 2008; Ginet et al., 2009). However, there is conflicting evidence as to whether the occurrence of autophagy augments brain damage (Koike et al., 2008; Puyal et al., 2009), or prevents the spread of necrotic cell death (Carloni et al., 2008). Artificially exclusive classification of cell death may hinder research and therapy development.

To add to this complexity, neonatal HI injury appears to activate several interacting molecular cascades. A simple schematic of the three major cascades is shown in Figure 3. The first is excitotoxicity, through which physiological glutamate neurotransmission leads to overactivation of postsynaptic receptors and cell death (reviewed in Hagberg et al., 1987; Choi, 1988, 1992; Hattori and Wasterlain, 1990; Danbolt, 2001). The $N$-methyl-D-aspartate (NMDA) receptor is relatively overexpressed in the developing brain (McDonald et al., 1989a; Represa et al., 1989; Fox et al., 1996). In P6 rats, the NMDA receptor is expressed at $150-200 \%$ of adult levels (Tremblay et al., 1988). The predominating combination of NMDA receptor subunits in the perinatal period seems to favor prolonged calcium influx for a given excitation (Danysz and Parsons, 1998). The same NMDA receptor that promotes plasticity can lead to massive $\mathrm{Na}^{+}$and water influx, cellular swelling, pathologically elevated intracellular calcium, and energy failure, leading to a 'spiral of death' (Choi, 1988). Oxygen glucose deprivation (OGD) in rat hippocampal neurons leads to a marked reduction in glutamate removal from the synapse (Jabaudon et al., 2000; Tao et al., 2001). Injection of NMDA into rat brain produces more extensive cell death in the neonate than in the adult (McDonald et al., 1988). Elevated glutamate has been documented in the cerebrospinal fluid (CSF) of infants who have suffered severe HI injury (Riikonen et al., 1992; Hagberg et al., 1993; Pu et al., 2008). The neonatal brain is much more prone to seizure activity than the mature brain (Holmes, 1991; Holmes and Ben-Ari, 2001), suggesting a prominent role for neuronal hyperexcitability and excitotoxicity although the molecular mechanisms behind this have not been fully elucidated (reviewed in Rakhade and Jensen, 2009). However, seizure activity could also be explained by paradoxical excitatory activity of the neurotransmitter gamma-amino butyric acid (GABA) in the developing brain (Staley et al., 1995). Drugs that block NMDA receptors are protective against $\mathrm{HI}$ injury in neonatal rodent models (McDonald et al., 1989a,b, 1990). Activation of AMPA receptors also contribute to injury ( $\mathrm{McD}$ onald and Johnston, 1992; Deng et al., 2003; Talos et al., 2006), however, AMPA antagonists are not as protective (Ikonomidou et al., 1999; Noh et al., 2006). These findings are yet to be exploited in human clinical trials, as the integral role of glutamate receptors in healthy neuronal plasticity (Ikonomidou et al., 1999; Failor et al., 2010; Rocha-Ferreira and Hristova, 2015) could be damaged by the use of NMDA and AMPA antagonists at such a sensitive developmental stage.

An integrally linked cascade is that of oxidative stress. Excitotoxicity causes energy depletion, mitochondrial dysfunction, and cytosolic calcium accumulation, which in turn leads to generation of free radicals (Ferriero et al., 1996; Ferriero, 2001). Free radicals alter membrane pump function, allowing more glutamate release and NMDA receptor activation, leading to more excitotoxicity (Schanne et al., 1979; Robertson 


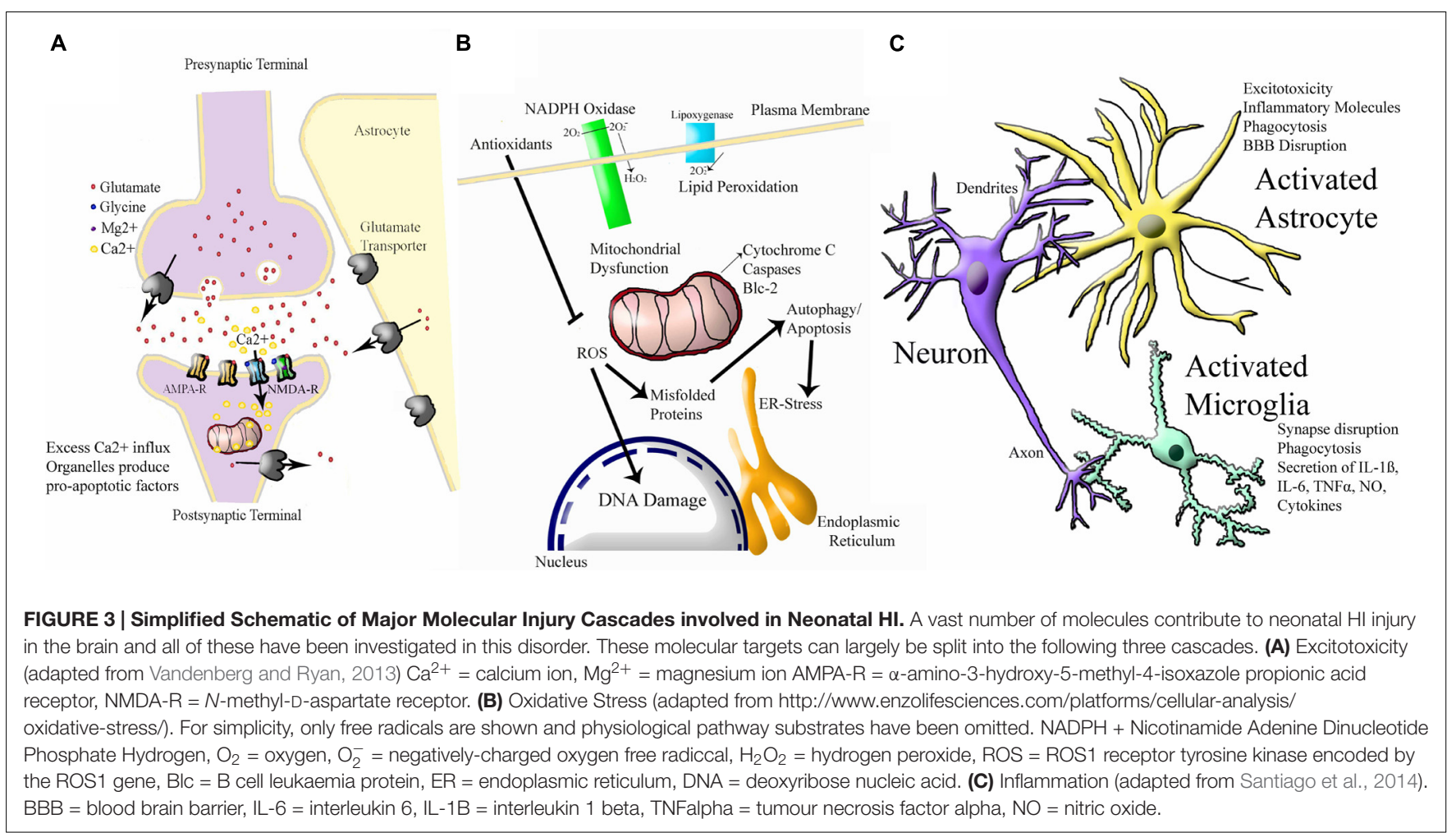

J.D. et al., 2002; Starkov et al., 2004). Oxidative stress is a general term for the increase in free radical production as a result of oxidative metabolism under pathologic conditions (Inder and Volpe, 2000; Ferriero, 2001). When oxygen floods the microenvironment of cells damaged by hypoxia, mitochondrial oxidative phosphorylation is overwhelmed and reactive oxygen species accumulate (Ferriero, 2001). Fetal life elapses in a low oxygen environment (East et al., 1998). In the first minutes of life, an abrupt increase in $\mathrm{O}_{2}$ partial pressure occurs, which creates a pro-oxidant condition (Stiller et al., 2002). During birth asphyxia, excess calcium influx and other factors lead to severe oxidative stress (Forder and Tymianski, 2009). There is accumulation of hydrogen peroxide after $\mathrm{HI}$ in neonatal mice but not in adults (Lafemina et al., 2006). Because of its high lipid content, the brain is particularly susceptible to free radical attack (O'Brien and Sampson, 1965; Northington et al., 2001). The polyunsaturated fatty acid content of the brain increases during gestation (Crawford and Sinclair, 1971; Mishra and Delivoria-Papadopoulos, 1989). Lipid peroxidation may be a major factor in the white matter damage (Back et al., 1998; Baud et al., 2004). The developing brain's immature antioxidant defense also contributes to sensitivity to oxidative stress ( $\mathrm{Li}$ et al., 1997; Mishra and Delivoria-Papadopoulos, 1999; Li and Jackson, 2002; Felderhoff-Mueser et al., 2002; Vannucci and Hagberg, 2004; Blomgren and Hagberg, 2006; Ikonomidou and Kaindl, 2011; Miller et al., 2012). Adequate stores of antioxidants are necessary to protect against oxidative injury. Specifically, depletion of neuronal reduced glutathione exacerbates oxidative injury (Chen and Liao, 2003; White and Cappai, 2003; Brongholi et al., 2006).
Finally, inflammation is a major component of neonatal HI injury. Low-dose treatment with intrauterine LPS dramatically increases severity of $\mathrm{HI}$ injury in neonatal mice, but protects against HI in adult rodents (Wang et al., 2007b). Intracerebral injection of NMDA receptor agonist produces a pattern of white matter injury, in which pretreatment with systemic IL-1ß, IL-6, IL-9, or TNF- $\alpha$ leads to a significant increase in lesion size (Marret et al., 1995; Dommergues et al., 2000). There is now substantial experimental evidence that intrauterine inflammation can exacerbate neonatal HI (Lehnardt et al., 2003; Eklind et al., 2005; Marini et al., 2007), which some have referred to as the "double-hit hypothesis" (reviewed in Agrawal and Hirsch, 2012; Hagberg et al., 2012; Dammann and Leviton, 2014). Microglia, the resident macrophages of the CNS, are among the first cells to become activated after HI (Fujimoto et al., 1989; Tahraoui et al., 2001; Kaur et al., 2007). Activated microglia migrate to damaged regions (Leonardo and Pennypacker, 2009) and produce inflammatory cytokines, glutamate, nitric oxide, and free radicals (Wood, 1995; Kaur and Ling, 2009). Drugs that block microglial activation protect the neonatal brain (Dommergues et al., 2003). Following hypoxia-ischemia, compromise of the $\mathrm{BBB}$ allows the entry of macrophages (Alvarez-Diaz et al., 2007; Leonardo and Pennypacker, 2009). Astrocytes also play a role in inflammation (Wang et al., 2003; Girard et al., 2008, 2009). CSF cytokines are elevated in term infants who later develop cerebral palsy (Savman et al., 1998; Dammann and O'Shea, 2008). The diverse network of interacting mechanisms demonstrate the molecular complexity of neonatal HI injury. Potential protective treatments should strive to tackle common mediators of these cascades relevant 
to all three pathways, otherwise full protection will not be achievable.

\section{EVALUATION OF AVAILABLE ANIMAL MODELS OF NEONATAL HYPOXIA ISCHAEMIA}

Neonatal hypoxia ischaemia has been modeled extensively in mice and rats (reviewed in Hagberg et al., 2002; van der Worp et al., 2007; Yager and Ashwal, 2009; Dean et al., 2015), with a minority of researchers also studying larger animals such as pigs, sheep (reviewed in Roohey et al., 1997; Dean et al., 2015) or primates (Fahn et al., 1979; Volpe, 2012). Models intending to replicate the clinical symptoms of neonatal human $\mathrm{HI}$ can be roughly divided into the four categories discussed below. All models have distinct advantages and disadvantages. A summary of available rodent models is shown in Figure 4.

\section{Rice-Vannucci Model of Term Hypoxia Ischaemia}

Most published studies modeling neonatal HI in animals have employed the Rice-Vannucci model (Rice et al., 1981). This model comprises unilateral carotid artery ligation, recovery with the dam for approximately $1 \mathrm{~h}$, followed by exposure to $8 \%$ oxygen for $1-3 \mathrm{~h}$ at $37^{\circ} \mathrm{C}$. Although, the model was initially described in rat (Rice et al., 1981), it has been successfully adapted for mouse with similar anatomical and behavioral effects (Ditelberg et al., 1996; Ferriero et al., 1996; Sheldon et al., 1998).

Rice' and Vannucci's model replicates anatomical damage seen in human neonates. Their initial study showed selective graymatter sensitivity to neuronal necrosis, with gray matter injury observed in cortex, hippocampus, thalamus, and basal ganglia (Rice et al., 1981; Andine et al., 1990; Towfighi et al., 1995; Vannucci et al., 1999), encompassing the sites damaged in human neonatal HI. Histologically, there is a gradation of injury that correlates with the duration or severity of insult (Towfighi et al., 1991, 1995). White matter lesions have also been described in this model (de Torres et al., 1997; Ness et al., 2001; Liu et al., 2002; Drobyshevsky et al., 2005, 2007b), the extent of which correlate with the duration of exposure to hypoxia (Liu et al., 2002). However, bilateral common carotid artery ligation appears a stronger model of white matter damage (Jelinski et al., 1999; Uehara et al., 1999; Cai et al., 2001). Metabolic alterations in the Rice-Vannucci model include decreased cerebral blood flow (Sakurada et al., 1978; Vannucci et al., 1988), brain acidosis (Welsh et al., 1982; Yager et al., 1991), and decreased cerebral glucose uptake (Vannucci et al., 1989; Sokoloff et al., 1977). An inflammatory response has also been demonstrated (Bona et al., 1998).

Another convincing aspect of the Rice-Vannucci model is its ability to predict the therapeutic effect of hypothermia following the neonatal HI event. Mice treated with hypothermia showed smaller lesion volumes, in addition to better performance on the Morris water maze and circling tests (Yager et al., 1993; Lee et al., 2010; Kida et al., 2013; Lin et al., 2014). Many papers have investigated the behavioral outcomes of Rice-Vannucci injury in adult rodents. This model gives rise to well documented behavioral phenotypes including: impaired spatial learning and memory (Balduini et al., 2000, 2001; Ikeda et al., 2001; Wang et al., 2002; Arteni et al., 2003; Pereira et al., 2007; Cai et al., 2009; Greggio et al., 2011; Hill et al., 2012; Zheng and Weiss, 2013; Alexander et al., 2014; Gillani et al., 2015); impaired motor function as assessed by rotarod test, open field and motor reflexes (Barth and Stanfield, 1990; Jansen and Low, 1996a,b; Jansen et al., 1997; Balduini et al., 2000, 2001; Tomimatsu et al., 2002; Ådén et al., 2003; Lubics et al., 2005; Pazaiti et al., 2009; Im et al., 2010; Nijboer et al., 2010; Karalis et al., 2011; Chen et al., 2012; Ruiz et al., 2012; Sanches et al., 2012; Zheng et al., 2012; Xiong et al., 2013; Alexander et al., 2014; Gillani et al., 2014, 2015; Kim et al., 2014; Zhang Q. et al., 2014; Park D. et al., 2015; Park W.S. et al., 2015); sensory processing abnormalities (Alexander et al., 2014); and other cognitive phenotypes, such as reduced attention (Buwalda et al., 1995; Martin et al., 1997; Sanches et al., 2013; Perera et al., 2014; Miguel et al., 2015). Despite this broad range of documented effects, there are some contradictions between individual investigators (reviewed in Lubics et al., 2005), which suggest that different genetic backgrounds, severity, or experimenters can significantly affect the outcome of Rice-Vannucci model.

The Rice-Vannucci model of neonatal hypoxia ischaemia has several advantages. One is its prevalence, allowing direct comparisons with many other published papers (Vannucci et al., 1993, 2005; Yager and Ashwal, 2009; Dean et al., 2015). Another is that the contralateral hemisphere, exposed to hypoxia in the absence of ischemia, appears normal (Yager et al., 1991, 1992, 1996; Vannucci and Yager, 1992), providing a control hemisphere within the experimental brain. Thorough behavioral characterization (Arteni et al., 2003; Lubics et al., 2005) support the long term consequences of this model mimicking neonatal HI. One significant drawback of this model is the high variability in size and severity of infarct between animals, making comparisons between experimenters difficult (Vannucci and Hagberg, 2004; Vannucci and Vannucci, 2005). Additionally, the invasive nature of severing the common carotid artery does not replicate human injury; such severe vascular abnormalities occur rarely, if at all (Ment et al., 1984; Hill, 1991).

\section{Hypoxia-Only Models}

Some experimenters induce hypoxia in rodents exclusively using an oxygen deprivation chamber, without a preceding ischaemic procedure. These models are not as widely used as the Rice-Vannucci method, but have the potential to describe milder injuries and avoid the unphysiological occlusion of the common carotid artery. There are currently no published reviews or meta-analyses of hypoxia-only investigations, Supplementary Table 1 contains a brief summary of 122 published papers using hypoxia-only methodology compiled from Pubmed search results.

Historically, these methods have been used to investigate hypoxic brain biochemistry. Several studies have documented altered levels of neurotransmitters (Hedner et al., 1980; Kaneko et al., 1985; Yamamoto et al., 1985; Yamamoto and Kato, 


\section{Rice-Vannucci Hypoxia Ischaemia}

A

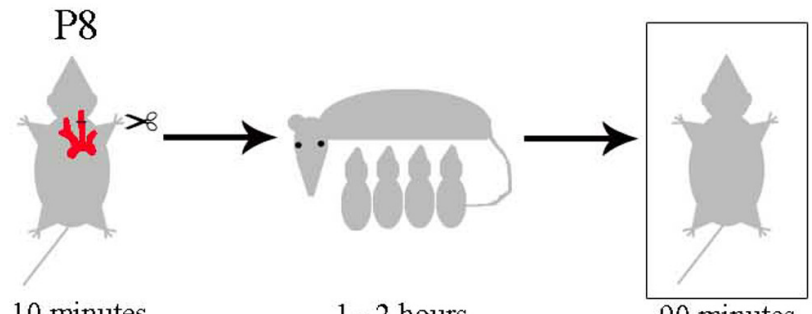

10 minutes

$1-2$ hours

90 minutes

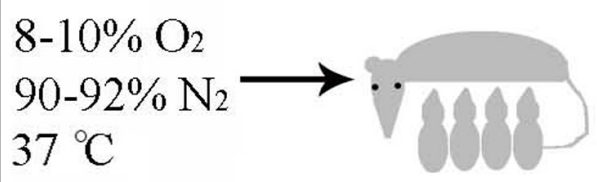

3 hours - weaning

\section{Hypoxia Only

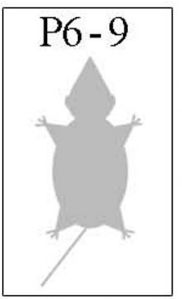 \\ 5 - 100 minutes \\ $0-10 \% \mathrm{O}_{2}$ \\ $0-5 \% \mathrm{CO}_{2}$ \\ $90-100 \% \mathrm{~N}_{2}$ \\ $18-37{ }^{\circ} \mathrm{C}$

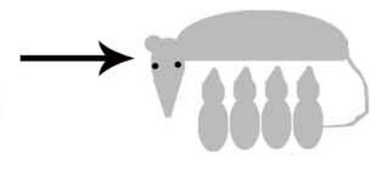 \\ 1 - 5 days}

\section{Preterm Inflammatory Injury}

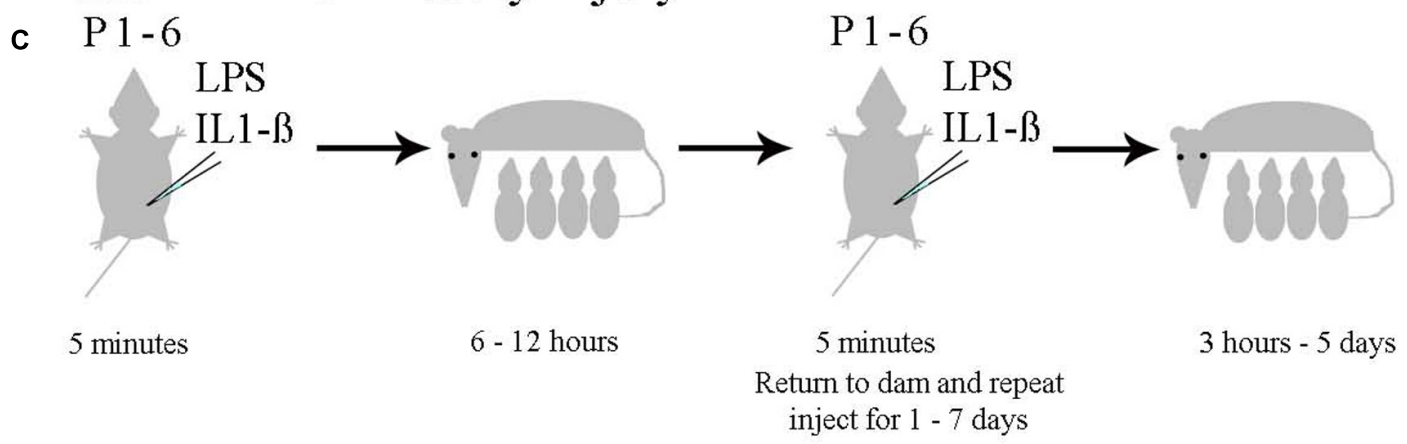

FIGURE 4 | Currently Used Rodent Models of Neonatal HI. (A) The Rice-Vannucci method as outlined in rats by Rice et al. (1981). (B) The general method with specifications taken from the pool of papers summarized in Supplementary Table 1. (C) The range of inflammatory models reviewed in Dean et al. (2015).

1986; Hadjiconstantinou et al., 1990; Seidler and Slotkin, 1990; Dell'Anna et al., 1993; Tanaka et al., 1995; Anju et al., 2010a,b; Anju and Paulose, 2011, 2013). However, there is little consensus over the direction or magnitude of changes (Decker M.J. et al., 2003; Decker et al., 2005). Hypoxia-only models have become an established model used to generate seizures in neonatal rats (Jensen et al., 1995; Applegate et al., 1996; Rodríguez-Alvárez et al., 2015; Sampath et al., 2015). In one such model, P6 rat pups were placed in chambers at $9 \% \mathrm{O}_{2}$ partial pressure and $20 \% \mathrm{CO}_{2}$ partial pressure for $60 \mathrm{~min}$. Some pups were immediately restored to room air, whereas others underwent gradual reduction of $\mathrm{CO}_{2}$ (Helmy et al., 2011; Tolner et al., 2011). Pups which underwent hypoxia with immediate restoration of $\mathrm{CO}_{2}$ had a greater mortality rate and higher seizure frequency.
However, subsequent anatomical analysis of these brains at P8 (Boss et al., 2005; Wang et al., unpublished), failed to show any differences in expression of cell death markers or layer-specific markers of healthy cortical neurons. Therefore, the hypoxiaonly insult resulting in seizures appears to generate only subtle injury to the brain, far short of that seen in some human patients.

A range of behavioral phenotypes have been reported in hypoxia-only models, including hyperactivity (Shimomura and Ohta, 1988; Dell'Anna et al., 1991; Speiser et al., 1991; Decker et al., 2005); increased aggression (Mikati et al., 2005; Tang et al., 2006), altered ultrasonic vocalization (Venerosi et al., 2006), and disturbed sleep (Decker M.B. et al., 2003). Relatively few investigators have pursued standard tests of spatial memory and 
A

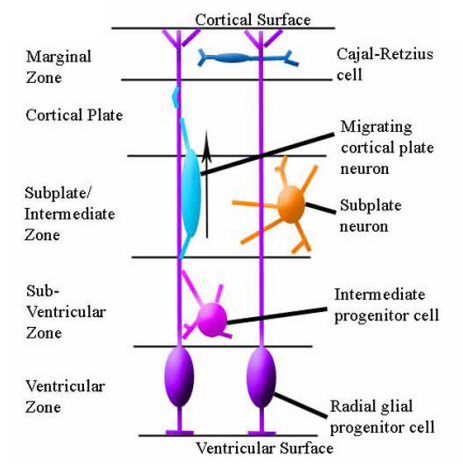

B

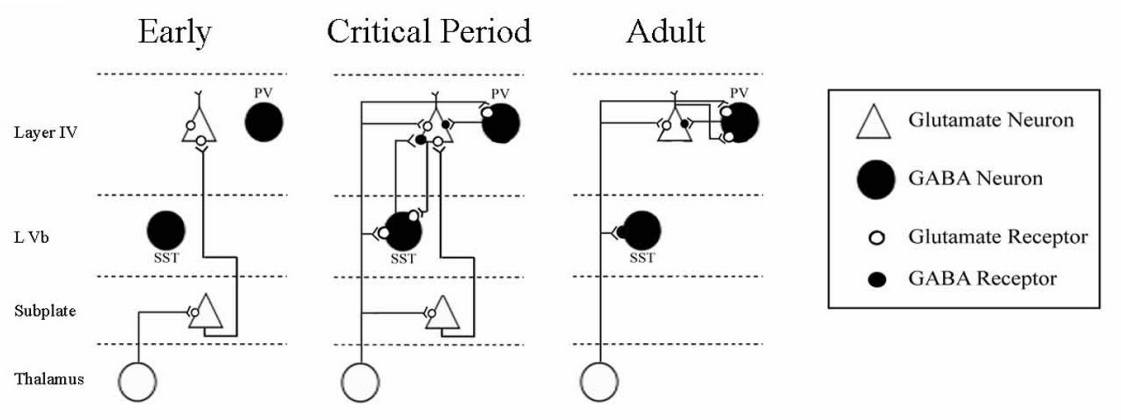

FIGURE 5 | Schematics of the anatomy and physiology of human subplate development. (A) Schematic coronal section showing the major cellular compartments within the developing human cortex at 26 post-conception weeks, reviewed in Hoerder-Suabedissen and Molnár (2015). The germinal zone (site of cell division) consists of the ventricular zone and subventricular zone. The subplate and intermediate zone lie between the germinal zone and the cortical plate (the site into which the permanent layers will migrate). The outermost layer is the early-born marginal zone. (B) Classical schematic of subplate architecture throughout development. In the earliest phase of thalamocortical circuit establishment subplate neurons (white) receive inputs from thalamus, and project axons to layer 4 . At the onset of critical period, both subplate neurons and thalamus project to layer 4 . In adult, subplate neurons have been eliminated by programmed cell death and layer 4 neurons receive inputs directly from thalamus. Adapted from Kanold (2009). This classical view has been augmented by the inclusion of GABA-ergic layer Vb interneurons which have been demonstrated to contribute to thalamocortical circuitry development in somatosensory mouse cortex (Marques-Smith et al., 2016).

locomotor behavior, and have obtained mixed results (Dell'Anna et al., 1991; Speiser et al., 1998; Rotstein et al., 2006; Coq et al., 2008; Raveendran and Skaria, 2013; Wang S. et al., 2015). The majority of hypoxia-only phenotypes are based on custom behavioral tests, making them difficult to compare to other established animal models. Additionally, some studies report no behavioral deficit following neonatal hypoxia alone (Buwalda et al., 1995; Iuvone et al., 1996; Casolini et al., 2005; Blaise et al., 2009; Mikhailenko et al., 2009; Anju et al., 2010c; Wang S. et al., 2015).

Although hypoxia-only models offer the potential to replicate the mechanism of hypoxia without major ischaemia seen in human neonatal HI patients, the models currently available are not ideal. One significant problem is the lack of methodological unity between different experimenters. There is little consensus on age of animal, background strain, oxygen partial pressure, time of exposure to hypoxia, or body temperature (see Supplementary Table 1). One example demonstrating the relevance of close control of these variables is temperature. $\mathrm{P} 0$ rat pups exposed to anoxia exhibit behavioral defects when anoxia was conducted at $39^{\circ} \mathrm{C}$, yet not at 33 and $36^{\circ} \mathrm{C}$ (Rogalska et al., 2004, 2009; Caputa et al., 2005; reviewed in Rogalska et al., 2006). Therefore, far more care is needed to justify the design of hypoxia-only experiments before these models can be considered dependable models of human neonatal HI.

\section{Inflammatory Models of Perinatal Brain Injury}

Intrauterine infection is strongly associated with preterm birth and brain injury (Stoll et al., 2004; Mitha et al., 2013; Strunk et al., 2014; Dean et al., 2015). Many models have been described which introduce different inflammation-inducing molecules at different ages (Dean et al., 2015), many of which cause cerebral inflammation and white matter damage seen in human patients.

Administration of live E. coli into the uterus of pregnant rats can result in neutrophil infiltration in the fetal brain, increased fetal reabsorption and stillbirth, while surviving pups exhibit increased brain chemokines, cytokines, white matter injury, and behavioral phenotypes (Debillon et al., 2003; RodtsPalenik et al., 2004; Pang et al., 2005; Yuan et al., 2005; Girard et al., 2009; Bergeron et al., 2013). The effects of bacterial mimetics such as the cell wall component lipopolysaccharide (LPS), have also been investigated. Intracervical injection in embryonic day 15 (E15) mice was associated with mild white matter injury but no behavioral deficits (Bell and Hallenbeck, 2002; Poggi et al., 2005; Wang et al., 2007a), whereas repeated intracervical LPS was associated with delayed neurosensory development (Toso et al., 2005; Rousset et al., 2006, 2013). Other inflammatory models include viral infection simulated by injection of poly(I:C), a synthetic double stranded viral RNA, injection of which is associated with long-term behavioral deficits (Shi et al., 2009; Richetto et al., 2013). Postnatal administration of inflammatory agents is widely used in rodents to model postnatal infection. Subcutaneous injection of live E. coli to P3 mouse pups was associated with microgliosis, loss of oligodendrocytes, and impaired motor coordination (Lieblein-Boff et al., 2013). However, most techniques which employ live bacterial injection have very high mortality rates (Rodewald et al., 1992; Tran and Weisman, 2004; Placencia et al., 2009; Loron et al., 2011). Postnatal intraperitoneal injection of LPS can also cause white matter damage and cerebral cytokine response (Brochu et al., 2011; Brehmer et al., 2012; Nobuta et al., 2012; Smith et al., 2014). Repeated daily injection of LPS in mice resulted in elevated serum IL-6, reduced gray matter volume, decreased oligodendrocyte numbers, and decreased myelin staining (Wang et al., 2009; Malaeb et al., 2014). Similarly, repeated IL-1 $\beta$ injection in 
P1-P5 mice has been associated with impaired oligodendrocyte progenitor maturation, and severe memory deficits (Favrais et al., 2011).

One of the strengths of the inflammation model is that it reflects the exposure to infectious or inflammatory agents present outside of the highly sterile individually ventilated cages where many academic institutions keep experimental animals. Most of the inflammatory risk factors for increased severity of $\mathrm{HI}$ injury in human patients, such as maternal infection (Stoll et al., 2004; Girard et al., 2012; Dean et al., 2015), will result in systemic inflammation in addition to CNS-specific recruitment of microglia. However, there is currently debate concerning the relevance of maternal inflammation to fetal brain damage (Leviton et al., 1999; Redline and O'Riordan, 2000; Neufeld et al., 2005). The debate intensifies when fetal systemic inflammation is contrasted with neuroinflammation. Although the majority of publications cited above administer pro-inflammatory agents by intracerebral injection, some studies have administered LPS by intravenous injection (reviewed in Wang et al., 2006). In fetal sheep, intravenous LPS causes white-matter specific damage (Garnier et al., 2001, 2006; Duncan et al., 2002; Mallard et al., 2003; Peebles et al., 2003; Svedin et al., 2005), suggesting that systemic inflammation may be sufficient to trigger brain injury. However, the results of these experiments could be explained by a secondary neuroinflammatory response to systemic inflammation causing the white matter injury. Separating these parameters in future experiments will prove demanding.

Data suggest that gene expression in mouse models of inflammation closely corresponds to that seen in humans (Takao and Miyakawa, 2015), however, postnatal murine response to inflammation is likely different to that experienced by a human fetus. An important limitation of inflammatory studies is impact on cardiovascular function and the potential for secondary cerebral HI (Eklind et al., 2001; Favrais et al., 2011; Wang C.T. et al., 2015). Another is that varying results have been reported. This may be due to differences in LPS used between groups, purification method (Westphal, 1965; Lam et al., 2014), or dose (Fujihara et al., 2003). Alternatively, there is increasing evidence that the considerable individual variability in response to clinical sepsis between patients is related to host genetics (Christaki and Giamarellos-Bourboulis, 2014). Therefore, although inflammation is doubtless an important factor in neonatal brain injury, the variation between different models makes these methods difficult to evaluate.

\section{Alternative Models}

In many ways, non-rodent models are more representative of neonatal HI as it affects human patients. Here follows a brief flavor of techniques. Relatively few studies have investigated neonatal HI in primates. Classical studies asphyxiated term monkey fetuses by covering their heads with a rubber sac and clamping the umbilical cord (Fahn et al., 1979). Fetuses resuscitated after $20 \mathrm{~min}$ had extremely high mortality. However, $12 \mathrm{~min}$ of asphyxia were required to produce any neuropathologic injury. The fetuses displayed damage predominantly within the brainstem. In a model of partial ischemia (Fahn et al., 1979), pregnant females were rendered hypotensive during the third trimester. When blood oxygen saturation was reduced to $10 \%$ for $5 \mathrm{~h}$, fetuses became profoundly acidemic. At birth, these displayed opisthotonus, decerebrate posturing, and convulsions. There is one model of whitematter injury based on baboons delivered prematurely by hysterotomy (Inder et al., 2004, 2005a,b). Premature baboons were treated in an intensive care setting. Approximately half displayed white-matter injury. Analysis of behavior has not been undertaken.

More work has been carried out in fetal sheep. Umbilical cord occlusion and term asphyxia has been carried out (Gunn et al., 1992; Williams et al., 1992; Mallard et al., 1993; Richardson B. et al., 1996; de Haan et al., 1997a,b,c; Richardson and Bocking, 1998; Dalitz et al., 2003), repeated asphyxia at 5-h intervals resulted in injury to the striatum almost exclusively, whereas episodes of asphyxia repeated every 5 min caused diffuse and extensive damage to cortex, thalamus, and cerebellum in $40 \%$ of animals, and selective neuronal necrosis in the remainder. White matter injury has also been investigated (Ting et al., 1983), only those fetuses in which the mean arterial blood pressure fell below $30 \mathrm{mmHg}$ exhibit brain damage, irrespective of hypoxia. Neuropathologic injury after carotid artery occlusion for $30 \mathrm{~min}$ caused both gray and white matter involvement, with cortical damage and selective neuronal necrosis in thalamus and striatum (Reddy et al., 1998; Petersson et al., 2002). Several laboratories have developed models in sheep after systemic endotoxemia (Duncan et al., 2002; Mallard et al., 2003). Unfortunately, no behavioral outcomes are currently available in sheep.

Finally, other small laboratory animals have been investigated. Preterm rabbit fetuses exposed to sustained placental insufficiency via intrauterine occlusion of the descending aorta displayed significant alterations in motor responses to olfactory stimuli, coordination of suck and swallow, and marked hypertonia, reminiscent of spastic quadriplegia (Yoon et al., 1997; Derrick et al., 2004, 2007; Saadani-Makki et al., 2008). Diffusion-weighted imaging detected a threshold in white matter loss below which all rabbit kits developed hypertonia, (Drobyshevsky et al., 2005, 2007a). Another promising model is that of the spiny mouse, a rodent which shows a similar level of brain development to a human neonate at birth (Brunjes, 1985, 1989, 1990; Gozzo et al., 1985; D’Udine and Alleva, 1988; Brunjes et al., 1989), which also shows varied motor deficits (Ireland et al., 2008, 2009, 2010) and neuroanatomical pathology (Hutton et al., 2009; O'Connell et al., 2013) following neonatal $\mathrm{HI}$.

In brief, large animals can better replicate the conditions of a single human fetus exposed to a non-sterile environment. However, none of these models have access to the same extent of transgenic manipulation or validated behavioral tests that are possible in rodent studies. These models are invaluable for aiding comparison of brain development at birth which occur between species (Clancy et al., 2007), whereas the relative immaturity of mouse and rat brains at birth introduce an unwelcome variable into these experiments. For the foreseeable future, insights from 
both rodent work and larger animals will be important for better understanding neonatal $\mathrm{HI}$.

\section{SUBPLATE: A REGION OF HYPER-SENSITIVITY TO NEONATAL HI?}

One brain region exemplifying how much remains unknown about the developing brain's response to $\mathrm{HI}$, and the uncertainties involved in interpreting results from animal studies, is subplate. The subplate is an early-born transitory neuronal layer of cerebral cortex which serves an important role in the establishment of thalamocortical connectivity during development (reviewed in Judas et al., 2010; Kanold and Luhmann, 2010; Kostovic and Judas, 2010; Hoerder-Suabedissen and Molnár, 2015) (see Figure 4). Thalamocortical axons associate with and grow alongside subplate neurons in the developing cortex (Herrmann et al., 1994; Molnár et al., 1998; Kostovic and Judas, 2006), and selective excitotoxic ablation of subplate disrupts thalamocortical connectivity in animal models (Ghosh et al., 1990; Ghosh and Shatz, 1992; Lein et al., 1999; Kanold et al., 2003; Kanold and Shatz, 2006; Magnani et al., 2013).

Subplate has been identified in a range of mammals by conserved molecular markers (Hoerder-Suabedissen et al., 2009; Hoerder-Suabedissen and Molnár, 2012; Oeschger et al., 2012; Pedraza et al., 2014). Neuronal death occurs in infant subplate during normal development (Chun et al., 1987; Al-Ghoul and Miller, 1989; Hamre et al., 1989; Kostovic and Rakic, 1990; Woo et al., 1991; Price et al., 1997). However, the molecular mechanisms behind this programmed cell-death remain unknown (McQuillen and Ferriero, 2005; Hoerder-Suabedissen and Molnár, 2015). Functional roles for subplate in thalamocortical (Allendoerfer and Shatz, 1994; Kanold and Luhmann, 2010) and corticothalamic (Grant et al., 2016) development have been described, demonstrating lasting significance of this transient population.

The susceptibility of subplate neurons to neonatal HI remains little understood. Early studies claimed subplate is selectively vulnerable. Cultured rat subplate neurons were more vulnerable to OGD compared to mixed cortical neurons (Nguyen and McQuillen, 2010). In rats exposed to systemic HI at E18, a significant decrease in Nurr1-expressing subplate neurons was documented by P2 (Jantzie et al., 2014, 2015a,b,c) and similarly in fetal sheep (Dean et al., 2011). However, Nurr1-expressing Layer VI neurons were also decreased. It is also possible that $\mathrm{HI}$ induced differential marker expression in subplate neurons, rather than cell death. In vitro electrophysiological recordings in neocortical slices from newborn rats have demonstrated a pronounced functional impairment of subplate neurons following OGD (Albrecht et al., 2005). Another influentiential study that claimed selective vulnerability of subplate to hypoxia used immunohistochemistry to detect cell-death in neurons labeled with BrdU at E10.5 following a modified Rice-Vannucci model in P1 rats (McQuillen et al., 2003; McQuillen and Ferriero, 2004, 2005). However, Layer VI neurons born at this date also expressed cell-death markers, suggesting subplate may not be selectively susceptible to HI injury. Conversely, a systematic quantification of cell death markers throughout subplate compared with other cortical layers was conducted using immunohistochemistry (Okusa et al., 2014). Three subplate-specific marker positive populations showed little costaining with caspase- 3 in brains with mild to moderate $\mathrm{HI}$ lesions. In severely damaged cases, caspase- 3 staining was found throughout the cortex. Therefore, layer-specific sensitivity of cortical neurons to HI remains debated. A double birthdating study, targeting subplate and layer V or VI combined with $\mathrm{HI}$ could resolve this issue. However, such an experiment has not yet been performed.

Human literature supports the proposition that interstitial white matter, the equivalent of subplate in the postnatal human brain (Clancy et al., 2009; Suarez-Sola et al., 2009; GarciaMarin et al., 2010; Hoerder-Suabedissen and Molnár, 2015), shows structural damage as a result of neonatal injury. Tissue from preterm human infants with periventricular leukomalacia showed a deficit in the number of MAP-2 expressing neurons throughout the interstitial white matter (Kinney et al., 2012). Scarring has been observed in interstitial white matter, alongside the expression of cell death markers, in brain tissue from human infants (Pogledic et al., 2014). The number of interstitial neurons present in white matter is known to peak at the developmental stage most sensitive to white matter injury (Kostovic et al., 2002; Kostovic and Judas, 2010). Immunohistochemical analysis on neonatal telencephalon samples obtained post-mortem from infants born at 25-32 weeks gestation showed a significant loss of GABA-ergic subplate neurons (Robinson et al., 2006). Many reviews have highlighted the interstitial white matter as a site which should be more thoroughly investigated in neonatal brain injury (Volpe et al., 1996; Leviton and Gressens, 2007; Volpe, 2009; Kostovic et al., 2011). Several of these reviews propose a role for subplate in resultant cognitive and behavioral deficits (Volpe, 2009, 1977; Kostovic et al., 2011), based on the established role of subplate in thalamocortical development. Unfortunately, post-mortem studies are unable to convey whether subplate pathology is responsible for any of the clinical outcomes in patients. The response of both human and rodent subplate to neonatal $\mathrm{HI}$ remains unclear, despite assertions of interest from the field. A systematic study of the subplate in vitro and in vivo following $\mathrm{HI}$ injury would provide valuable information. As subplate transiently integrates within the developing cortical circuitry (see Figure 5) interactions between subplate neurons and other cortical neurons, such as key interneuron populations, should also be further investigated (Marques-Smith et al., 2016).

There are several reasons for believing that subplate could be critical in neonatal HI. One is the proposed transient secretory function. Subplate is enriched in CSPGs, whereas the adjacent intermediate zone is not (Kostovic et al., 2014). Chondroitin sulfate proteoglycans (CSPGs) are generally secreted from cells, and the subplate transcriptome catalogs a plethora of genes involved in production of extracellular matrix and proteoglycans (Belgard et al., 2011; Hoerder-Suabedissen et al., 2013). Additional genes with subplate-restricted expression in the cortex encode secreted proteins, including neuroserpin (Serpini1), neuronal pentraxin 1 (Nptx1), and insulin-like 
growth factor binding protein 5 (Igfbp5) (Hoerder-Suabedissen et al., 2013), several of which have been validated by immunohistochemistry (Kondo et al., 2015). Connective tissue growth factor (CTGF), secreted extracellular matrix-associated protein involved in regulation of cellular adhesion, migration, mitogenesis, differentiation and survival (Brigstock, 1999; Stritt et al., 2009), is also detectable in the subplate at E18, increasing in intensity at P3 and P8 (Hoerder-Suabedissen et al., 2009, 2013). It is unknown whether subplate-secreted proteins serve a protective function in the developing brain or not. Related to this secretory function, subplate neurons express relatively mature rER (Kondo et al., 2015), an organelle essential for production of secreted proteins (reviewed in Novikoff, 1976; Pfeffer and Rothman, 1987; Lodish, 1988; Hurtley and Helenius, 1989; Pelham, 1989). As a result of the cellular pressures of high protein production, cells activate a series of mechanisms referred to as the ER stress response (Schroder and Kaufman, 2005; Wu and Kaufman, 2006; Kondo et al., 2011). Nissl staining demonstrates enriched protein production in subplate at P8 in mouse, although staining is much fainter in adult (Kondo et al., 2015). Morphology of subplate neurons is similar to that of rER-rich plasma cells under EM (Bloom, 1968; Kondo et al., 2015), and immunohistochemistry for ER stress marker binding immunoglobulin protein (BiP) confirmed that ER stress occurs in developing subplate (Okiyoneda et al., 2004; Kondo et al., 2005, 2012, 2015). BiP protein synthesis is up-regulated in whole brain under stress conditions, such as glucose deprivation, hypoxia, or the presence of toxins (Lee, 1987, 2001, 2005). It is not known exactly which proteins are secreted throughout development by the subplate, but this enhanced metabolic stress during hypoxia and the potential for neuroprotective secretion reinforce the value of further study of subplate in neonatal HI models and human patients.

\section{NEUROSERPIN: A CASE FOR A NOVEL NEUROPROTECTIVE TREATMENT}

The development of novel treatments to supplement the sole currently licensed therapy, hypothermia (Jacobs et al., 2005, 2013; Shah et al., 2007; Tagin et al., 2012), is imperative. Since the discovery of this groundbreaking treatment, little progress has been made in identifying additive pharmacological therapies. Few potential treatments have translated to human clinical trials. Resuscitation at room temperature (Vento et al., 2001a,b; Rabi et al., 2007) and xenon gas administration alongside hypothermia (Hobbs et al., 2008; Thoresen et al., 2009) are the only therapies shown to have any additive effect. However, more recent publications have questioned the efficacy of xenon as an additive therapy alongside hypothermia. For example, randomized clinical trials have demonstrated that although xenon gas is a safe treatment, there is little or no therapeutic effect of combined hypothermia and xenon gas in moderate and severe cases of neonatal $\mathrm{HI}$ at 18 months follow-up (Azzopardi et al., 2013, 2015; Dingley et al., 2014). A similar experiment in rats found that xenon treatment made no difference to lesion size or neuronal cell numbers in cases of severe HI (Sabir et al., 2016). Barbiturate anticonvulsants have no effect on long-term neurological development when given following neonatal HI (reviewed in Goldberg et al., 1986; Hall et al., 1998; Singh et al., 2004; Vargas-Origel et al., 2004; Evans et al., 2007). Recent clinical studies suggest that high dose erythropoietin (EPo) treatment in term HI neonates reduces disability (Strunk et al., 2008; Zhu et al., 2009; McPherson and Juul, 2010). However, even proponents of this potential treatment advise caution in interpreting these early results, and the therapeutic effect by no means completely prevents disability. Combination therapy of $\mathrm{N}$-acetylcysteine, a free radical scavenger, and systemic hypothermia reduces infarct volume after focal HI injury (Jatana et al., 2006). Another free radical scavenger, allopurinol, reduces cerebral edema and neuropathological damage (Palmer et al., 1990). However, these treatments have only been trialed in animals, and the field is still awaiting a candidate neuroprotectice molecule which is both safe and effective in neonatal humans (Lai and Yang, 2011; Pazos et al., 2012).

Another therapeutic approach under development for neonatal HI is stem cell therapy (reviewed in Parolini et al., 2010; Zhang X. et al., 2014; Douglas-Escobar and Weiss, 2015; González-Portillo et al., 2015; Ruiz et al., 2017). These therapies make use of evidence that transplantation of human bone-marrow derived stem cells into the lesion can assist brain plasticity (Bonifacio et al., 2011; Tajiri et al., 2013). Results of this therapy have been promising in animal models (Jendelová et al., 2004; Daadi et al., 2009a,b), however, the technique awaits validation in a clinical setting. Additionally, the use of stem cell therapy for cerebral palsy in human patients has produced mixed results (Li et al., 2012; Liao et al., 2013; Sharma, 2014).

Therefore, new approaches are required to identify potential neuroprotective molecules as treatments for neonatal HI (Tuor et al., 1995; Ferriero, 2004; Fan et al., 2010). Drawing on our detailed yet incomplete knowledge of the physiology of neonatal HI, several factors must be satisfied in a new potential therapy. All potential treatments should be safe for vulnerable neonates and not interfere with essential developmental milestones. This challenges the NMDA-inhibition strategies (Meldrum, 1990; Johnston, 2001, 2005), as the glutamate system is essential for setting up normal synaptic plasticity within the developing brain (Hattori and Wasterlain, 1990; Ikonomidou et al., 1999; Johnston, 2009). Treatments should also be specific, to avoid extreme adverse effects in these vulnerable infants. The ideal treatment would target molecules common to the excitotoxicity, oxidative stress and inflammation pathways (Chaudhari et al., 2014; Fischer and Maier, 2015; Chamorro et al., 2016; Burd et al., 2016). Targeting these common mediators would allow a single therapy to be efficacious against multiple mediators of brain damage, instead of merely eliciting a reshuffle of pathways to favor a different method of cell death. Here follows an outline of one potential therapy under development which may satisfy these theoretical restraints as a model to incite debate concerning how future therapies are identified. Enter: neuroserpin. 


\section{Neuroserpin's Molecular Pedigree}

Neuroserpin is a neuronally secreted serine-protease inhibitor enzyme with roles in cell death, neural plasticity, and microglial activation. Neuroserpin was first identified in the secreted product of cultured neuronal axons (Osterwalder et al., 1996). Protein expression is primarily localized to neurons (Osterwalder et al., 1996; Hastings et al., 1997; Lee et al., 2015b). The protein neuroserpin is encoded in mouse and human by the gene Serpini1. Serpini1 mRNA expression is specific to the CNS, both in mouse (Krueger et al., 1997) and human (Teesalu et al., 2004). In situ hybridization studies have demonstrated expression of Serpini1 throughout cortex, hippocampus, and olfactory bulbs, with scattered expression in cerebellum, pons, and thalamus from birth until adulthood (Krueger et al., 1997). High Serpini1 expression has been identified in subplate relative to Layer VI of cortex in P8 mouse brain by microarray (Hoerder-Suabedissen et al., 2009), confirmed by immunohistochemistry (Kondo et al., 2015). Although Serpinil expression has been demonstrated in human brain tissue (Teesalu et al., 2004), detailed maps of expression are currently missing. This highly specific localisation suggests that Serpini1/neuroserpin modulatory treatments may not create dangerous side effects in other vulnerable organs such as the cardiovascular and pulmonary systems.

Neuroserpin is an inhibitory enzyme. Its primary target is the adult human stroke treatment, tissue plasminogen activator (tPA) (Osterwalder et al., 1996, 1998; Barker-Carlson et al., 2002; Yepes and Lawrence, 2004a; Miranda and Lomas, 2006; Ricagno et al., 2009, 2010). Neuroserpin has also been shown to exhibit weak inhibition of plasmin and urokinase plasminogen activator (Osterwalder et al., 1998). This function is conserved across species (Schrimpf et al., 1997; Hill et al., 2001; Ellisdon et al., 2014). Through inhibition of tPA, neuroserpin has the potential to influence many distinct molecular cascades (Yepes and Lawrence, 2004b,c; Benarroch, 2007; Yepes, 2015). tPA, also secreted by neurons (Krystosek and Seeds, 1981a,b; Lochner et al., 2006), has been shown to interact with a large number of pathways; activating NMDA receptors (Qian et al., 1993; Nicole et al., 2001), activating microglia (Benchenane et al., 2004), and recruitment of cell death related cascades (Yepes and Lawrence, 2004a; Zhao et al., 2007), in addition to its function of cleaving vascular thrombosis (Rijken et al., 1979, 1980). The known components of the neuroserpin/tPA molecular cascade are summarized in Figure 6.

Other, tPA-independent enzymatic pathways for neuroserpin have also been described (Ma et al., 2012a). Cell lines over-expressing neuroserpin demonstrate an increase in $\mathrm{N}$-cadherin protein expression and related cell adhesion, maintained when the tPA binding site of neuroserpin is mutated (Lee et al., 2008). In vitro, neuroserpin has been shown to prevent excitotoxic neuronal death induced by plasmin and kainic acid ( $\mathrm{Wu}$ et al., 2010), and the 20 methionine residues present within neuroserpin have been claimed to convey protection against oxidative stress (Mohsenifar et al., 2007), and exogenous neuroserpin has been shown to possess anti-inflammatory properties (Munuswamy-Ramanujam et al., 2010). The molecular cascades behind these tPA independent functions are not well understood (Ma et al., 2012a). Therefore, neuroserpin has the pedigree to target multiple cell death pathways occurring in the brain during neonatal HI.

\section{Cell Death, Inflammation, and Plasticity}

Neuroserpin's physiological actions can be broadly categorized into three major pathways: cell death, neuronal plasticity, and immune cell activation. These closely follow the major classes of molecular change proposed by pathological theories of neonatal $\mathrm{HI}$, suggesting that neuroserpin offers the potential to target multiple brain-damage pathways.

Neuroserpin has been implicated in protection against neuronal death (Galliciotti and Sonderegger, 2006). Exogenous neuroserpin administration in vitro decreases apoptosis caused by tPA, NMDA, kainic acid, and OGD (Lebeurrier et al., 2005a,b; Mohsenifar et al., 2007; Lee et al., 2008; Wu et al., 2010; Rodríguez-González et al., 2011a; Ma et al., 2012b). In addition, aberrant initiation of neuroserpin expression in cancer cells preserves the tumor and has been linked with increased treatment-resistance in prostate cancer (Chang et al., 2000; Hasumi et al., 2005; Valiente et al., 2014). Exogenous neuroserpin reduces spread of kainate-induced seizures in mouse, and decreases the expression of cell death markers (Yepes et al., 2002).

Of the three classes of neuroserpin function, its role in inflammation is the least well understood. When applied to vascular plaques in vitro, recombinant neuroserpin reduced T-Cell lymphocyte invasion (Munuswamy-Ramanujam et al., 2010). Administration of intracerebral neuroserpin directly following adult $\mathrm{HI}$ stroke in mouse, showed a qualitative decrease in the volume of infarct infiltrated by activated microglia (Yepes et al., 2000), and lower microglial inflammatory marker expression (Gelderblom et al., 2013). In human adult stroke patients, higher levels of neuroserpin in blood samples correlate with lower levels of immune marker proteins (RodríguezGonzález et al., 2011c). There is considerable debate whether microglial activation is beneficial or detrimental in neonatal HI (McRae et al., 1995; Mallard et al., 2013; Kaur et al., 2013), so understanding the role of neuroserpin in balancing this cascade could provide important data. The lack of a complete molecular network explaining these anti-inflammatory effects highlights the complexity of the pathways involved in cell death and inflammation. Understanding the underlying explanation for these changes will be an important preliminary to administration in human infants who do not live in the highly sterile environments maintained for experimental animals.

In addition, neuroserpin is involved in neuronal plasticity. This could be problematic in the development of neuroserpin as a neonatal HI treatment for human patients, as the neonatal human brain circuitry is undergoing a great deal of developmental plasticity modifications (reviewed in Aoki and Siekevitz, 1988; Partanen et al., 2013; Simpson et al., 2014). The first evidence that neuroserpin may have a role in neuronal plasticity originated from studies of endocrine cell lines, which grow neurite-like processes when neuroserpin is administered to their media (Hill et al., 2001; Jacovina et al., 2001; Borges et al., 2010). At the molecular level, neuroserpin secretion from dense core vesicles is enhanced by depolarisation in cultured neurons (Berger et al., 1999; Ishigami et al., 2007). Monocular 


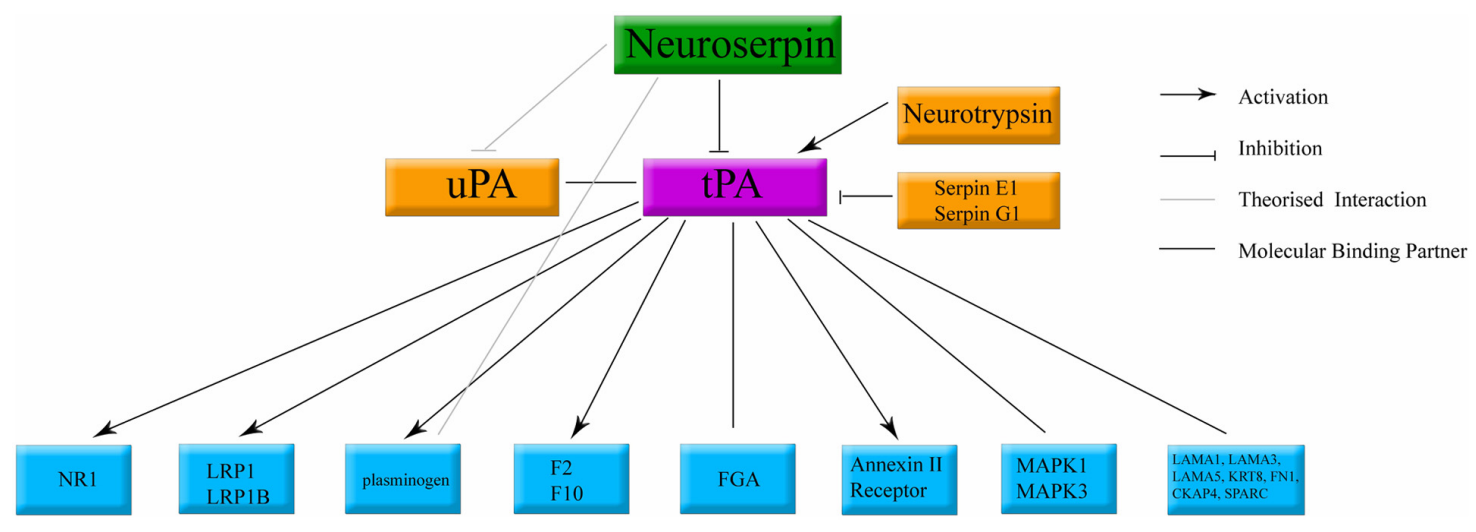

FIGURE 6 | Classical binding cascade for neuroserpin protein. The main molecular target of neuroserpin is inhibition of tPA. Confirmed molecular binding partners are shown with a black line. Arrows denote confirmed activation. Orthogonal lines denote confirmed inactivation. Lines without caps denote confirmed binding with no documented physiological data. tPA, tissue plasminogen activator; uPA, urokinase plasminogen activator. All other abbreviations denote standard gene names.

enucleation at P11 in mouse led to decreased Serpini1 mRNA expression in contralateral primary visual cortex compared to the control hemisphere (Wannier-Morino et al., 2003). The relative importance of this molecular cascade for human plasticity is as yet unclear.

\section{Neuroserpin in In Vitro and Adult Hypoxia Ischaemia}

Neuroserpin has been studied extensively in cell culture models of HI stroke. Administration of neuroserpin protects mouse cortical neurons in vitro against NMDA-induced excitotoxicity, but not AMPA-induced excitotoxicity (Lebeurrier et al., 2005a,b; Ma et al., 2012b). Further, neuroserpin is protective in an in vitro model of HI, OGD (Wu et al., 2010; Rodríguez-González et al., 2011a; Ma et al., 2012b). Both neurons and astrocytes cultured in OGD undergo less apoptosis and do not exhibit damaged neural processes when exogenous neuroserpin is administered following OGD (Rodríguez-González et al., 2011a; Ma et al., 2012b). Hippocampal neurons from both wild-type and tPA knockout mice were protected from OGD, plasmin-mediated cell death and kainic acid by neuroserpin administration (Wu et al., 2010), demonstrating that neuroserpin's neuroprotective role is not exclusively dependent on tPA inhibition.

Neuroserpin is also neuroprotective in vivo. The major model used to simulate hypoxic-ischaemic stroke in adult rodents is analogous to the Rice-Vannucci model described above for neonates (Eklöf and Siesjö, 1973; Rice et al., 1981; Bederson et al., 1986). Adult rats injected with neuroserpin before left common carotid artery ligation followed by acute hypoxia showed a decrease in infarct volume compared to controls, in addition to a decrease in expression of apoptosis markers (Yepes et al., 2000). Neuroserpin knockout mice show increased lesion volumes following adult HI (Cinelli et al., 2001; Gelderblom et al., 2013), whereas transgenic mice expressing six-times normal neuroserpin expression demonstrate smaller infarct volumes (Cinelli et al., 2001). Exogenous neuroserpin injection is also protective against NMDA injection in live adult rat (Lebeurrier et al., 2005a). Currently, the only evidence for this has come from adults models of $\mathrm{HI}$ stroke, far from conclusive evidence of neonatal protection due to the differences in neuroanatomy and neurochemistry between the developing and adult brain. However, this work remains of utility, as at the very least investigating the neuroserpin-tPA system in neonatal models will add to understanding of the differences between neonatal and adult response to $\mathrm{HI}$.

Neuroserpin administration in rats increases the window for effective tPA treatment in a model of adult stroke (Zhang et al., 2002). Increased tPA expression is found in neuroserpin knockout mice undergoing adult $\mathrm{HI}$ injury compared to controls (Cinelli et al., 2001; Gelderblom et al., 2013). However, exogenous neuroserpin is neuroprotective in tPA knockout mice (Wu et al., 2010). Ischaemic-reperfusion-induced injury in the retina of tPA knockout mice demonstrated rescued retinal apoptotic marker expression when injected with neuroserpin (Gu et al., 2015). Therefore, the neuroprotective properties of neuroserpin in adult $\mathrm{HI}$ appear to involve both neuroserpin's tPA-dependent and tPA-independent molecular cascades.

A role for neuroserpin in human adult $\mathrm{HI}$ stroke has also been described. Correlative studies have shown that high concentrations of neuroserpin in blood samples from human patients are associated with better functional outcome (Rodríguez-González et al., 2011b) and reduced inflammation (Rodríguez-González et al., 2011c). However, attempts to find a relationship between neuroserpin polymorphisms in humans and likelihood of stroke have produced little evidence of protective neuroserpin variants (Cole et al., 2007; Tjärnlund-Wolf et al., 2011). Mutations in the neuroserpin gene have been associated with two rare hereditary disorders (Galliciotti and Sonderegger, 2006); individuals present either with epilepsy (Yepes et al., 2002; Coutelier et al., 2008) or dementia with neuroserpin inclusion bodies (Davis et al., 1999a,b, 2002; Yazaki et al., 2001; Ricagno et al., 2010). It is not currently known whether these disorders are caused by novel functions of the mutated protein or by loss of physiological functions (Lee et al., 2015a). 


\section{Neuroserpin in Neonatal Hypoxia-Ischaemia}

The evidence above from adult models of HI stroke is far from conclusive evidence of neonatal protection due to differences between the developing and adult brain. However, this work remains of utility, as at the very least investigating neuroserpin in neonatal models will add to understanding of the differences between neonatal and adult response to $\mathrm{HI}$.

Evidence for a role of neuroserpin in neonatal $\mathrm{HI}$ is not entirely absent. A patent application published online claims that neuroserpin injection $4 \mathrm{~h}$ after neonatal $\mathrm{HI}$ in rat pups reduced infarct volume, but had no effect on LPS-sensitized HI (Kuan et al., 2010). However, the small number of published rodent microarrays following neonatal $\mathrm{HI}$ have failed to detect significant changes in Serpinil expression (Carmel et al., 2004; Hedtjarn et al., 2004a,b; Juul et al., 2009; Nagel et al., 2012; Rognlien et al., 2014). This could be explained by the delay between $\mathrm{HI}$ injury and sample collection, $6 \mathrm{~h}$ to 7 days post injury in this sample, which may be too early or too late to expect to see genomic changes in Serpinil expression. Also, microarray studies cannot reveal whether neonatal HI causes differences in neuroserpin translation or secretion, neither of which have yet been studied in neonatal $\mathrm{HI}$.

Despite the lack of evidence for neuroserpin's direct role in neonatal $\mathrm{HI}$, substantially more has been published documenting effects of its primary molecular target, tPA, in neonatal HI. tPA is broadly considered to be deleterious to cerebral recovery from neonatal HI (Adhami et al., 2008; Omouendze et al., 2013). In P7 rats which underwent unilateral common carotid artery ligation, tPA treatment was found to impair blood flow throughout the brain, an effect which was rescued by injection of the tPA inhibitor $\alpha 2$-antiplasmin (Adhami et al., 2008). Release of tPA by the cerebral microvasculature, as seen following neonatal $\mathrm{HI}$, has also been shown to compromise the glucose content of the extracellular medium in neonatal mouse cortical culture (Henry et al., 2013). Administration of tPA inhibitor Plasminogen-activator-inhibitor 1 (PAI1) reduces locomotor disorder and white matter damage in LPS-sensitized neonatal HI rats (Yang et al., 2013a,b; Yang and Kuan, 2015). This pathway is relatively understudied in neonatal HI research, despite the potential to target a multitude of injury-relevant molecules. Drawing attention to molecules like neuroserpin and tPA, potential common moderators of injury pathways, will be essential to the development of new efficacious pharmacological treatments.

\section{CONCLUSION}

Neonatal HI remains the most common cause of infant death and disability globally. Reducing the burden of morbidity should be a high priority for biomedical research. A dearth of treatments are currently available postnatally for these vulnerable infants, restricted to only hypothermia, a breakthrough treatment which is not fully effective in all cases, with no currently licensed additive pharmacological treatments. A complex network of interacting molecular cascades, including excitotoxicity, oxidative stress, and inflammation contribute to the gradually developing pattern of neuronal cell death seen in asphyxiated neonates. Targeting common mediators of these pathways with specific targets linked to far-reaching effects offers a potential approach to generating new pharmacological treatments to exact neuroprotection in these neonatal patients.

\section{AUTHOR CONTRIBUTIONS}

All authors listed have made substantial, direct, and intellectual contribution to this work, and approved its final version for publication. LM, LS, AH-S, and ZM: conceived the review focus, conducted literature review, evaluated the literature. LM: reviewed literature, wrote first draft, critically revised the first draft, and finalized the manuscript. LS, AH-S, and ZM: gave feedback, and finalized the manuscript. All authors approved final version of manuscript.

\section{FUNDING}

This work was supported by the Department of Physiology, Anatomy and Genetics, University of Oxford, Oxford UK. LM is funded by the Clarendon Fund, Oxford, UK; University College, University of Oxford, UK; and the Department of Physiology, Anatomy and Genetics, University of Oxford, Oxford, UK. ZM is funded by the Department of Physiology, Anatomy and Genetics, University of Oxford, Oxford, UK. LS, AH-S and ZM are funded by the Medical Research Council Grant numbers: G00700311 and G00900901. LS and ZM are funded by The Academy of Medical Sciences Newton Advanced Fellowship in partnership with The Royal Society and The National Natural Science Foundation of China for collaborative projects (UK/China grant numbers: NA160314/8161101585).

\section{ACKNOWLEDGMENTS}

We thank Prof. David Edwards, Prof. Pierre Gressens, Dr. Bobbi Fleiss, Dr. Claire Thornton, and Dr. Ana Baburamani for informative discussions on neonatal hypoxia ischaemia and its models.

\section{SUPPLEMENTARY MATERIAL}

The Supplementary Material for this article can be found online at: http://journal.frontiersin.org/article/10.3389/fncel. 2017.00078/full\#supplementary-material 


\section{REFERENCES}

Adamsons, K., and Myers, R. E. (1973). Perinatal asphyxia, causes, detection and neurologic sequelae. Pediatr. Clin. North Am. 20, 465-480. doi: 10.1016/S00313955(16)32855-3

Ådén, U., Halldner, L., Lagercrantz, H., Dalmau, I., Ledent, C., and Fredholm, B. B. (2003). Aggravated brain damage after hypoxic ischemia in immature adenosine A2A knockout mice. Stroke 34, 739-744. doi: 10.1161/01.STR.0000060204.67672.8B

Adhami, F., Yu, D., Yin, W., Schloemer, A., Burns, K. A., Liao, G., et al. (2008). Deleterious effects of plasminogen activators in neonatal cerebral hypoxiaischemia. Am. J. Pathol. 172, 1704-1716. doi: 10.2353/ajpath.2008.070979

Agrawal, V., and Hirsch, E. (2012). Intrauterine infection and preterm labor. Semin. Fetal Neonatal Med. 17, 12-19. doi: 10.1016/j.siny.2011.09.001

al Naqeeb, N., Edwards, A. D., Cowan, F. M., and Azzopardi, D. (1999). Assessment of neonatal encephalopathy by amplitude-integrated electroencephalography. Pediatrics 103, 1263-1271. doi: 10.1542/peds.103.6.1263

Albrecht, J., Hanganu, I. L., Heck, N., and Luhmann, H. J. (2005). Oxygen and glucose deprivation induces major dysfunction in the somatosensory cortex of the newborn rat. Eur. J. Neurosci. 22, 2295-2305. doi: 10.1111/j.1460-9568.2005. 04398.x

Alexander, M., Garbus, H., Smith, A., Rosenkrantz, T., and Fitch, R. (2014). Behavioral and histological outcomes following neonatal $\mathrm{HI}$ injury in a preterm (P3) and term (P7) rodent model. Behav. Brain Res. 259, 85-96. doi: 10.1016/j. bbr.2013.10.038

Al-Ghoul, W. M., and Miller, M. W. (1989). Transient expression of Alz-50 immunoreactivity in developing rat neocortex: a marker for naturally occurring neuronal death? Brain Res. 481, 361-367. doi: 10.1016/0006-8993(89)90815-9

Allendoerfer, K. L., and Shatz, C. J. (1994). The subplate, a transient neocortical structure: its role in the development of connections between thalamus and cortex. Annu. Rev. Neurosci. 17, 185-218. doi: 10.1146/annurev.ne.17.030194. 001153

Alsharnoubi, J. M., Odland, H. H., and Saugstad, O. D. (2012). Nicotine does not influence NF-kappaB activity in neonatal mice reoxygenated with roomair or 100\% oxygen. J. Mater. Fetal Neonatal Med. 25, 2102-2105. doi: 10.3109/ 14767058.2012.678434

Alvarez-Diaz, A., Hilario, E., de Cerio, F. G., Valls-i-Soler, A., and Alvarez-Diaz, F. J. (2007). Hypoxic-ischemic injury in the immature brain-key vascular and cellular players. Neonatology 92, 227-235. doi: 10.1159/000103741

Andine, P., Thordstein, M., Kjellmer, I., Nordborg, C., Thiringer, K., Wennberg, E., et al. (1990). Evaluation of brain damage in a rat model of neonatal hypoxicischemia. J. Neurosci. Methods 35, 253-260. doi: 10.1016/0165-0270(90) 90131-X

Anju, T. R., Abraham, P. M., Antony, S., and Paulose, C. S. (2010a). Alterations in cortical GABAB receptors in neonatal rats exposed to hypoxic stress: role of glucose, oxygen, and epinephrine resuscitation. Mol. Cell. Biochem. 343, 1-11. doi: 10.1007/s11010-010-0491-9

Anju, T. R., Ajayan, M. S., and Paulose, C. S. (2013a). Disruption of cerebellar cholinergic system in hypoxic neonatal rats and its regulation with glucose, oxygen and epinephrine resuscitations. Neuroscience 236, 253-261. doi: 10.1016/j.neuroscience.2012.12.056

Anju, T. R., Binoy, J., Anitha, M., and Paulose, C. S. (2012a). Striatal GABA receptor alterations in hypoxic neonatal rats: role of glucose, oxygen and epinephrine treatment. Neurochem. Res. 37, 629-638. doi: 10.1007/s11064-011-0654-4

Anju, T. R., Jayanarayanan, S., and Paulose, C. S. (2011a). Decreased GABAB receptor function in the cerebellum and brain stem of hypoxic neonatal rats: role of glucose, oxygen and epinephrine resuscitation. J. Biomed. Sci. 18:31. doi: 10.1186/1423-0127-18-31

Anju, T. R., Korah, P. K., Jayanarayanan, S., and Paulose, C. S. (2011b). Enhanced brain stem $5 \mathrm{HT}(2) \mathrm{A}$ receptor function under neonatal hypoxic insult: role of glucose, oxygen, and epinephrine resuscitation. Mol. Cell. Biochem. 354, 151-160. doi: 10.1007/s11010-011-0814-5

Anju, T. R., Mathew, J., Jayanarayanan, S., and Paulose, C. S. (2010b). Cerebellar 5HT2A receptor function under hypoxia in neonatal rats: role of glucose, oxygen, and epinephrine resuscitation. Respir. Physiol. Neurobiol. 172, 147-153. doi: 10.1016/j.resp.2010.05.009

Anju, T. R., Naijil, G., Shilpa, J., Roshni, T., and Paulose, C. S. (2013b). Neonatal hypoxic insult-mediated cholinergic disturbances in the brain stem: effect of glucose, oxygen and epinephrine resuscitation. Neurol. Sci. 34, 287-296. doi: 10.1007/s10072-012-0989-x

Anju, T. R., Nandhu, M. S., Jes, P., and Paulose, C. S. (2011c). Endocrine regulation of neonatal hypoxia: role of glucose, oxygen, and epinephrine supplementation. Fetal Pediatr. Pathol. 30, 338-349. doi: 10.3109/15513815.2011.587498

Anju, T. R., Peeyush Kumar, T., and Paulose, C. S. (2010c). Decreased GABAA receptors functional regulation in the cerebral cortex and brainstem of hypoxic neonatal rats: effect of glucose and oxygen supplementation. Cell Mol. Neurobiol. 30, 599-606. doi: 10.1007/s10571-009-9485-0

Anju, T. R., Smijin, S., Chinthu, R., and Paulose, C. S. (2012b). Decreased cholinergic function in the cerebral cortex of hypoxic neonatal rats: role of glucose, oxygen and epinephrine resuscitation. Respir. Physiol. Neurobiol. 180, 8-13. doi: 10.1016/j.resp.2011.08.013

Anju, T. R., Smijin, S., Korah, P. K., and Paulose, C. S. (2011d). Cortical 5HT 2A receptor function under hypoxia in neonatal rats: role of glucose, oxygen, and epinephrine resuscitation. J. Mol. Neurosci. 43, 350-357. doi: 10.1007/s12031010-9449-3

Anju, T. R., and Paulose, C. S. (2011). Amelioration of hypoxia-induced striatal 5-HT(2A) receptor, 5-HT transporter and HIF1 alterations by glucose, oxygen and epinephrine in neonatal rats. Neurosci. Lett. 502, 129-132. doi: 10.1016/j. neulet.2011.05.236

Anju, T. R., and Paulose, C. S. (2013). Striatal cholinergic functional alterations in hypoxic neonatal rats: role of glucose, oxygen, and epinephrine resuscitation. Biochem. Cell Biol. 91, 350-356. doi: 10.1139/bcb-2012-0102

Aoki, C., and Siekevitz, P. (1988). Plasticity in brain development. Sci. Am. 259, 56-64. doi: 10.1038/scientificamerican1288-56

Applegate, C. D., Jensen, F., Burchfiel, J. L., and Lombroso, C. (1996). The effects of neonatal hypoxia on kindled seizure development and electroconvulsive shock profiles. Epilepsia 37, 723-727. doi: 10.1111/j.1528-1157.1996.tb00642.x

Arteni, N. S., Salgueiro, J., Torres, I., Achaval, M., and Netto, C. A. (2003). Neonatal cerebral hypoxia-ischemia causes lateralized memory impairments in the adult rat. Brain Res. 973, 171-178. doi: 10.1016/S0006-8993(03)02436-3

Aso, K., Scher, M. S., and Barmada, M. A. (1989). Neonatal electroencephalography and neuropathology. J. Clin. Neurophysiol. 6, 103-123. doi: 10.1097/00004691198904000-00001

Aujla, P. K., Fetell, M. R., and Jensen, F. E. (2009). Talampanel suppresses the acute and chronic effects of seizures in a rodent neonatal seizure model. Epilepsia 50, 694-701. doi: 10.1111/j.1528-1167.2008.01947.x

Autheman, D., Sheldon, R. A., Chaudhuri, N., von Arx, S., Siegenthaler, C., Ferriero, D. M., et al. (2012). Glutathione peroxidase overexpression causes aberrant ERK activation in neonatal mouse cortex after hypoxic preconditioning. Pediatr. Res. 72, 568-575. doi: 10.1038/pr.2012.124

Azzopardi, D., Robertson, N. J., Bainbridge, A., Cady, E., Charles-Edwards, G., Deierl, A., et al. (2015). Moderate hypothermia within $6 \mathrm{~h}$ of birth plus inhaled xenon versus moderate hypothermia alone after birth asphyxia (TOBY-Xe): a proof-of-concept, open-label, randomised controlled trial. Lancet Neurol. doi: 10.1016/S1474-4422(15)00347-6 [Epub ahead of print].

Azzopardi, D., Robertson, N. J., Kapetanakis, A., Griffiths, J., Rennie, J. M., Mathieson, S. R., et al. (2013). Anticonvulsant effect of xenon on neonatal asphyxial seizures. Arch. Dis. Child. Fetal Neonatal Ed. 98, F437-F439. doi: 10.1136/archdischild-2013-303786

Azzopardi, D. V., Strohm, B., Edwards, A. D., Dyet, L., Halliday, H. L., Juszczak, E., et al. (2009). Moderate hypothermia to treat perinatal asphyxial encephalopathy. N. Engl. J. Med. 361, 1349-1358. doi: 10.1056/NEJMoa 0900854

Baburamani, A. A., Ek, C. J., Walker, D. W., and Castillo-Melendez, M. (2012). Vulnerability of the developing brain to hypoxic-ischemic damage: contribution of the cerebral vasculature to injury and repair? Front. Physiol. 3:424. doi: 10.3389/fphys.2012.00424

Back, S. A., Gan, X., Li, Y., Rosenberg, P. A., and Volpe, J. J. (1998). Maturationdependent vulnerability of oligodendrocytes to oxidative stress-induced death caused by glutathione depletion. J. Neurosci. 18, 6241-6253.

Balduini, W., Carloni, S., and Buonocore, G. (2012). Autophagy in hypoxiaischemia induced brain injury. J. Matern. Fetal Neonatal Med. 25(Suppl. 1), 30-34. doi: 10.3109/14767058.2012.663176

Balduini, W., De Angelis, V., Mazzoni, E., and Cimino, M. (2000). Long-lasting behavioral alterations following a hypoxic/ischemic brain injury in neonatal rats. Brain Res. 859, 318-325. doi: 10.1016/S0006-8993(00)01997-1 
Balduini, W., De Angelis, V., Mazzoni, E., and Cimino, M. (2001). Simvastatin protects against long-lasting behavioral and morphological consequences of neonatal hypoxic/ischemic brain injury. Stroke 32, 2185-2191. doi: 10.1161/ hs0901.094287

Barker-Carlson, K., Lawrence, D. A., and Schwartz, B. S. (2002). Acyl-enzyme complexes between tissue-type plasminogen activator and neuroserpin are short-lived in vitro. J. Biol. Chem. 277, 46852-46857. doi: 10.1074/jbc. M207740200

Barkovich, A. J., Miller, S. P., Bartha, A., Newton, N., Hamrick, S. E., Mukherjee, P., et al. (2006). MR imaging, MR spectroscopy, and diffusion tensor imaging of sequential studies in neonates with encephalopathy. AJNR Am. J. Neuroradiolo. 27, 533-547.

Barkovich, A. J., Westmark, K., Partridge, C., Sola, A., and Ferriero, D. M. (1995). Perinatal asphyxia: MR findings in the first 10 days. AJNR Am. J. Neuroradiol. $16,427-438$

Barth, T. M., and Stanfield, B. B. (1990). The recovery of forelimb-placing behavior in rats with neonatal unilateral cortical damage involves the remaining hemisphere. J. Neurosci. 10, 3449-3459.

Baud, O., Daire, J. L., Dalmaz, Y., Fontaine, R. H., Krueger, R. C., Sebag, G., et al. (2004). Gestational hypoxia induces white matter damage in neonatal rats: a new model of periventricular leukomalacia. Brain Pathol. 14, 1-10. doi: 10.1111/j.1750-3639.2004.tb00492.x

Bauer, H. C., Bauer, H., Lametschwandtner, A., Amberger, A., Ruiz, P., and Steiner, M. (1993). Neovascularization and the appearance of morphological characteristics of the blood-brain barrier in the embryonic mouse central nervous system. Brain Res. Dev. Brain Res. 75, 269-278. doi: 10.1016/01653806(93)90031-5

Bederson, J. B., Pitts, L. H., Tsuji, M., Nishimura, M. C., Davis, R. L., and Bartkowski, H. (1986). Rat middle cerebral artery occlusion: evaluation of the model and development of a neurologic examination. Stroke 17, 472-476. doi: 10.1161/01.STR.17.3.472

Belgard, T. G., Marques, A. C., Oliver, P. L., Abaan, H. O., Sirey, T. M., HoerderSuabedissen, A., et al. (2011). A transcriptomic atlas of mouse neocortical layers. Neuron 71, 605-616. doi: 10.1016/j.neuron.2011.06.039

Bell, M. J., and Hallenbeck, J. M. (2002). Effects of intrauterine inflammation on developing rat brain. J. Neurosci. Res. 70, 570-579. doi: 10.1002/jnr. 10423

Benarroch, E. E. (2007). Tissue plasminogen activator: beyond thrombolysis. Neurology 69, 799-802. doi: 10.1212/01.wnl.0000269668. 08747.78

Benchenane, K., López-Atalaya, J. P., Fernández-Monreal, M., Touzani, O., and Vivien, D. (2004). Equivocal roles of tissue-type plasminogen activator in stroke-induced injury. Trends Neurosci. 27, 155-160. doi: 10.1016/j.tins.2003. 12.011

Bennet, L., Peebles, D. M., Edwards, A. D., Rios, A., and Hanson, M. A. (1998). The cerebral hemodynamic response to asphyxia and hypoxia in the near-term fetal sheep as measured by near infrared spectroscopy. Pediatr. Res. 44, 951-957. doi: 10.1203/00006450-199812000-00022

Berger, P., Kozlov, S. V., Cinelli, P., Krüger, S. R., Vogt, L., and Sonderegger, P. (1999). Neuronal depolarization enhances the transcription of the neuronal serine protease inhibitor neuroserpin. Mol. Cell. Neurosci. 14, 455-467. doi: 10.1006/mcne.1999.0804

Bergeron, J. D., Deslauriers, J., Grignon, S., Fortier, L. C., Lepage, M., Stroh, T., et al. (2013). White matter injury and autistic-like behavior predominantly affecting male rat offspring exposed to group B streptococcal maternal inflammation. Dev. Neurosci. 35, 504-515. doi: 10.1159/000355656

Bernard, S. A., Gray, T. W., Buist, M. D., Jones, B. M., Silvester, W., Gutteridge, G., et al. (2002). Treatment of comatose survivors of out-of-hospital cardiac arrest with induced hypothermia. N. Engl. J. Med. 346, 557-563. doi: 10.1056/ NEJMoa003289

Biagioni, E., Mercuri, E., Rutherford, M., Cowan, F., Azzopardi, D., Frisone, M. F., et al. (2001). Combined use of electroencephalogram and magnetic resonance imaging in full-term neonates with acute encephalopathy. Pediatrics 107, 461-468. doi: 10.1542/peds.107.3.461

Billiards, S. S., Haynes, R. L., Folkerth, R. D., Borenstein, N. S., Trachtenberg, F. L., Rowitch, D. H., et al. (2008). Myelin abnormalities without oligodendrocyte loss in periventricular leukomalacia. Brain Pathol. 18, 153-163. doi: 10.1111/j.17503639.2007.00107.x
Blaise, S. A., Nedelec, E., Alberto, J. M., Schroeder, H., Audonnet, S., Bossenmeyer-Pourie, C., et al. (2009). Short hypoxia could attenuate the adverse effects of hyperhomocysteinemia on the developing rat brain by inducing neurogenesis. Exp. Neurol. 216, 231-238. doi: 10.1016/j.expneurol.2008. 11.020

Blomgren, K., and Hagberg, H. (2006). Free radicals, mitochondria, and hypoxiaischemia in the developing brain. Free Radic. Biol. Med. 40, 388-397. doi: 10.1016/j.freeradbiomed.2005.08.040

Bloom, W. (1968). DW Fawcett A Textbook of Histology. Amsterdam: Saunders, 582.

Boksa, P., Zhang, Y., and Nouel, D. (2015). Maternal oxytocin administration before birth influences the effects of birth anoxia on the neonatal rat brain. Neurochem. Res. 40, 1631-1643. doi: 10.1007/s11064-0151645-7

Bona, E., Hagberg, H., Løberg, E. M., Bågenholm, R., and Thoresen, M. (1998). Protective effects of moderate hypothermia after neonatal hypoxiaischemia: short-and long-term outcome. Pediatr. Res. 43, 738-745. doi: 10.1203/ 00006450-199806000-00005

Bonifacio, S. L., Glass, H. C., Peloquin, S., and Ferriero, D. M. (2011). A new neurological focus in neonatal intensive care. Nat. Rev. Neurol. 7, 485-494. doi: 10.1038/nrneurol.2011.119

Borges, V. M., Lee, T. W., Christie, D. L., and Birch, N. P. (2010). Neuroserpin regulates the density of dendritic protrusions and dendritic spine shape in cultured hippocampal neurons. J. Neurosci. Res. 88, 2610-2617. doi: 10.1002/ jnr.22428

Boss, V., Sola, A., Wen, T. C., and Decker, M. J. (2005). Mild intermittent hypoxia does not induce stress responses in the neonatal rat brain. Biol. Neonate 88, 313-320. doi: 10.1159/000087629

Boylan, G. B., Young, K., Panerai, R. B., Rennie, J. M., and Evans, D. H. (2000). Dynamic cerebral autoregulation in sick newborn infants. Pediatr. Res. 48, 12-17. doi: 10.1203/00006450-200007000-00005

Brackmann, F. A., Link, A. S., Jung, S., Richter, M., Zoglauer, D., Walkinshaw, G., et al. (2013). Activin A regulation under global hypoxia in developing mouse brain. Brain Res. 1531, 65-74. doi: 10.1016/j.brainres.2013. 07.039

Brehmer, F., Bendix, I., Prager, S., van de Looij, Y., Reinboth, B. S., Zimmermanns, J., et al. (2012). Interaction of inflammation and hyperoxia in a rat model of neonatal white matter damage. PLoS ONE 7:e49023. doi: 10.1371/journal.pone.0049023

Brigstock, D. R. (1999). The Connective Tissue Growth Factor/Cysteine-Rich 61/Nephroblastoma Overexpressed (CCN) Family 1. Endocr. Rev. 20, 189-206. doi: 10.1210/er.20.2.189

Brochu, M. E., Girard, S., Lavoie, K., and Sebire, G. (2011). Developmental regulation of the neuroinflammatory responses to LPS and/or hypoxia-ischemia between preterm and term neonates: an experimental study. J. Neuroinflamm. 20, 55. doi: 10.1186/1742-2094-8-55

Brongholi, K., Souza, D. G., Bainy, A. C., Dafre, A. L., and Tasca, C. I. (2006). Oxygen-glucose deprivation decreases glutathione levels and glutamate uptake in rat hippocampal slices. Brain Res. 1083, 211-218. doi: 10.1016/j.brainres. 2006.02.003

Brooks, K. J., Clark, J. B., and Bates, T. E. (1996). Assessment of energy metabolism in the developing brain following aglycemic hypoxia by1H and31P NMR. Neurochem. Res. 21, 1089-1095. doi: 10.1007/BF02532419

Brunjes, P. C. (1985). A stereological study of neocortical maturation in the precocial mouse, Acomys cahirinus. Brain Res. 351, 279-287. doi: 10.1016/01653806(85)90199-3

Brunjes, P. C. (1989). A comparative study of prenatal development in the olfactory bulb, neocortex and hippocampal region of the precocial mouse Acomys cahirinus and rat. Brain Res. Dev. Brain Res. 49, 7-25. doi: 10.1016/01653806(89)90055-2

Brunjes, P. C. (1990). The precocial mouse, Acomys cahirinus. Psychobiology 18, 339-350.

Brunjes, P. C., Korol, D. L., and Stern, K. G. (1989). Prenatal neurogenesis in the telencephalon of the precocial mouse Acomys cahirinus. Neurosci. Lett. 107, 114-119. doi: 10.1016/0304-3940(89)90801-x

Budday, S., Raybaud, C., and Kuhl, E. (2014). A mechanical model predicts morphological abnormalities in the developing human brain. Sci. Rep. 4:5644. doi: $10.1038 /$ srep 05644 
Burd, I., Welling, J., Kannan, G., and Johnston, M. V. (2016). Chapter fiveexcitotoxicity as a common mechanism for fetal neuronal injury with hypoxia and intrauterine inflammation. Adv. Pharmacol. 76, 85-101. doi: 10.1016/bs. apha.2016.02.003

Bustamante, D., Morales, P., Pereyra, J. T., Goiny, M., and Herrera-Marschitz, M. (2007). Nicotinamide prevents the effect of perinatal asphyxia on dopamine release evaluated with in vivo microdialysis 3 months after birth. Exp. Brain Res. 177, 358-369. doi: 10.1007/s00221-006-0679-0

Buwalda, B., Nyakas, C., Vosselman, H. J., and Luiten, P. G. (1995). Effects of early postnatal anoxia on adult learning and emotion in rats. Behav. Brain Res. 67, 85-90. doi: 10.1016/0166-4328(94)00108-R

Cai, J., Kang, Z., Liu, K., Liu, W., Li, R., Zhang, J. H., et al. (2009). Neuroprotective effects of hydrogen saline in neonatal hypoxia-ischemia rat model. Brain Res. 1256, 129-137. doi: 10.1016/j.brainres.2008.11.048

Cai, Z., Pang, Y., Xiao, F., and Rhodes, P. G. (2001). Chronic ischemia preferentially causes white matter injury in the neonatal rat brain. Brain Res. 898, 126-135. doi: 10.1016/S0006-8993(01)02180-1

Caputa, M., Rogalska, J., Wentowska, K., and Nowakowska, A. (2005). Perinatal asphyxia, hyperthermia and hyperferremia as factors inducing behavioural disturbances in adulthood: a rat model. Behav. Brain Res. 163, 246-256. doi: 10.1016/j.bbr.2005.05.015

Carloni, S., Buonocore, G., and Balduini, W. (2008). Protective role of autophagy in neonatal hypoxia-ischemia induced brain injury. Neurobiol. Dis. 32, 329-339. doi: 10.1016/j.nbd.2008.07.022

Carloni, S., Carnevali, A., Cimino, M., and Balduini, W. (2007). Extended role of necrotic cell death after hypoxia-ischemia-induced neurodegeneration in the neonatal rat. Neurobiol. Dis. 27, 354-361. doi: 10.1016/j.nbd.2007.06.009

Carlos, R., Seidler, F. J., Lappi, S., and Slotkin, T. A. (1991a). Fetal dexamethasone exposure affects basal ornithine decarboxylase activity in developing rat brain regions and alters acute responses to hypoxia and maternal separation. Neonatology 59, 69-77.

Carlos, R., Seidler, F. J., and Slotkin, T. A. (1991b). Fetal dexamethasone exposure sensitizes neonatal rat brain to hypoxia: effects on protein and DNA synthesis. Dev. Brain Res. 64, 161-166.

Carmel, J. B., Kakinohana, O., Mestril, R., Young, W., Marsala, M., and Hart, R. P. (2004). Mediators of ischemic preconditioning identified by microarray analysis of rat spinal cord. Exp. Neurol. 185, 81-96. doi: 10.1016/j.expneurol.2003.09.007

Carmeliet, P., and Storkebaum, E. (2002). Vascular and neuronal effects of VEGF in the nervous system: implications for neurological disorders. Semin. Cell Dev. Biol. 13, 39-53. doi: 10.1006/scdb.2001.0290

Casolini, P., Zuena, A. R., Cinque, C., Matteucci, P., Alema, G. S., Adriani, W., et al. (2005). Sub-neurotoxic neonatal anoxia induces subtle behavioural changes and specific abnormalities in brain group-I metabotropic glutamate receptors in rats. J. Neurochem. 95, 137-145. doi: 10.1111/j.1471-4159.2005. 03349.x

Chamorro, A., Dirnagl, U., Urra, X., and Planas, A. M. (2016). Neuroprotection in acute stroke: targeting excitotoxicity, oxidative and nitrosative stress, and inflammation. Lancet Neurol. 15, 869-881. doi: 10.1016/S1474-4422(16) 00114-9

Chang, W. W., Chang, N., Lin, S., Wu, C., and Wu, F. Y. (2000). Tissue-specific cancer-related serpin gene cluster at human chromosome band 3q26. Genes Chromosomes Cancer 29, 240-255. doi: 10.1002/1098-2264(2000)9999:9999<:: AID-GCC1029>3.0.CO;2-A

Chau, V., Clément, J., Robitaille, Y., D’Anjou, G., and Vanasse, M. (2008). Congenital axonal neuropathy and encephalopathy. Pediatr. Neurol. 38, 261-266. doi: 10.1016/j.pediatrneurol.2007.11.005

Chau, V., Poskitt, K. J., and Miller, S. P. (2012). Magnetic resonance imaging in hypoxic-ischemic encephalopathy: still a cool test. Arch. Pediatr. Adolesc. Med. 166, 669-671. doi: 10.1001/archpediatrics.2012.579

Chau, V., Poskitt, K. J., Sargent, M. A., Lupton, B. A., Hill, A., Roland, E., et al. (2009). Comparison of computer tomography and magnetic resonance imaging scans on the third day of life in term newborns with neonatal encephalopathy. Pediatrics 123, 319-326. doi: 10.1542/peds.2008-0283

Chau, V., Synnes, A., Grunau, R. E., Poskitt, K. J., Brant, R., and Miller, S. P. (2013). Abnormal brain maturation in preterm neonates associated with adverse developmental outcomes. Neurology 81, 2082-2089. doi: 10.1212/01. wnl.0000437298.43688.b9
Chaudhari, P., Ye, Z., and Jang, Y. Y. (2014). Roles of reactive oxygen species in the fate of stem cells. Antioxid. Redox Signal. 20, 1881-1890. doi: 10.1089/ars.2012. 4963

Chavez-Valdez, R., Martin, L. J., Razdan, S., Gauda, E. B., and Northington, F. J. (2014). Sexual dimorphism in BDNF signaling after neonatal hypoxia-ischemia and treatment with necrostatin-1. Neuroscience 260, 106-119. doi: 10.1016/j. neuroscience.2013.12.023

Chen, C. J., and Liao, S. L. (2003). Zinc toxicity on neonatal cortical neurons: involvement of glutathione chelation. J. Neurochem. 85, 443-453. doi: 10.1046/ j.1471-4159.2003.01691.x

Chen, H., Spagnoli, F., Burris, M., Rolland, W. B., Fajilan, A., Dou, H., et al. (2012). Nanoerythropoietin is 10-times more effective than regular erythropoietin in neuroprotection in a neonatal rat model of hypoxia and ischemia. Stroke 43, 884-887. doi: 10.1161/STROKEAHA.111.637090

Cheng, Y., Deshmukh, M., D’Costa, A., Demaro, J. A., Gidday, J. M., Shah, A., et al. (1998). Caspase inhibitor affords neuroprotection with delayed administration in a rat model of neonatal hypoxic-ischemic brain injury. J. Clin. Invest. 101, 1992-1999. doi: 10.1172/JCI2169

Chiappe-Gutierrez, M., Kitzmueller, E., Labudova, O., Fuerst, G., Hoeger, H., Hardmeier, R., et al. (1998). mRNA levels of the hypoxia inducible factor (HIF1) and DNA repair genes in perinatal asphyxia of the rat. Life Sci. 63, 1157-1167. doi: 10.1016/S0024-3205(98)00377-4

Choi, D. W. (1988). Calcium-mediated neurotoxicity: relationship to specific channel types and role in ischemic damage. Trends Neurosci. 11, 465-469. doi: 10.1016/0166-2236(88)90200-7

Choi, D. W. (1992). Excitotoxic cell death. J. Neurobiol. 23, 1261-1276. doi: 10.1002/neu.480230915

Choi, H. A., Badjatia, N., and Mayer, S. A. (2012). Hypothermia for acute brain injury-mechanisms and practical aspects. Nat. Rev. Neurol. 8, 214-222. doi: $10.1038 /$ nrneurol.2012.21

Christaki, E., and Giamarellos-Bourboulis, E. J. (2014). The beginning of personalized medicine in sepsis: small steps to a bright future. Clin. Genet. 86, 56-61. doi: $10.1111 /$ cge. 12368

Chun, J. J., Nakamura, M. J., and Shatz, C. J. (1987). Transient cells of the developing mammalian telencephalon are peptide-immunoreactive neurons. Nature 325, 617-620. doi: 10.1038/325617a0

Cinelli, P., Madani, R., Tsuzuki, N., Vallet, P., Arras, M., Zhao, C. N., et al. (2001). Neuroserpin, a neuroprotective factor in focal ischemic stroke. Mol. Cell. Neurosci. 18, 443-457. doi: 10.1006/mcne.2001.1028

Clancy, B., Finlay, B. L., Darlington, R. B., and Anand, K. J. (2007). Extrapolating brain development from experimental species to humans. Neurotoxicology 28, 931-937. doi: 10.1016/j.neuro.2007.01.014

Clancy, B., Teague-Ross, T. J., and Nagarajan, R. (2009). Cross-species analyses of the cortical GABAergic and subplate neural populations. Front. Neuroanat. 3:20. doi: 10.3389/neuro.05.020.2009

Cleary, R. T., Sun, H., Huynh, T., Manning, S. M., Li, Y., Rotenberg, A., et al. (2013). Bumetanide enhances phenobarbital efficacy in a rat model of hypoxic neonatal seizures. PLoS ONE 8:e57148. doi: 10.1371/journal.pone.0057148

Cohen, M. C., and Scheimberg, I. (2008). Evidence of occurrence of intradural and subdural hemorrhage in the perinatal and neonatal period in the context of hypoxic ischemic encephalopathy: an observational study from two referral institutions in the United Kingdom. Pediatr. Dev. Pathol. 12, 169-176. doi: 10.2350/08-08-0509.1

Cole, J. W., Naj, A. C., O'Connell, J. R., Stine, O. C., Sorkin, J. D., Wozniak, M. A., et al. (2007). Neuroserpin polymorphisms and stroke risk in a biracial population: the stroke prevention in young women study. BMC Neurol. 7:1. doi: $10.1186 / 1471-2377-7-37$

Coq, J. O., Strata, F., Russier, M., Safadi, F. F., Merzenich, M. M., Byl, N. N. et al. (2008). Impact of neonatal asphyxia and hind limb immobilization on musculoskeletal tissues and S1 map organization: implications for cerebral palsy. Exp. Neurol. 210, 95-108. doi: 10.1016/j.expneurol.2007.10.006

Coutelier, M., Andries, S., Ghariani, S., Dan, B., Duyckaerts, C., van Rijckevorsel, K., et al. (2008). Neuroserpin mutation causes electrical status epilepticus of slow-wave sleep. Neurology 71, 64-66. doi: 10.1212/01.wnl.0000316306.08751.28

Cowan, F., Rutherford, M., Groenendaal, F., Eken, P., Mercuri, E., Bydder, G. M., et al. (2003). Origin and timing of brain lesions in term infants with 
neonatal encephalopathy. Lancet 361, 736-742. doi: 10.1016/S0140-6736(03) 12658-X

Craig, A., Ling Luo, N., Beardsley, D. J., Wingate-Pearse, N., Walker, D. W., Hohimer, A. R., et al. (2003). Quantitative analysis of perinatal rodent oligodendrocyte lineage progression and its correlation with human. Exp. Neurol. 181, 231-240. doi: 10.1016/S0014-4886(03)00032-3

Crawford, M. A., and Sinclair, A. J. (1971). "Nutritional influences in the evolution of mammalian brain," in Proceedings of the Lipids, Malnutrition of the Developing Brain. Ciba Foundation Symposium, Amsterdam, 267-292.

Daadi, M. M., Lee, S. H., Arac, A., Grueter, B. A., Bhatnagar, R., Maag, A. L., et al. (2009a). Functional engraftment of the medial ganglionic eminence cells in experimental stroke model. Cell Transplant. 18, 815-826. doi: 10.3727/ 096368909X470829

Daadi, M. M., Li, Z., Arac, A., Grueter, B. A., Sofilos, M., Malenka, R. C., et al. (2009b). Molecular and magnetic resonance imaging of human embryonic stem cell-derived neural stem cell grafts in ischemic rat brain. Mol. Ther. 17, 1282-1291. doi: 10.1038/mt.2009.104

Dalitz, P., Harding, R., Rees, S. M., and Cock, M. L. (2003). Prolonged reductions in placental blood flow and cerebral oxygen delivery in preterm fetal sheep exposed to endotoxin: possible factors in white matter injury after acute infection. J. Soc. Gynecol. Investig. 10, 283-290. doi: 10.1016/S1071-5576(03) 00090-X

Dammann, O., and Leviton, A. (2014). Intermittent or sustained systemic inflammation and the preterm brain. Pediatr. Res. 75, 376-380. doi: 10.1038/ pr.2013.238

Dammann, O., and O'Shea, T. M. (2008). Cytokines and perinatal brain damage. Clin. Perinatol. 35, 643-663. doi: 10.1016/j.clp.2008.07.011

Danbolt, N. C. (2001). Glutamate uptake. Prog. Neurobiol. 65, 1-105. doi: 10.1016/ S0301-0082(00)00067-8

Daneman, A., Epelman, M., Blaser, S., and Jarrin, J. R. (2006). Imaging of the brain in full-term neonates: does sonography still play a role? Pediatr. Radiol. 36, 636-646. doi: 10.1007/s00247-006-0201-7

Daneman, A., Navarro, O. M., Somers, G. R., Mohanta, A., Jarrín, J. R., and Traubici, J. (2010). Renal pyramids: focused sonography of normal and pathologic processes 1. Radiographics 30, 1287-1307. doi: 10.1148/rg.305095222

Danysz, W., and Parsons, C. G. (1998). Glycine and N-methyl-D-aspartate receptors: physiological significance and possible therapeutic applications. Pharmacol. Rev. 50, 597-664.

Daval, J. L., Pourie, G., Grojean, S., Lievre, V., Strazielle, C., Blaise, S., et al. (2004). Neonatal hypoxia triggers transient apoptosis followed by neurogenesis in the rat CA1 hippocampus. Pediatr. Res. 55, 561-567. doi: 10.1203/01.PDR. 0000113771.51317 .37

Daval, J. L., and Vert, P. (2004). Apoptosis and neurogenesis after transient hypoxia in the developing rat brain. Semin. Perinatol. 28, 257-263. doi: 10.1053/j. semperi.2004.08.002

Davis, R. L., Holohan, P. D., Shrimpton, A. E., Tatum, A. H., Daucher, J., Collins, G. H., et al. (1999a). Familial encephalopathy with neuroserpin inclusion bodies. Am. J. Pathol. 155, 1901-1913. doi: 10.1016/S0002-9440(10)65510-1

Davis, R. L., Shrimpton, A. E., Holohan, P. D., Bradshaw, C., Feiglin, D., Collins, G. H., et al. (1999b). Familial dementia caused by polymerization of mutant neuroserpin. Nature 401, 376-379.

Davis, R. L., Shrimpton, A. E., Carrell, R. W., Lomas, D. A., Gerhard, L., Baumann, B., et al. (2002). Association between conformational mutations in neuroserpin and onset and severity of dementia. Lancet 359, 2242-2247. doi: 10.1016/S0140-6736(02)09293-0

de Haan, H. H., Gunn, A. J., and Gluckman, P. D. (1997a). Fetal heart rate changes do not reflect cardiovascular deterioration during brief repeated umbilical cord occlusions in near-term fetal lambs. Am. J. Obstet. Gynecol. 176(1 Pt 1), 8-17. doi: 10.1016/S0002-9378(97)80004-X

de Haan, H. H., Gunn, A. J., Williams, C. E., and Gluckman, P. D. (1997b). Brief repeated umbilical cord occlusions cause sustained cytotoxic cerebral edema and focal infarcts in near-term fetal lambs. Pediatr. Res. 41, 96-104.

de Haan, H. H., Gunn, A. J., Williams, C. E., Heymann, M. A., and Gluckman, P. D. (1997c). Magnesium sulfate therapy during asphyxia in near-term fetal lambs does not compromise the fetus but does not reduce cerebral injury. Am. J. Obstet. Gynecol. 176(1 Pt 1), 18-27.

De Souza, S. W., and Richards, B. (1978). Neurological sequelae in newborn babies after perinatal asphyxia. Arch. Dis. Child. 53, 564-569. doi: 10.1136/adc.53.7.564 de Torres, C., Munell, F., Ferrer, I., Reventós, J., and Macaya, A. (1997). Identification of necrotic cell death by the TUNEL assay in the hypoxicischemic neonatal rat brain. Neurosci. Lett. 230, 1-4. doi: 10.1016/S03043940(97)00445-X

de Vries, L. S., and Groenendaal, F. (2010). Patterns of neonatal hypoxic-ischaemic brain injury. Neuroradiology 52, 555-566. doi: 10.1007/s00234-010-0674-9

Dean, J. M., Shi, Z., Fleiss, B., Gunn, K. C., Groenendaal, F., van Bel, F., et al. (2015). A critical review of models of perinatal infection. Dev. Neurosci. 37, 289-304. doi: $10.1159 / 000370309$

Dean, J. M., van de Looij, Y., Sizonenko, S. V., Lodygensky, G. A., Lazeyras, F., Bolouri, H., et al. (2011). Delayed cortical impairment following lipopolysaccharide exposure in preterm fetal sheep. Ann. Neurol. 70, 846-856. doi: 10.1002/ana.22480

Debillon, T., Gras-Leguen, C., Leroy, S., Caillon, J., Roze, J. C., and Gressens, P. (2003). Patterns of cerebral inflammatory response in a rabbit model of intrauterine infection-mediated brain lesion. Brain Res. Dev. Brain Res. 145, 39-48. doi: 10.1016/S0165-3806(03)00193-7

Decker, M. B., Breitburg, D. L., and Marcus, N. H. (2003). Geographical differences in behavioral responses to hypoxia: local adaptation to an anthropogenic stressor? Ecol. Appl. 13, 1104-1109. doi: 10.1890/1051-0761(2003)13[1104: gdibrt]2.0.co;2

Decker, M. J., Hue, G., Caudle, W., Miller, G., Keating, G., and Rye, D. (2003). Episodic neonatal hypoxia evokes executive dysfunction and regionally specific alterations in markers of dopamine signaling. Neuroscience 117, 417-425. doi: 10.1016/S0306-4522(02)00805-9

Decker, M. J., Jones, K. A., Solomon, I. G., Keating, G. L., and Rye, D. B. (2005). Reduced extracellular dopamine and increased responsiveness to novelty: neurochemical and behavioral sequelae of intermittent hypoxia. Sleep 28, $169-176$.

Dell'Anna, E., Geloso, M. C., Magarelli, M., and Molinari, M. (1996). Development of GABA and calcium binding proteins immunoreactivity in the rat hippocampus following neonatal anoxia. Neurosci. Lett. 211, 93-96. doi: 10.1016/0304-3940(96)12733-6

Dell'Anna, M., Calzolari, S., Molinari, M., Iuvone, L., and Calimici, R. (1991). Neonatal anoxia induces transitory hyperactivity, permanent spatial memory deficits and CA1 cell density reduction in developing rats. Behav. Brain Res. 45, 125-134. doi: 10.1016/S0166-4328(05)80078-6

Dell'Anna, M. E., Geloso, M. C., Draisci, G., and Luthman, J. (1995). Transient changes in Fos and GFAP immunoreactivity precede neuronal loss in the rat hippocampus following neonatal anoxia. Exp. Neurol. 131, 144-156. doi: 10. 1016/0014-4886(95)90016-0

Dell'Anna, M. E., Luthman, J., Lindqvist, E., and Olson, L. (1993). Development of monoamine systems after neonatal anoxia in rats. Brain Res. Bull. 32, 159-170. doi: 10.1016/0361-9230(93)90070-R

Demarest, T. G., Schuh, R. A., Waite, E. L., Waddell, J., McKenna, M. C., and Fiskum, G. (2016a). Sex dependent alterations in mitochondrial eectron transport chain proteins following neonatal rat cerebral hypoxicischemia. J. Bioenerg. Biomembr. 48, 591-598. doi: 10.1007/s10863-016-9 678-4

Demarest, T. G., Waite, E. L., Kristian, T., Puche, A. C., Waddell, J., McKenna, M. C., et al. (2016b). Sex-dependent mitophagy and neuronal death following rat neonatal hypoxia-ischemia. Neuroscience 335, 103-113. doi: 10.1016/j. neuroscience.2016.08.026

Deng, W., Rosenberg, P. A., Volpe, J. J., and Jensen, F. E. (2003). Calciumpermeable AMPA/kainate receptors mediate toxicity and preconditioning by oxygen-glucose deprivation in oligodendrocyte precursors. Proc. Natl. Acad. Sci. U.S.A. 100, 6801-6806. doi: 10.1073/pnas.1136624100

Deng, Y. Y., Lu, J., Ling, E. A., and Kaur, C. (2009). Monocyte chemoattractant protein-1 (MCP-1) produced via NF-kappaB signaling pathway mediates migration of amoeboid microglia in the periventricular white matter in hypoxic neonatal rats. Glia 57, 604-621. doi: 10.1002/glia.20790

Derrick, M., Drobyshevsky, A., Ji, X., and Tan, S. (2007). A model of cerebral palsy from fetal hypoxia-ischemia. Stroke 38(Suppl.), 731-735. doi: 10.1161/01.STR. 0000251445.94697.64

Derrick, M., Luo, N. L., Bregman, J. C., Jilling, T., Ji, X., Fisher, K., et al. (2004). Preterm fetal hypoxia-ischemia causes hypertonia and motor deficits in the neonatal rabbit: a model for human cerebral palsy? J. Neurosci. 24, 24-34. doi: 10.1523/JNEUROSCI.2816-03.2004 
Dilenge, M. E., Majnemer, A., and Shevell, M. I. (2001). Long-term developmental outcome of asphyxiated term neonates. J. Child Neurol. 16, 781-792. doi: 10. 1177/08830738010160110201

Dingley, J., Tooley, J., Liu, X., Scull-Brown, E., Elstad, M., Chakkarapani, E., et al. (2014). Xenon ventilation during therapeutic hypothermia in neonatal encephalopathy: a feasibility study. Pediatrics 133, 809-818. doi: 10.1542/peds. 2013-0787

Ditelberg, J. S., Sheldon, R. A., Epstein, C. J., and Ferriero, D. M. (1996). Brain injury after perinatal hypoxia-ischemia is exacerbated in copper/zinc superoxide dismutase transgenic mice. Pediatr. Res. 39, 204-208. doi: 10.1203/ 00006450-199602000-00003

Dommergues, M., Plaisant, F., Verney, C., and Gressens, P. (2003). Early microglial activation following neonatal excitotoxic brain damage in mice: a potential target for neuroprotection. Neuroscience 121, 619-628. doi: 10.1016/S03064522(03)00558-X

Dommergues, M. A., Patkai, J., Renauld, J. C., Evrard, P., and Gressens, P. (2000). Proinflammatory cytokines and interleukin- 9 exacerbate excitotoxic lesions of the newborn murine neopallium. Ann. Neurol. 47, 54-63. doi: 10.1002/15318249(200001)47:1<54::AID-ANA10>3.0.CO;2-Y

Douglas-Escobar, M., and Weiss, M. D. (2015). Hypoxic-ischemic encephalopathy: a review for the clinician. JAMA Pediatr. 169, 397-403. doi: 10.1001/ jamapediatrics.2014.3269

Doyle, O., Temko, A., Murray, D., Lightbody, G., Marnane, W., and Boylan, G. (2010). "Predicting the neurodevelopmental outcome in newborns with hypoxic-ischaemic injury," in Proceedings of the Engineering in Medicine and Biology Society (EMBC), 2010 Annual International Conference of the IEEE, Buenos Aires, 1370-1373. doi: 10.1109/IEMBS.2010. 5626736

Drobyshevsky, A., Derrick, M., Prasad, P. V., Ji, X., Englof, I., and Tan, S. (2007a). Fetal brain magnetic resonance imaging response acutely to hypoxia-ischemia predicts postnatal outcome. Ann. Neurol. 61, 307-314.

Drobyshevsky, A., Derrick, M., Wyrwicz, A. M., Ji, X., Englof, I., Ullman, L. M., et al. (2007b). White matter injury correlates with hypertonia in an animal model of cerebral palsy. J. Cereb. Blood Flow Metab. 27, 270-281.

Drobyshevsky, A., Song, S. K., Gamkrelidze, G., Wyrwicz, A. M., Derrick, M., Meng, F., et al. (2005). Developmental changes in diffusion anisotropy coincide with immature oligodendrocyte progression and maturation of compound action potential. J. Neurosci. 25, 5988-5997. doi: 10.1523/JNEUROSCI.498304.2005

Du, L., Hickey, R. W., Bayir, H., Watkins, S. C., Tyurin, V. A., Guo, F., et al. (2009). Starving neurons show sex difference in autophagy. J. Biol. Chem. 284, 2383-2396. doi: 10.1074/jbc.M804396200

D'Udine, B., and Alleva, E. (1988). The Acomys cahirinus (spiny mouse) as a new model for biological and neurobehavioural studies. Pol. J. Pharmacol. Pharm. 40, 525-534.

Duncan, J. R., Cock, M. L., Scheerlinck, J. P., Westcott, K. T., McLean, C., Harding, R., et al. (2002). White matter injury after repeated endotoxin exposure in the preterm ovine fetus. Pediatr. Res. 52, 941-949. doi: 10.1203/ 00006450-200212000-00021

East, C. E., Dunster, K. R., and Colditz, P. B. (1998). Fetal oxygen saturation and uterine contractions during labor. Am. J. Perinatol. 15, 345-349. doi: 10.1055/ s-2007-993955

Edwards, A., and Mehmet, H. (1996). Apoptosis in perinatal hypoxic-ischaemic cerebral damage. Neuropathol. Appl. Neurobiol. 22, 494-498. doi: 10.1111/j. 1365-2990.1996.tb01122.x

Edwards, A., Yue, X., Cox, P., Hope, P., Azzopardi, D., Squier, M., et al. (1997). Apoptosis in the brains of infants suffering intrauterine cerebral injury. Pediatr. Res. 42, 684-689. doi: 10.1203/00006450-199711000-00022

Eicher, D. J., Wagner, C. L., Katikaneni, L. P., Hulsey, T. C., Bass, W. T., Kaufman, D. A., et al. (2005). Moderate hypothermia in neonatal encephalopathy: efficacy outcomes. Pediatr. Neurol. 32, 11-17. doi: 10.1016/j.pediatrneurol.2004. 06.014

Ek, C. J., Dziegielewska, K. M., Stolp, H., and Saunders, N. R. (2006). Functional effectiveness of the blood-brain barrier to small water-soluble molecules in developing and adult opossum (Monodelphis domestica). J. Comp. Neurol. 496, 13-26. doi: 10.1002/cne.20885

Ek, C. J., Habgood, M. D., Dziegielewska, K. M., and Saunders, N. R. (2003). Structural characteristics and barrier properties of the choroid plexuses in developing brain of the opossum (Monodelphis domestica). J. Comp. Neurol. 460, 451-464. doi: 10.1002/cne.10661

Eken, P., Jansen, G. H., Groenendaal, F., Rademaker, K. J., and de Vries, L. S. (1994). Intracranial lesions in the fullterm infant with hypoxic ischaemic encephalopathy: ultrasound and autopsy correlation. Neuropediatrics 25, 301-307. doi: 10.1055/s-2008-1073044

Eklind, S., Mallard, C., Arvidsson, P., and Hagberg, H. (2005). Lipopolysaccharide induces both a primary and a secondary phase of sensitization in the developing rat brain. Pediatr. Res. 58, 112-116. doi: 10.1203/01.PDR.0000163513.03619.8D

Eklind, S., Mallard, C., Leverin, A. L., Gilland, E., Blomgren, K., MattsbyBaltzer, I., et al. (2001). Bacterial endotoxin sensitizes the immature brain to hypoxic-ischaemic injury. Eur. J. Neurosci. 13, 1101-1106. doi: 10.1046/j.0953816x.2001.01474.x

Eklöf, B., and Siesjö, B. K. (1973). Cerebral blood flow in ischemia caused by carotid artery ligation in the rat. Acta Physiol. Scand. 87, 69-77. doi: 10.1111/j.17481716.1973.tb05367.x

El-Khoury, N., Braun, A., Hu, F., Pandey, M., Nedergaard, M., Lagamma, E. F., et al. (2006). Astrocyte end-feet in germinal matrix, cerebral cortex, and white matter in developing infants. Pediatr. Res. 59, 673-679. doi: 10.1203/01.pdr. $0000214975.85311 .9 \mathrm{c}$

Ellisdon, A. M., Zhang, Q., Henstridge, M. A., Johnson, T. K., Warr, C. G., Law, R. H., et al. (2014). High resolution structure of cleaved Serpin $42 \mathrm{Da}$ from Drosophila melanogaster. BMC Struct. Biol. 14:1. doi: 10.1186/1472-680714-14

Eskiocak, S., Tutunculer, F., Basaran, U. N., Taskiran, A., and Cakir, E. (2007). The effect of melatonin on protein oxidation and nitric oxide in the brain tissue of hypoxic neonatal rats. Brain Dev. 29, 19-24. doi: 10.1016/j.braindev.2006. 05.007

Evans, D. J., Levene, M. I., and Tsakmakis, M. (2007). Anticonvulsants for preventing mortality and morbidity in full term newborns with perinatal asphyxia. Cochrane Database Syst. Rev. 3:CD001240. doi: 10.1002/14651858. CD001240.pub2

Ezquer, M. E., Valdez, S. R., and Seltzer, A. M. (2006). Inflammatory responses of the substantia nigra after acute hypoxia in neonatal rats. Exp. Neurol. 197, 391-398. doi: 10.1016/j.expneurol.2005.10.015

Ezquer, M. E., Valdez, S. R., Seltzer, A. M., and Jahn, G. A. (2008). Advancement of reproductive senescence and changes in the early expression of estrogen, progesterone and micro-opioid receptors induced by neonatal hypoxia in the female rat. Brain Res. 1214, 73-83. doi: 10.1016/j.brainres.2008.03.029

Fahn, S., Davis, J. N., and Rowland, L. P. (1979). Cerebral Hypoxia and Its Consequences. New York, NY: Raven Press.

Failor, S., Nguyen, V., Darcy, D. P., Cang, J., Wendland, M. F., Stryker, M. P., et al. (2010). Neonatal cerebral hypoxia-ischemia impairs plasticity in rat visual cortex. J. Neurosci. 30, 81-92. doi: 10.1523/JNEUROSCI.5656-08.2010

Fan, X., Kavelaars, A., Heijnen, C. J., Groenendaal, F., and van Bel, F. (2010). Pharmacological neuroprotection after perinatal hypoxic-ischemic brain injury. Curr. Neuropharmacol. 8, 324-334. doi: 10.2174/157015910793358150

Fatemi, A., Wilson, M. A., and Johnston, M. V. (2009). Hypoxic-ischemic encephalopathy in the term infant. Clin. Perinatol. 36, 835-vii. doi: 10.1016/j. clp.2009.07.011

Favrais, G., van de Looij, Y., Fleiss, B., Ramanantsoa, N., Bonnin, P., StoltenburgDidinger, G., et al. (2011). Systemic inflammation disrupts the developmental program of white matter. Ann. Neurol. 70, 550-565. doi: 10.1002/ana.22489

Felderhoff-Mueser, U., Sifringer, M., Pesditschek, S., Kuckuck, H., Moysich, A., Bittigau, P., et al. (2002). Pathways leading to apoptotic neurodegeneration following trauma to the developing rat brain. Neurobiol. Dis. 11, 231-245. doi: 10.1006/nbdi.2002.0521

Fellman, V., Hellström-Westas, L., Norman, M., Westgren, M., Källén, K., Lagercrantz, H., et al. (2010). One-year survival of extremely preterm infants after active perinatal care in Sweden. Obstet. Anesth. Dig. 30, 22-23. doi: 10.1097/01.aoa.0000367003.25266.35

Ferrari, D. C., Nesic, O., and Perez-Polo, J. R. (2010). Perspectives on neonatal hypoxia/ischemia-induced edema formation. Neurochem. Res. 35, 1957-1965. doi: 10.1007/s11064-010-0308-y

Ferriero, D. M. (2001). Oxidant mechanisms in neonatal hypoxia-ischemia. Dev. Neurosci. 23, 198-202. doi: 10.1159/000046143

Ferriero, D. M. (2004). Neonatal brain injury. N. Engl. J. Med. 351, 1985-1995. doi: 10.1056/NEJMra041996 
Ferriero, D. M., Holtzman, D. M., Black, S. M., and Sheldon, R. A. (1996). Neonatal mice lacking neuronal nitric oxide synthase are less vulnerable to hypoxic-ischemic injury. Neurobiol. Dis. 3, 64-71. doi: 10.1006/nbdi.1996.0006

Finer, N., Robertson, C., Richards, R., Pinnell, L., and Peters, K. (1981). Hypoxicischemic encephalopathy in term neonates: perinatal factors and outcome. J. Pediatr. 98, 112-117. doi: 10.1016/S0022-3476(81)80555-0

Finer, N. N., Robertson, C. M., Peters, K. L., and Coward, J. H. (1983). Factors affecting outcome in hypoxic-ischemic encephalopathy in term infants. Am. J. Dis. Child. 137, 21-25. doi: 10.1001/archpedi.1983.02140270017006

Fischer, R., and Maier, O. (2015). Interrelation of oxidative stress and inflammation in neurodegenerative disease: role of TNF. Oxid. Med. Cell. Longev. 2015:610813. doi: 10.1155/2015/610813

Fleiss, B., and Gressens, P. (2012). Tertiary mechanisms of brain damage: a new hope for treatment of cerebral palsy? Lancet Neurol. 11, 556-566. doi: 10.1016/ S1474-4422(12)70058-3

Folkerth, R. D. (2005). Neuropathologic substrate of cerebral palsy. J. Child Neurol. 20, 940-949. doi: 10.1177/08830738050200120301

Forder, J. P., and Tymianski, M. (2009). Postsynaptic mechanisms of excitotoxicity: involvement of postsynaptic density proteins, radicals, and oxidant molecules. Neuroscience 158, 293-300. doi: 10.1016/j.neuroscience.2008.10.021

Fox, K., Schlaggar, B. L., Glazewski, S., and O’Leary, D. D. (1996). Glutamate receptor blockade at cortical synapses disrupts development of thalamocortical and columnar organization in somatosensory cortex. Proc. Natl. Acad. Sci. U.S.A. 93, 5584-5589. doi: 10.1073/pnas.93.11.5584

Fujihara, M., Muroi, M., Tanamoto, K., Suzuki, T., Azuma, H., and Ikeda, H. (2003). Molecular mechanisms of macrophage activation and deactivation by lipopolysaccharide: roles of the receptor complex. Pharmacol. Ther. 100, 171-194. doi: 10.1016/j.pharmthera.2003.08.003

Fujimoto, E., Miki, A., and Mizoguti, H. (1989). Histochemical study of the differentiation of microglial cells in the developing human cerebral hemispheres. J. Anat. 166, 253-264.

Galliciotti, G., and Sonderegger, P. (2006). Neuroserpin. Front. Biosci. 11:33-45. doi: $10.2741 / 1778$

Garcia-Marin, V., Blazquez-Llorca, L., Rodriguez, J. R., Gonzalez-Soriano, J., and DeFelipe, J. (2010). Differential distribution of neurons in the gyral white matter of the human cerebral cortex. J. Comp. Neurol. 518, 4740-4759. doi: 10.1002/ cne. 22485

Garnier, Y., Berger, R., Alm, S., von Duering, M. U., Coumans, A. B., Michetti, F., et al. (2006). Systemic endotoxin administration results in increased S100B protein blood levels and periventricular brain white matter injury in the preterm fetal sheep. Eur. J. Obstet. Gynecol. Reprod. Biol. 124, 15-22. doi: 10.1016/j.ejogrb.2005.05.014

Garnier, Y., Coumans, A., Berger, R., Jensen, A., and Hasaart, T. H. (2001). Endotoxemia severely affects circulation during normoxia and asphyxia in immature fetal sheep. J. Soc. Gynecol. Investig. 8, 134-142. doi: 10.1016/S10715576(01)00101-0

Gelderblom, M., Neumann, M., Ludewig, P., Bernreuther, C., Krasemann, S., Arunachalam, P., et al. (2013). Deficiency in serine protease inhibitor neuroserpin exacerbates ischemic brain injury by increased postischemic inflammation. PLoS ONE 8:e63118. doi: 10.1371/journal.pone.0063118

Ghosh, A., Antonini, A., McConnell, S. K., and Shatz, C. J. (1990). Requirement for subplate neurons in the formation of thalamocortical connections. Nature 347, 179-181. doi: 10.1038/347179a0

Ghosh, A., and Shatz, C. J. (1992). Involvement of subplate neurons in the formation of ocular dominance columns. Science 255, 1441-1443. doi: 10.1126/ science. 1542795

Gillani, Q. A., Akbar, A., Ali, M., and Iqbal, F. (2015). Gender-specific effects of CGP 55845, GABAB receptor antagonist, on neuromuscular coordination, learning and memory formation in albino mouse following neonatal hypoxia-ischemia insult. Neurol. Sci. 36, 961-969. doi: 10.1007/s10072-0152205-2

Gillani, Q. A., Iqbal, S., Arfa, F., Khakwani, S., Akbar, A., Ullah, A., et al. (2014). Effect of GABA B receptor antagonist (CGP35348) on learning and memory in albino mice. Sci. World J. 2014:983651. doi: 10.1155/2014/983651

Ginet, V., Puyal, J., Clarke, P. G., and Truttmann, A. C. (2009). Enhancement of autophagic flux after neonatal cerebral hypoxia-ischemia and its regionspecific relationship to apoptotic mechanisms. Am. J. Pathol. 175, 1962-1974. doi: 10.2353/ajpath.2009.090463
Girard, S., Kadhim, H., Beaudet, N., Sarret, P., and Sebire, G. (2009). Developmental motor deficits induced by combined fetal exposure to lipopolysaccharide and early neonatal hypoxia/ischemia: a novel animal model for cerebral palsy in very premature infants. Neuroscience 158, 673-682. doi: 10.1016/j.neuroscience.2008.10.032

Girard, S., Kadhim, H., Larouche, A., Roy, M., Gobeil, F., and Sebire, G. (2008). Pro-inflammatory disequilibrium of the IL-1 beta/IL-1ra ratio in an experimental model of perinatal brain damages induced by lipopolysaccharide and hypoxia-ischemia. Cytokine 43, 54-62. doi: 10.1016/j.cyto.2008. 04.007

Girard, S., Sebire, H., Brochu, M. E., Briota, S., Sarret, P., and Sebire, G. (2012). Postnatal administration of IL-1Ra exerts neuroprotective effects following perinatal inflammation and/or hypoxic-ischemic injuries. Brain Behav. Immun. 26, 1331-1339. doi: 10.1016/j.bbi.2012.09.001

Glenn, O. A., Ludeman, N. A., Berman, J. I., Wu, Y. W., Lu, Y., Bartha, A. I., et al. (2007). Diffusion tensor MR imaging tractography of the pyramidal tracts correlates with clinical motor function in children with congenital hemiparesis. AJNR. Am. J. Neuroradiol. 28, 1796-1802. doi: 10.3174/ajnr.A0676

Gluckman, P. D., Wyatt, J. S., Azzopardi, D., Ballard, R., Edwards, A. D., Ferriero, D. M., et al. (2005). Selective head cooling with mild systemic hypothermia after neonatal encephalopathy: multicentre randomised trial. Lancet 365, 663-670. doi: 10.1016/S0140-6736(05)17946-X

Goldberg, R. N., Moscoso, P., Bauer, C. R., Bloom, F. L., Curless, R. G., Burke, B., et al. (1986). Use of barbiturate therapy in severe perinatal asphyxia: a randomized controlled trial. J. Pediatr. 109, 851-856. doi: 10.1016/S00223476(86)80713-2

Gonzalez, F. F., and Miller, S. P. (2006). Does perinatal asphyxia impair cognitive function without cerebral palsy? Arch. Dis. Child. Fetal Neonatal Ed. 91, F454-F459.

González-Portillo, A., Domínguez-Antolínez, I., and Muniategui-Azkona, E. (2015). Crisis of the welfare state: an analysis of the responses from social work. Rev. Cercetare Interventie Soc. 49, 173-186.

Gozzo, S., Dimitrieva, N., Iacopino, C., and D’Udine, B. (1985). A comparative study of mossy fiber distribution in the brain of the precocial Acomys cahirinus and of the altricial Rattus norvegicus: neuroanatomical bases and behavioral correlates. Int. J. Neurosci. 28, 163-172. doi: 10.3109/00207458508985387

Graham, E. M., Ruis, K. A., Hartman, A. L., Northington, F. J., and Fox, H. E. (2008). A systematic review of the role of intrapartum hypoxia-ischemia in the causation of neonatal encephalopathy. Am. J. Obstet. Gynecol. 199, 587-595. doi: 10.1016/j.ajog.2008.06.094

Grant, E., Hoerder-Suabedissen, A., and Molnár, Z. (2016). The regulation of corticofugal fiber targeting by retinal inputs. Cereb. Cortex 26, 1336-1348. doi: 10.1093/cercor/bhv315

Greggio, S., de Paula, S., de Oliveira, I. M., Trindade, C., Rosa, R. M., Henriques, J. A., et al. (2011). NAP prevents acute cerebral oxidative stress and protects against long-term brain injury and cognitive impairment in a model of neonatal hypoxia-ischemia. Neurobiol. Dis. 44, 152-159. doi: 10.1016/j.nbd.2011.06.018 Greggio, S., Rosa, R. M., Dolganov, A., de Oliveira, I. M., Menegat, F. D., Henriques, J. A., et al. (2009). NAP prevents hippocampal oxidative damage in neonatal rats subjected to hypoxia-induced seizures. Neurobiol. Dis. 36, 435-444. doi: 10.1016/j.nbd.2009.08.008

Groenendaal, F., de Vries, L. S., and van Bel, F. (2006). Favourable results with surgical treatment in 43 children with hypoplastic left-heart syndrome or similar disorders, 1999-2005. Ned. Tijdschr. Geneeskd. 150, 2731-2732.

Groenendaal, F., Meiners, L. C., Gooskens, R., and de Vries, L. S. (1994). Cerebral proton magnetic resonance spectroscopic imaging in a neonate with tuberous sclerosis. Neuropediatrics 25, 154-157. doi: 10.1055/s-2008-1073014

Grow, J., and Barks, J. D. (2002). Pathogenesis of hypoxic-ischemic cerebral injury in the term infant: current concepts. Clin. Perinatol. 29, 585-602. doi: 10.1016/ S0095-5108(02)00059-3

Gu, R., Fu, L., Jiang, C., Xu, Y., Wang, X., and Yu, J. (2015). Retina is protected by neuroserpin from ischemic/reperfusion-induced injury independent of tissuetype plasminogen activator. PLOS ONE 10:e0130440. doi: 10.1371/journal.pone. 0130440

Gunn, A. J., Battin, M., Gluckman, P. D., Gunn, T. R., and Bennet, L. (2005). Therapeutic hypothermia: from lab to NICU. J. Perinat. Med. 33, 340-346. doi: 10.1515/JPM.2005.061 
Gunn, A. J., and Gunn, T. R. (1998). Thepharmacology'of neuronal rescue with cerebral hypothermia. Early Hum. Dev. 53, 19-35. doi: 10.1016/S0378-3782(98) 00033-4

Gunn, A. J., Gunn, T. R., de Haan, H. H., Williams, C. E., and Gluckman, P. D. (1997). Dramatic neuronal rescue with prolonged selective head cooling after ischemia in fetal lambs. J. Clin. Invest. 99, 248-256. doi: 10.1172/JCI119153

Gunn, A. J., Parer, J. T., Mallard, E. C., Williams, C. E., and Gluckman, P. D. (1992). Cerebral histologic and electrocorticographic changes after asphyxia in fetal sheep. Pediatr. Res. 31, 486-491. doi: 10.1203/00006450-199205000-00016

Hack, M., Breslau, N., Aram, D., Weissman, B., Klein, N., and Borawski-Clark, E. (1992). The effect of very low birth weight and social risk on neurocognitive abilities at school age. J. Dev. Behav. Pediatr. 13, 412-420. doi: 10.1097/ 00004703-199212000-00005

Hadjiconstantinou, M., Yates, A. J., and Neff, N. H. (1990). Hypoxia-induced neurotransmitter deficits in neonatal rats are partially corrected by exogenous GM1 ganglioside. J. Neurochem. 55, 864-869. doi: 10.1111/j.1471-4159.1990. tb04571.x

Hagberg, H., Andersson, P., Kjellmer, I., Thiringer, K., and Thordstein, M. (1987). Extracellular overflow of glutamate, aspartate, GABA and taurine in the cortex and basal ganglia of fetal lambs during hypoxia-ischemia. Neurosci. Lett. 78, 311-317. doi: 10.1016/0304-3940(87)90379-X

Hagberg, H., Gressens, P., and Mallard, C. (2012). Inflammation during fetal and neonatal life: implications for neurologic and neuropsychiatric disease in children and adults. Ann. Neurol. 71, 444-457. doi: 10.1002/ana.22620

Hagberg, H., Mallard, C., Ferriero, D. M., Vannucci, S. J., Levison, S. W., Vexler, Z. S., et al. (2015). The role of inflammation in perinatal brain injury. Nat. Rev. Neurol. 11, 192-208. doi: 10.1038/nrneurol.2015.13

Hagberg, H., Mallard, C., Rousset, C. I., and Xiaoyang, W. (2009). Apoptotic mechanisms in the immature brain: involvement of mitochondria. J. Child Neurol. 24, 1141-1146. doi: 10.1177/0883073809338212

Hagberg, H., Peebles, D., and Mallard, C. (2002). Models of white matter injury: comparison of infectious, hypoxic-ischemic, and excitotoxic insults. Ment. Retard. Dev. Disabil. Res. Rev. 8, 30-38. doi: 10.1002/mrdd.10007

Hagberg, H., Thornberg, E., Blennow, M., Kjellmer, I., Lagercrantz, H., Thiringer, K., et al. (1993). Excitatory amino acids in the cerebrospinal fluid of asphyxiated infants: relationship to hypoxic-ischemic encephalopathy. Acta Paediatr. 82, 925-929. doi: 10.1111/j.1651-2227.1993.tb12601.x

Hall, R. T., Hall, F. K., and Daily, D. K. (1998). High-dose phenobarbital therapy in term newborn infants with severe perinatal asphyxia: a randomized, prospective study with three-year follow-up. J. Pediatr. 132, 345-348. doi: 10.1016/S00223476(98)70458-5

Hamre, K. M., Hyman, B. T., Goodlett, C. R., West, J. R., and Van Hoesen, G. W. (1989). Alz-50 immunoreactivity in the neonatal rat: changes in development and co-distribution with MAP-2 immunoreactivity. Neurosci. Lett. 98, 264-271. doi: 10.1016/0304-3940(89)90411-4

Hamrick, S. E., and Ferriero, D. M. (2003). The injury response in the term newborn brain: can we neuroprotect? Curr. Opin. Neurol. 16, 147-154. doi: 10.1097/00019052-200304000-00005

Hardy, P., Nuyt, A. M., Dumont, I., Peri, K. G., Hou, X., Varma, D. R., et al. (1999). Developmentally increased cerebrovascular NO in newborn pigs curtails cerebral blood flow autoregulation. Pediatr. Res. 46, 375-382. doi: 10.1203/00006450-199910000-00004

Hasegawa, K., Yoshioka, H., Sawada, T., and Nishikawa, H. (1991). Lipid peroxidation in neonatal mouse brain subjected to two different types of hypoxia. Brain Dev. 13, 101-103. doi: 10.1016/S0387-7604(12)80115-X

Hasegawa, K., Yoshioka, H., Sawada, T., and Nishikawa, H. (1993). Direct measurement of free radicals in the neonatal mouse brain subjected to hypoxia: an electron spin resonance spectroscopic study. Brain Res. 607, 161-166. doi: 10.1016/0006-8993(93)91502-J

Hastings, G. A., Coleman, T. A., Haudenschild, C. C., Stefansson, S., Smith, E. P., Barthlow, R., et al. (1997). Neuroserpin, a brain-associated inhibitor of tissue plasminogen activator is localized primarily in neurons. Implications for the regulation of motor learning and neuronal survival. J. Biol. Chem. 272, 33062-33067. doi: 10.1074/jbc.272.52.33062

Hasumi, H., Ishiguro, H., Nakamura, M., Sugiura, S., Osada, Y., Miyoshi, Y., et al. (2005). Neuroserpin (PI-12) is upregulated in high-grade prostate cancer and is associated with survival. Int. J. Cancer 115, 911-916. doi: 10.1002/ijc.20967
Hattori, H., and Wasterlain, C. G. (1990). Excitatory amino acids in the developing brain: ontogeny, plasticity, and excitotoxicity. Pediatr. Neurol. 6, 219-228. doi: 10.1016/0887-8994(90)90111-D

Hedner, T., Bergman, B., and Holmgren, M. (1980). Adrenal catecholamines during and following hypoxia in neonatal rats. Med. Biol. 58, 228-231.

Hedner, T., and Lundborg, P. (1980a). 5-HIAA levels in brain and cerebrospinal fluid of the neonatal rat during oxygen deprivation. Neurosci. Lett. 19, 315-318.

Hedner, T., and Lundborg, P. (1980b). Catecholamine metabolism in neonatal rat brain during asphyxia and recovery. Acta Physiol. Scand. 109, 169-175. doi: 10.1111/j.1748-1716.1980.tb06583.x

Hedner, T., and Lundborg, P. (1980c). Serotonin metabolism in neonatal rat brain during asphyxia and recovery. Acta Physiol. Scand. 109, 163-168.

Hedtjarn, M., Mallard, C., Eklind, S., Gustafson-Brywe, K., and Hagberg, H. (2004a). Global gene expression in the immature brain after hypoxia-ischemia. J. Cereb. Blood Flow Metab. 24, 1317-1332. doi: 10.1097/01.WCB.0000141558. 40491.75

Hedtjarn, M., Mallard, C., and Hagberg, H. (2004b). Inflammatory gene profiling in the developing mouse brain after hypoxia-ischemia. J. Cereb. Blood Flow Metab. 24, 1333-1351.

Helmy, M. M., Tolner, E. A., Vanhatalo, S., Voipio, J., and Kaila, K. (2011). Brain alkalosis causes birth asphyxia seizures, suggesting therapeutic strategy. Ann. Neurol. 69, 493-500. doi: 10.1002/ana.22223

Henry, V. J., Lecointre, M., Laudenbach, V., Ali, C., Macrez, R., Jullienne, A., et al. (2013). High tPA release by neonate brain microvascular endothelial cells under glutamate exposure affects neuronal fate. Neurobiol. Dis. 50, 201-208. doi: 10.1016/j.nbd.2012.10.020

Herrmann, K., Antonini, A., and Shatz, C. J. (1994). Ultrastructural evidence for synaptic interactions between thalamocortical axons and subplate neurons. Eur. J. Neurosci. 6, 1729-1742. doi: 10.1111/j.1460-9568.1994.tb00565.x

Hida, K., Suzuki, N., Kwee, I. L., and Nakada, T. (1991). pH-lactate dissociation in neonatal anoxia: proton and 31P NMR spectroscopic studies in rat pups. Magn. Reson. Med. 22, 128-132. doi: 10.1002/mrm.1910220113

Hill, A. (1991). Current concepts of hypoxic-ischemic cerebral injury in the term newborn. Pediatr. Neurol. 7, 317-325. doi: 10.1016/0887-8994(91) 90060-X

Hill, C. A., Alexander, M. L., McCullough, L. D., and Fitch, R. H. (2012). Inhibition of X-linked inhibitor of apoptosis with embelin differentially affects male versus female behavioral outcome following neonatal hypoxia-ischemia in rats. Dev. Neurosci. 33, 494-504. doi: 10.1159/000331651

Hill, C. A., and Fitch, R. H. (2012). Sex differences in mechanisms and outcome of neonatal hypoxia-ischemia in rodent models: implications for sex-specific neuroprotection in clinical neonatal practice. Neurol. Res. Int. 2012:867531. doi: $10.1155 / 2012 / 867531$

Hill, I. E., MacManus, J. P., Rasquinha, I., and Tuor, U. I. (1995). DNA fragmentation indicative of apoptosis following unilateral cerebral hypoxia-ischemia in the neonatal rat. Brain Res. 676, 398-403. doi: 10.1016/0006-8993(95)00145-G

Hill, R. M., Brennan, S. O., and Birch, N. P. (2001). Expression, purification, and functional characterization of the serine protease inhibitor neuroserpin expressed in Drosophila S2 cells. Protein Expr. Purif. 22, 406-413. doi: 10.1006/ prep. 2001.1463

Himmelmann, K., Hagberg, G., Beckung, E., Hagberg, B., and Uvebrant, P. (2005). The changing panorama of cerebral palsy in Sweden. IX. Prevalence and origin in the birth-year period 1995-1998. Acta Paediatr. 94, 287-294. doi: 10.1111/j. 1651-2227.2005.tb03071.x

Himmelmann, K., Hagberg, G., Wiklund, L. M., Eek, M. N., and Uvebrant, P. (2007). Dyskinetic cerebral palsy: a population-based study of children born between 1991 and 1998. Dev. Med. Child Neurol. 49, 246-251. doi: 10.1111/j. 1469-8749.2007.00246.x

Hisanaga, K., Onodera, H., and Kogure, K. (1986). Changes in levels of purine and pyrimidine nucleotides during acute hypoxia and recovery in neonatal rat brain. J. Neurochem. 47, 1344-1350. doi: 10.1111/j.1471-4159.1986.tb00763.x

Hobbs, C., Thoresen, M., Tucker, A., Aquilina, K., Chakkarapani, E., and Dingley, J. (2008). Xenon and hypothermia combine additively, offering long-term functional and histopathologic neuroprotection after neonatal hypoxia/ischemia. Stroke 39, 1307-1313. doi: 10.1161/STROKEAHA.107. 499822 
Hoerder-Suabedissen, A., and Molnár, Z. (2012). Morphology of mouse subplate cells with identified projection targets changes with age. J. Comp. Neurol. 520, 174-185. doi: 10.1002/cne.22725

Hoerder-Suabedissen, A., and Molnár, Z. (2015). Development, evolution and pathology of neocortical subplate neurons. Nat. Rev. Neurosci. 16, 133-146. doi: $10.1038 / \mathrm{nrn} 3915$

Hoerder-Suabedissen, A., Oeschger, F. M., Krishnan, M. L., Belgard, T. G., Wang, W. Z., Lee, S., et al. (2013). Expression profiling of mouse subplate reveals a dynamic gene network and disease association with autism and schizophrenia. Proc. Natl. Acad. Sci. U.S.A. 110, 3555-3560. doi: 10.1073/pnas.1218 510110

Hoerder-Suabedissen, A., Wang, W. Z., Lee, S., Davies, K. E., Goffinet, A. M., Rakic, S., et al. (2009). Novel markers reveal subpopulations of subplate neurons in the murine cerebral cortex. Cereb. Cortex 19, 1738-1750. doi: 10.1093/cercor/ bhn 195

Holmes, G. L. (1991). The long-term effects of seizures on the developing brain: clinical and laboratory issues. Brain Dev. 13, 393-409. doi: 10.1016/S03877604(12)80037-4

Holmes, G. L., and Ben-Ari, Y. (2001). The neurobiology and consequences of epilepsy in the developing brain. Pediatr. Res. 49, 320-325. doi: 10.1203/ 00006450-200103000-00004

Horn, E. P., Bein, B., Broch, O., Iden, T., Bohm, R., Latz, S. K., et al. (2016). Warming before and after epidural block before general anaesthesia for major abdominal surgery prevents perioperative hypothermia: a randomised controlled trial. Eur. J. Anaesthesiol. 33, 334-340. doi: 10.1097/EJA.0000000000000369

Hou, S. T., Jiang, S. X., Huang, D., and Desbois, A. (2007). A novel adenoviral vector-mediated neuronal selective gene expression in neonatal mouse brain in response to hypoxia. Neurosci. Lett. 419, 23-27. doi: 10.1016/j.neulet.2007. 03.059

Hou, X., Ding, H., Teng, Y., Zhou, C., Tang, X., Li, S., et al. (2007). Research on the relationship between brain anoxia at different regional oxygen saturations and brain damage using near-infrared spectroscopy. Physiol. Meas. 28, 1251-1265. doi: 10.1088/0967-3334/28/10/010

Hou, X. L., Ding, H. Y., Zhou, C. L., Tang, X. Y., Ding, H. S., Teng, Y. C., et al. (2007). Correlation of brain hypoxia at different degrees with brain function and brain damage investigated using near infrared spectroscopy. Zhonghua Er Ke Za Zhi 45, 523-528.

Hu, B. R., Liu, C. L., Ouyang, Y., Blomgren, K., and Siesjo, B. K. (2000). Involvement of caspase- 3 in cell death after hypoxia-ischemia declines during brain maturation. J. Cerebral Blood Flow Metab. 20, 1294-1300. doi: 10.1097/ 00004647-200009000-00003

Hu, C. J., Wang, L. Y., Chodosh, L. A., Keith, B., and Simon, M. C. (2003). Differential roles of hypoxia-inducible factor 1alpha (HIF-1alpha) and HIF2alpha in hypoxic gene regulation. Mol. Cell. Biol. 23, 9361-9374. doi: 10.1128/ MCB.23.24.9361-9374.2003

Hu, X., Qiu, J., Grafe, M. R., Rea, H. C., Rassin, D. K., and Perez-Polo, J. R. (2003). Bcl-2 family members make different contributions to cell death in hypoxia and/or hyperoxia in rat cerebral cortex. Int. J. Dev. Neurosci. 21, 371-377. doi: 10.1016/S0736-5748(03)00089-3

Hunt, R. W., Neil, J. J., Coleman, L. T., Kean, M. J., and Inder, T. E. (2004). Apparent diffusion coefficient in the posterior limb of the internal capsule predicts outcome after perinatal asphyxia. Pediatrics 114, 999-1003. doi: 10.1542/peds.2003-0935-L

Hurtley, S. M., and Helenius, A. (1989). Protein oligomerization in the endoplasmic reticulum. Annu. Rev. Cell Biol. 5, 277-307. doi: 10.1146/annurev.cb.05.110189. 001425

Hutton, L. C., Abbass, M., Dickinson, H., Ireland, Z., and Walker, D. W. (2009). Neuroprotective properties of melatonin in a model of birth asphyxia in the spiny mouse (Acomys cahirinus). Dev. Neurosci. 31, 437-451. doi: 10.1159/ 000232562

Ikeda, K., Tanihara, H., Honda, Y., Tatsuno, T., Noguchi, H., and Nakayama, C. (1999). BDNF attenuates retinal cell death caused by chemically induced hypoxia in rats. Invest. Ophthalmol. Vis. Sci. 40, 2130-2140.

Ikeda, T., Mishima, K., Yoshikawa, T., Iwasaki, K., Fujiwara, M., Xia, Y. X., et al. (2001). Selective and long-term learning impairment following neonatal hypoxic-ischemic brain insult in rats. Behav. Brain Res. 118, 17-25. doi: 10.1016/ S0166-4328(00)00287-4
Ikonomidou, C., Bosch, F., Miksa, M., Bittigau, P., Vockler, J., Dikranian, K., et al. (1999). Blockade of NMDA receptors and apoptotic neurodegeneration in the developing brain. Science 283, 70-74. doi: 10.1126/science.283. 5398.70

Ikonomidou, C., and Kaindl, A. M. (2011). Neuronal death and oxidative stress in the developing brain. Antioxid. Redox Signal. 14, 1535-1550. doi: 10.1089/ars. 2010.3581

Im, S., Yu, J., Park, E., Lee, J., Kim, H., Park, K., et al. (2010). Induction of striatal neurogenesis enhances functional recovery in an adult animal model of neonatal hypoxic-ischemic brain injury. Neuroscience 169, 259-268. doi: 10.1016/j.neuroscience.2010.04.038

Inder, T., Neil, J., Kroenke, C., Dieni, S., Yoder, B., and Rees, S. (2005a). Investigation of cerebral development and injury in the prematurely born primate by magnetic resonance imaging and histopathology. Dev. Neurosci. 27, $100-111$.

Inder, T., Neil, J., Yoder, B., and Rees, S. (2005b). Patterns of cerebral injury in a primate model of preterm birth and neonatal intensive care. J. Child Neurol. 20, 965-967.

Inder, T. E., Hunt, R. W., Morley, C. J., Coleman, L., Stewart, M., Doyle, L. W., et al. (2004). Randomized trial of systemic hypothermia selectively protects the cortex on MRI in term hypoxic-ischemic encephalopathy. J. Pediatr. 145, 835-837. doi: 10.1016/j.jpeds.2004.07.034

Inder, T. E., Huppi, P. S., Warfield, S., Kikinis, R., Zientara, G. P., Barnes, P. D., et al. (1999). Periventricular white matter injury in the premature infant is followed by reduced cerebral cortical gray matter volume at term. Ann. Neurol. 46, 755-760. doi: 10.1002/1531-8249(199911)46:5<755::AID-ANA11>3.0.CO;2-0

Inder, T. E., and Volpe, J. J. (2000). Mechanisms of perinatal brain injury. Semin. Neonatol. 5, 3-16. doi: 10.1053/siny.1999.0112

Ireland, Z., Dickinson, H., Fleiss, B., Hutton, L. C., and Walker, D. W. (2010). Behavioural effects of near-term acute fetal hypoxia in a small precocial animal, the spiny mouse (Acomys cahirinus). Neonatology 97, 45-51. doi: 10.1159/ 000227293

Ireland, Z., Dickinson, H., Snow, R., and Walker, D. W. (2008). Maternal creatine: does it reach the fetus and improve survival after an acute hypoxic episode in the spiny mouse (Acomys cahirinus)? Am. J. Obstet. Gynecol. 198, 431.e1-6. doi: 10.1016/j.ajog.2007.10.790

Ireland, Z., Russell, A. P., Wallimann, T., Walker, D. W., and Snow, R. (2009). Developmental changes in the expression of creatine synthesizing enzymes and creatine transporter in a precocial rodent, the spiny mouse. BMC Dev. Biol. 9:39. doi: 10.1186/1471-213X-9-39

Ishigami, S., Sandkvist, M., Tsui, F., Moore, E., Coleman, T. A., and Lawrence, D. A. (2007). Identification of a novel targeting sequence for regulated secretion in the serine protease inhibitor neuroserpin. Biochem. J. 402, 25-34. doi: 10.1042/ BJ20061170

Iuvone, L., Geloso, M. C., and Dell'Anna, E. (1996). Changes in open field behavior, spatial memory, and hippocampal parvalbumin immunoreactivity following enrichment in rats exposed to neonatal anoxia. Exp. Neurol. 139, 25-33. doi: 10.1006/exnr.1996.0077

Iyer, N. V., Leung, S. W., and Semenza, G. L. (1998). The human hypoxia-inducible factor lalpha gene: HIF1A structure and evolutionary conservation. Genomics 52, 159-165. doi: 10.1006/geno.1998.5416

Jabaudon, D., Scanziani, M., Gahwiler, B. H., and Gerber, U. (2000). Acute decrease in net glutamate uptake during energy deprivation. Proc. Natl. Acad. Sci. U.S.A. 97, 5610-5615. doi: 10.1073/pnas.97.10.5610

Jacobs, S., Hunt, R., Tarnow-Mordi, W., Inder, T., and Davis, P. (2005). 181 cooling for newborns with hypoxic ischaemic encephalopathy. Pediatr. Res. 58, 385-385. doi: 10.1016/j.arcped.2012.11.007

Jacobs, S. E., Berg, M., Hunt, R., Tarnow-Mordi, W. O., Inder, T. E., and Davis, P. G. (2013). Cooling for newborns with hypoxic ischaemic encephalopathy. Cochrane Database Syst. Rev. 4, CD003311. doi: 10.1002/14651858.CD003311. pub3

Jacovina, A. T., Zhong, F., Khazanova, E., Lev, E., Deora, A. B., and Hajjar, K. A. (2001). Neuritogenesis and the nerve growth factor-induced differentiation of PC-12 cells requires annexin II-mediated plasmin generation. J. Biol. Chem. 276, 49350-49358. doi: 10.1074/jbc.M106289200

Jansen, E. M., and Low, W. C. (1996a). Long-term effects of neonatal ischemichypoxic brain injury on sensorimotor and locomotor tasks in rats. Behav. Brain Res. 78, 189-194. 
Jansen, E. M., and Low, W. C. (1996b). Quantitative analysis of contralateral hemisphere hypertrophy and sensorimotor performance in adult rats following unilateral neonatal ischemic-hypoxic brain injury. Brain Res. 708, 93-99.

Jansen, E. M., Solberg, L., Underhill, S., Wilson, S., Cozzari, C., Hartman, B. K., et al. (1997). Transplantation of fetal neocortex ameliorates sensorimotor and locomotor deficits following neonatal ischemic-hypoxic brain injury in rats. Exp. Neurol. 147, 487-497. doi: 10.1006/exnr.1997.6596

Jantzie, L. L., Corbett, C. J., Berglass, J., Firl, D. J., Flores, J., Mannix, R., et al. (2014). Complex pattern of interaction between in utero hypoxia-ischemia and intra-amniotic inflammation disrupts brain development and motor function. J. Neuroinflammation 11:131. doi: 10.1186/1742-2094-11-131

Jantzie, L. L., Corbett, C. J., Firl, D. J., and Robinson, S. (2015a). Postnatal erythropoietin mitigates impaired cerebral cortical development following subplate loss from prenatal hypoxia-ischemia. Cereb.Cortex 25, 2683-2695. doi: $10.1093 /$ cercor/bhu066

Jantzie, L. L., Hu, M. Y., Park, H. K., Jackson, M. C., Yu, J., Maxwell, J. R., et al. (2015b). Chloride cotransporter NKCC1 inhibitor bumetanide protects against white matter injury in a rodent model of periventricular leukomalacia. Pediatr. Res. 77, 554-562. doi: 10.1038/pr.2015.9

Jantzie, L. L., Winer, J. L., Maxwell, J. R., Chan, L. A., and Robinson, S. (2015c). Modeling encephalopathy of prematurity using prenatal Hypoxia-ischemia with Intra-amniotic lipopolysaccharide in rats. J. Vis. Exp. 105:e53196. doi: $10.3791 / 53196$

Jarvis, S., Glinianaia, S. V., Arnaud, C., Fauconnier, J., Johnson, A., McManus, V., et al. (2005). Case gender and severity in cerebral palsy varies with intrauterine growth. Arch. Dis. Child. 90, 474-479. doi: 10.1136/adc.2004.052670

Jatana, M., Singh, I., Singh, A. K., and Jenkins, D. (2006). Combination of systemic hypothermia and $\mathrm{N}$-acetylcysteine attenuates hypoxic-ischemic brain injury in neonatal rats. Pediatr. Res. 59, 684-689. doi: 10.1203/01.pdr.0000215045. 91122.44

Jelinski, S. E., Yager, J. Y., and Juurlink, B. H. (1999). Preferential injury of oligodendroblasts by a short hypoxic-ischemic insult. Brain Res. 815, 150-153. doi: 10.1016/S0006-8993(98)01053-1

Jendelová, P., Herynek, V., Urdzikova, L., Glogarová, K., Kroupová, J., Andersson, B., et al. (2004). Magnetic resonance tracking of transplanted bone marrow and embryonic stem cells labeled by iron oxide nanoparticles in rat brain and spinal cord. J. Neurosci. Res. 76, 232-243. doi: 10.1002/jnr.20041

Jensen, A., Garnier, Y., and Berger, R. (1999). Dynamics of fetal circulatory responses to hypoxia and asphyxia. Eur. J. Obstet. Gynecol. Reprod. Biol. 84, 155-172. doi: 10.1016/S0301-2115(98)00325-X

Jensen, F. (1995). An animal model of hypoxia-induced perinatal seizures. Ital. J. Neurol. Sci. 16, 59-68. doi: 10.1007/BF02229075

Jensen, F., Blume, H., Alvarado, S., Firkusny, I., and Geary, C. (1995). NBQX blocks acute and late epileptogenic effects of perinatal hypoxia. Epilepsia 36, 966-972. doi: 10.1111/j.1528-1157.1995.tb00954.x

Johnston, M. V. (2001). Excitotoxicity in neonatal hypoxia. Ment. Retard. Dev. Disabil. Res. Rev. 7, 229-234. doi: 10.1002/mrdd.1032

Johnston, M. V. (2005). Excitotoxicity in perinatal brain injury. Brain Pathol. 15, 234-240. doi: 10.1111/j.1750-3639.2005.tb00526.x

Johnston, M. V. (2009). Plasticity in the developing brain: implications for rehabilitation. Dev. Disab. Res. Rev. 15, 94-101. doi: 10.1002/ddrr.64

Johnston, M. V., Fatemi, A., Wilson, M. A., and Northington, F. (2011). Treatment advances in neonatal neuroprotection and neurointensive care. Lancet Neurol. 10, 372-382. doi: 10.1016/S1474-4422(11)70016-3

Johnston, M. V., and Hagberg, H. (2007). Sex and the pathogenesis of cerebral palsy. Dev. Med. Child Neurol. 49, 74-78. doi: 10.1017/S001216220700 0199.x

Jones, M. K., Szabo, I. L., Kawanaka, H., Husain, S. S., and Tarnawski, A. S. (2002). von Hippel Lindau tumor suppressor and HIF-1alpha: new targets of NSAIDs inhibition of hypoxia-induced angiogenesis. FASEB J. 16, 264-266.

Joseph, B., Nandhu, M. S., and Paulose, C. S. (2010). Dopamine D1 and D2 receptor functional down regulation in the cerebellum of hypoxic neonatal rats: neuroprotective role of glucose and oxygen, epinephrine resuscitation. Pharmacol. Res. 61, 136-141. doi: 10.1016/j.phrs.2009.08.007

Judas, M., Sedmak, G., Pletikos, M., and Jovanov-Milosevic, N. (2010). Populations of subplate and interstitial neurons in fetal and adult human telencephalon. J. Anat. 217, 381-399. doi: 10.1111/j.1469-7580.2010.01284.x
Juul, S. E., Beyer, R. P., Bammler, T. K., McPherson, R. J., Wilkerson, J., and Farin, F. M. (2009). Microarray analysis of high-dose recombinant erythropoietin treatment of unilateral brain injury in neonatal mouse hippocampus. Pediatr. Res. 65, 485-492. doi: 10.1203/PDR.0b013e31819d90c8

Kali, G. T., Martinez-Biarge, M., Van Zyl, J., Smith, J., and Rutherford, M. (2015). Management of therapeutic hypothermia for neonatal hypoxic ischaemic encephalopathy in a tertiary centre in South Africa. Arch. Dis. Child. Fetal Neonatal. Ed. 100, F519-F523. doi: 10.1136/archdischild-2015-308398

Kaneko, K. (1985a). The effect of perinatal anoxia on amino acid metabolism in the developing brain. Part I: the effect of experimental anoxia on the free amino acid patterns in the brain of neonatal rats. Brain Dev. 7, 392-399.

Kaneko, K. (1985b). The effect of perinatal anoxia on amino acid metabolism in the developing brain. Part II: the effect of perinatal anoxia on the free amino acid patterns in CSF of infants and children. Brain Dev. 7, 400-407.

Kaneko, T., Sawada, T., Kinugawa, H., Kuriyama, Y., and Naritomi, H. (1985). A case of inverse ocular bobbing associated with cluster respiration in hypoxic encephalopathy. Rinsho shinkeigaku 25, 1192-1195.

Kanold, P. O. (2009). Subplate neurons: crucial regulators of cortical development and plasticity. Front. Neuroanat. 3:16. doi: 10.3389/neuro.05.016. 2009

Kanold, P. O., Kara, P., Reid, R. C., and Shatz, C. J. (2003). Role of subplate neurons in functional maturation of visual cortical columns. Science 301, 521-525. doi: $10.1126 /$ science. 1084152

Kanold, P. O., and Luhmann, H. J. (2010). The subplate and early cortical circuits. Annu. Rev. Neurosci. 33, 23-48. doi: 10.1146/annurev-neuro-060909-153244

Kanold, P. O., and Shatz, C. J. (2006). Subplate neurons regulate maturation of cortical inhibition and outcome of ocular dominance plasticity. Neuron 51, 627-638. doi: 10.1016/j.neuron.2006.07.008

Karalis, F., Soubasi, V., Georgiou, T., Nakas, C. T., Simeonidou, C., GuibaTziampiri, O., et al. (2011). Resveratrol ameliorates hypoxia/ischemia-induced behavioral deficits and brain injury in the neonatal rat brain. Brain Res. 1425, 98-110. doi: 10.1016/j.brainres.2011.09.044

Kattwinkel, J., Perlman, J. M., Aziz, K., Colby, C., Fairchild, K., Gallagher, J., et al. (2010). Part 15: neonatal resuscitation: 2010 American heart association guidelines for cardiopulmonary resuscitation and emergency cardiovascular care. Circulation 122(18 Suppl. 3), S909-S919. doi: 10.1161/CIRCULATIONAHA.110.971119

Kaufman, S. A., Miller, S. P., Ferriero, D. M., Glidden, D. H., Barkovich, A. J., and Partridge, J. C. (2003). Encephalopathy as a predictor of magnetic resonance imaging abnormalities in asphyxiated newborns. Pediatr. Neurol. 28, 342-346. doi: 10.1016/S0887-8994(03)00015-8

Kaur, C., Dheen, S. T., and Ling, E. A. (2007). From blood to brain: amoeboid microglial cell, a nascent macrophage and its functions in developing brain. Acta Pharmacol. Sin. 28, 1087-1096. doi: 10.1111/j.1745-7254.2007.00625.x

Kaur, C., and Ling, E. A. (2009). Periventricular white matter damage in the hypoxic neonatal brain: role of microglial cells. Prog. Neurobiol. 87, 264-280. doi: 10.1016/j.pneurobio.2009.01.003

Kaur, C., Rathnasamy, G., and Ling, E. (2013). Roles of activated microglia in hypoxia induced neuroinflammation in the developing brain and the retina. J. Neuroimmune Pharmacol. 8, 66-78. doi: 10.1007/s11481-012-9347-2

Kemp, G. J., and Radda, G. K. (1994). Quantitative interpretation of bioenergetic data from $31 \mathrm{P}$ and $1 \mathrm{H}$ magnetic resonance spectroscopic studies of skeletal muscle: an analytical review. Magn. Reson. Q. 10, 43-63.

Kida, H., Nomura, S., Shinoyama, M., Ideguchi, M., Owada, Y., and Suzuki, M. (2013). The effect of hypothermia therapy on cortical laminar disruption following ischemic injury in neonatal mice. PLoS ONE 8:e68877. doi: 10.1371/ journal.pone.0068877

Kim, G. S., Cho, S., Nelson, J. W., Zipfel, G. J., and Han, B. H. (2014). TrkB agonist antibody pretreatment enhances neuronal survival and long-term sensory motor function following hypoxic ischemic injury in neonatal rats. PLoS ONE 9:e88962. doi: 10.1371/journal.pone.0088962

Kinney, H. C., Haynes, R. L., Xu, G., Andiman, S. E., Folkerth, R. D., Sleeper, L. A., et al. (2012). Neuron deficit in the white matter and subplate in periventricular leukomalacia. Ann. Neurol. 71, 397-406. doi: 10.1002/ana.22612

Kletkiewicz, H., Nowakowska, A., Siejka, A., Mila-Kierzenkowska, C., Wozniak, A., Caputa, M., et al. (2016). Deferoxamine prevents cerebral glutathione and vitamin $\mathrm{E}$ depletions in asphyxiated neonatal rats: role of body temperature. Int. J. Hyperthermia 32, 211-220. doi: 10.3109/02656736.2015.1125955 
Klionsky, D. J., and Emr, S. D. (2000). Autophagy as a regulated pathway of cellular degradation. Science 290, 1717-1721. doi: 10.1126/science.290.5497.1717

Kniesel, U., Risau, W., and Wolburg, H. (1996). Development of blood-brain barrier tight junctions in the rat cortex. Brain Res. Dev. Brain Res. 96, 229-240. doi: 10.1016/0165-3806(96)00117-4

Koh, S., and Jensen, F. E. (2001). Topiramate blocks perinatal hypoxia-induced seizures in rat pups. Ann. Neurol. 50, 366-372. doi: 10.1002/ana.1122

Koike, M., Shibata, M., Tadakoshi, M., Gotoh, K., Komatsu, M., Waguri, S., et al. (2008). Inhibition of autophagy prevents hippocampal pyramidal neuron death after hypoxic-ischemic injury. Am. J. Pathol. 172, 454-469. doi: 10.2353/ajpath. 2008.070876

Kondo, S., Al-Hasani, H., Hoerder-Suabedissen, A., Wang, W. Z., and Molnár, Z. (2015). Secretory function in subplate neurons during cortical development. Front. Neurosci. 9:100. doi: 10.3389/fnins.2015.00100

Kondo, S., Hino, S. I., Saito, A., Kanemoto, S., Kawasaki, N., Asada, R., et al. (2012). Activation of OASIS family, ER stress transducers, is dependent on its stabilization. Cell Death Differ. 19, 1939-1949. doi: 10.1038/cdd.2012.77

Kondo, S., Murakami, T., Tatsumi, K., Ogata, M., Kanemoto, S., Otori, K., et al. (2005). OASIS, a CREB/ATF-family member, modulates UPR signalling in astrocytes. Nat. Cell Biol. 7, 186-194. doi: 10.1038/ncb1213

Kondo, S., Saito, A., Asada, R., Kanemoto, S., and Imaizumi, K. (2011). Physiological unfolded protein response regulated by OASIS family members, transmembrane bZIP transcription factors. IUBMB Life 63, 233-239. doi: 10.1002/iub.433

Kostovic, I., Jovanov-Milosevic, N., Rados, M., Sedmak, G., Benjak, V., KostovicSrzentic, M., et al. (2014). Perinatal and early postnatal reorganization of the subplate and related cellular compartments in the human cerebral wall as revealed by histological and MRI approaches. Brain Struct. Funct. 219, 231-253. doi: 10.1007/s00429-012-0496-0

Kostovic, I., and Judas, M. (2006). Prolonged coexistence of transient and permanent circuitry elements in the developing cerebral cortex of fetuses and preterm infants. Dev. Med. Child Neurol. 48, 388-393. doi: 10.1017/ S0012162206000831

Kostovic, I., and Judas, M. (2010). The development of the subplate and thalamocortical connections in the human foetal brain. Acta Paediatr. 99, 1119-1127. doi: 10.1111/j.1651-2227.2010.01811.x

Kostovic, I., Judas, M., Rados, M., and Hrabac, P. (2002). Laminar organization of the human fetal cerebrum revealed by histochemical markers and magnetic resonance imaging. Cereb. Cortex 12, 536-544. doi: 10.1093/cercor/12.5.536

Kostovic, I., Judas, M., and Sedmak, G. (2011). Developmental history of the subplate zone, subplate neurons and interstitial white matter neurons: relevance for schizophrenia. Int. J. Dev. Neurosci. 29, 193-205. doi: 10.1016/j.ijdevneu. 2010.09.005

Kostovic, I., and Rakic, P. (1990). Developmental history of the transient subplate zone in the visual and somatosensory cortex of the macaque monkey and human brain. J. Comp. Neurol. 297, 441-470. doi: 10.1002/cne.902970309

Kracer, B., Hintz, S. R., Van Meurs, K. P., and Lee, H. C. (2014). Hypothermia therapy for neonatal hypoxic ischemic encephalopathy in the state of California. J. Pediatr. 165, 267-273. doi: 10.1016/j.jpeds.2014.04.052

Krajnc, D., Norton, H. N., and Hadjiconstantinou, M. (1996). Glutamate, glutamine and glutamine synthetase in the neonatal rat brain following hypoxia. Brain Res. 707, 134-137. doi: 10.1016/0006-8993(95)01372-5

Krajnc, D., Wemlinger, T. A., Neff, N. H., and Hadjiconstantinou, M. (1994). Neonatal hypoxia: early neurotransmitter responses and the consequences of treatment with GM1 ganglioside. J. Pharmacol. Exp. Ther. 271, 1299-1305.

Krueger, S. R., Ghisu, G. P., Cinelli, P., Gschwend, T. P., Osterwalder, T., Wolfer, D. P., et al. (1997). Expression of neuroserpin, an inhibitor of tissue plasminogen activator, in the developing and adult nervous system of the mouse. J. Neurosci. 17, 8984-8996.

Krystosek, A., and Seeds, N. W. (1981a). Plasminogen activator release at the neuronal growth cone. Science 213, 1532-1534.

Krystosek, A., and Seeds, N. W. (1981b). Plasminogen activator secretion by granule neurons in cultures of developing cerebellum. Proc. Natl. Acad. Sci. U.S.A. 78, 7810-7814.

Kuan, C., Lawrence, D. A., Yang, D. E., and Adhami, F. (2010). Plasminogen Activator Inhibitor Amelioration of Newborn Hypoxic Ischemic Brain Injury. US 20100286053 .
L'Abee, C., de Vries, L. S., van der Grond, J., and Groenendaal, F. (2005). Early diffusion-weighted MRI and $1 \mathrm{H}$-magnetic resonance spectroscopy in asphyxiated full-term neonates. Biol. Neonate 88, 306-312. doi: 10.1159/ 000087628

Lafemina, M. J., Sheldon, R. A., and Ferriero, D. M. (2006). Acute hypoxia-ischemia results in hydrogen peroxide accumulation in neonatal but not adult mouse brain. Pediatr. Res. 59, 680-683. doi: 10.1203/01.pdr.0000214891.35363.6a

Lai, M. C., and Yang, S. N. (2011). Perinatal hypoxic-ischemic encephalopathy. J. Biomed. Biotechnol. 2011:609813. doi: 10.1155/2011/609813

Lam, J. S., Anderson, E. M., and Hao, Y. (2014). LPS quantitation procedures. Methods Mol. Biol. 1149, 375-402. doi: 10.1007/978-1-4939-0473-0_31

Laptook, A. R., Shankaran, S., Ambalavanan, N., Carlo, W. A., McDonald, S. A., Higgins, R. D., et al. (2009). Outcome of term infants using apgar scores at 10 minutes following hypoxic-ischemic encephalopathy. Pediatrics 124 , 1619-1626. doi: 10.1542/peds.2009-0934

Laroia, N., McBride, L., Baggs, R., and Guillet, R. (1997). Dextromethorphan ameliorates effects of neonatal hypoxia on brain morphology and seizure threshold in rats. Dev. Brain Res. 100, 29-34. doi: 10.1016/S0165-3806(97) 00018-7

Larroche, J. C. (1977). Developmental Pathology of the Neonate. Amsterdam: Excerpta Medica.

Larroque, B., Breart, G., Kaminski, M., Dehan, M., Andre, M., Burguet, A., et al. (2004). Survival of very preterm infants: epipage, a population based cohort study. Arch. Dis. Child. Fetal Neonatal Ed. 89, F139-F144. doi: 10.1136/adc. 2002.020396

Lawn, J. E., Cousens, S., Zupan, J., and Lancet Neonatal Survival Steering Team. (2005). 4 million neonatal deaths: when? Where? Why? Lancet 365, 891-900.

Lebeurrier, N., Liot, G., Lopez-Atalaya, J., Fernandez-Monreal, M., Sonderegger, P., Vivien, D., et al. (2005a). Neuroprotective activity of neuroserpin against NMDA receptor-mediated excitotoxicity. J. Cereb. Blood Flow Metab. 25, S455.

Lebeurrier, N., Liot, G., Lopez-Atalaya, J. P., Orset, C., Fernandez-Monreal, M., Sonderegger, P., et al. (2005b). The brain-specific tissue-type plasminogen activator inhibitor, neuroserpin, protects neurons against excitotoxicity both in vitro and in vivo. Mol. Cell. Neurosci. 30, 552-558.

Lee, A. C., Kozuki, N., Blencowe, H., Vos, T., Bahalim, A., Darmstadt, G. L., et al. (2013). Intrapartum-related neonatal encephalopathy incidence and impairment at regional and global levels for 2010 with trends from 1990. Pediatr. Res. 74(Suppl. 1), 50-72. doi: 10.1038/pr.2013.206

Lee, A. S. (1987). Coordinated regulation of a set of genes by glucose and calcium ionophores in mammalian cells. Trends Biochem. Sci. 12, 20-23. doi: 10.1016/ 0968-0004(87)90011-9

Lee, A. S. (2001). The glucose-regulated proteins: stress induction and clinical applications. Trends Biochem. Sci. 26, 504-510. doi: 10.1016/S0968-0004(01) 01908-9

Lee, A. S. (2005). The ER chaperone and signaling regulator GRP78/BiP as a monitor of endoplasmic reticulum stress. Methods 35, 373-381. doi: 10.1016/ j.ymeth.2004.10.010

Lee, B. S., Woo, C., Kim, S., and Kim, K. (2010). Long-term neuroprotective effect of postischemic hypothermia in a neonatal rat model of severe hypoxic ischemic encephalopathy: a comparative study on the duration and depth of hypothermia. Pediatr. Res. 68, 303-308. doi: 10.1203/00006450-20101100100592

Lee, T. W., Coates, L. C., and Birch, N. P. (2008). Neuroserpin regulates $\mathrm{N}$-cadherin-mediated cell adhesion independently of its activity as an inhibitor of tissue plasminogen activator. J. Neurosci. Res. 86, 1243-1253. doi: 10.1002/ jnr.21592

Lee, T. W., Tsang, V. W., and Birch, N. P. (2015a). Physiological and pathological roles of tissue plasminogen activator and its inhibitor neuroserpin in the nervous system. Front. Cell. Neurosci. 9:396. doi: 10.3389/fncel.2015. 00396

Lee, T. W., Yang, A. S., Brittain, T., and Birch, N. P. (2015b). An analysis approach to identify specific functional sites in orthologous proteins using sequence and structural information: application to neuroserpin reveals regions that differentially regulate inhibitory activity. Proteins 83 , 135-152. doi: 10.1002/ prot. 24711

Legido, A., Clancy, R. R., and Berman, P. H. (1991). Neurologic outcome after electroencephalographically proven neonatal seizures. Pediatrics 88, 583-596. 
Lehnardt, S., Massillon, L., Follett, P., Jensen, F. E., Ratan, R., Rosenberg, P. A., et al. (2003). Activation of innate immunity in the CNS triggers neurodegeneration through a Toll-like receptor 4-dependent pathway. Proc. Natl. Acad. Sci. U.S.A. 100, 8514-8519. doi: 10.1073/pnas.1432609100

Lein, E. S., Finney, E. M., McQuillen, P. S., and Shatz, C. J. (1999). Subplate neuron ablation alters neurotrophin expression and ocular dominance column formation. Proc. Natl. Acad. Sci. U.S.A. 96, 13491-13495. doi: 10.1073/pnas.96. 23.13491

Leonardo, C. C., and Pennypacker, K. R. (2009). Neuroinflammation and MMPs: potential therapeutic targets in neonatal hypoxic-ischemic injury. J. Neuroinflammation 6:13. doi: 10.1186/1742-2094-6-13

Levene, M., Grindulis, H., Sands, C., and Moore, J. (1986). Comparison of two methods of predicting outcome in perinatal asphyxia. Lancet 327, 67-69. doi: 10.1016/S0140-6736(86)90718-X

Leviton, A., and Gressens, P. (2007). Neuronal damage accompanies perinatal white-matter damage. Trends Neurosci. 30, 473-478. doi: 10.1016/j.tins.2007. 05.009

Leviton, A., Paneth, N., Reuss, M. L., Susser, M., Allred, E. N., Dammann, O., et al. (1999). Maternal infection, fetal inflammatory response, and brain damage in very low birth weight infants. Dev. Epidemiol. Network Invest. Pediatr. Res. 46, 566-575. doi: 10.1203/00006450-199911000-00013

Li, A. M., Chau, V., Poskitt, K. J., Sargent, M. A., Lupton, B. A., Hill, A., et al. (2009). White matter injury in term newborns with neonatal encephalopathy. Pediatr. Res. 61, 85-89. doi: 10.1203/PDR.0b013e31818912d2

Li, C., and Jackson, R. M. (2002). Reactive species mechanisms of cellular hypoxia-reoxygenation injury. Am. J. Physiol. Cell Physiol. 282, C227-C241. doi: 10.1152/ajpcell.00112.2001

Li, M., Yu, A., Zhang, F., Dai, G., Cheng, H., Wang, X., et al. (2012). Treatment of one case of cerebral palsy combined with posterior visual pathway injury using autologous bone marrow mesenchymal stem cells. J. Trans. Med. 10:100. doi: 10.1186/1479-5876-10-100

Li, P., Nijhawan, D., Budihardjo, I., Srinivasula, S. M., Ahmad, M., Alnemri, E. S., et al. (1997). Cytochrome c and dATP-dependent formation of Apaf1/caspase-9 complex initiates an apoptotic protease cascade. Cell 91, 479-489. doi: 10.1016/S0092-8674(00)80434-1

Liao, Y., Cotten, M., Tan, S., Kurtzberg, J., and Cairo, M. S. (2013). Rescuing the neonatal brain from hypoxic injury with autologous cord blood. Bone Marrow Transplant. 48, 890-900. doi: 10.1038/bmt.2012.169

Liauw, L., van Wezel-Meijler, G., Veen, S., van Buchem, M. A., and van der Grond, J. (2009). Do apparent diffusion coefficient measurements predict outcome in children with neonatal hypoxic-ischemic encephalopathy? AJNR Am. J. Neuroradiol. 30, 264-270. doi: 10.3174/ajnr.A1318

Lieblein-Boff, J. C., McKim, D. B., Shea, D. T., Wei, P., Deng, Z., Sawicki, C., et al. (2013). Neonatal E. coli infection causes neuro-behavioral deficits associated with hypomyelination and neuronal sequestration of iron. J. Neurosci. 33, 16334-16345. doi: 10.1523/JNEUROSCI.0708-13.2013

Lin, E. P., Miles, L., Hughes, E. A., McCann, J. C., Vorhees, C. V., McAuliffe, J. J., et al. (2014). A combination of mild hypothermia and sevoflurane affords long-term protection in a modified neonatal mouse model of cerebral hypoxiaischemia. Anesth. Analg. 119, 1158-1173. doi: 10.1213/ANE.00000000000 00262

Liu, Y., Silverstein, F. S., Skoff, R., and Barks, J. D. (2002). Hypoxic-ischemic oligodendroglial injury in neonatal rat brain. Pediatr. Res. 51, 25-33. doi: 10.1203/00006450-200201000-00007

Lochner, J. E., Honigman, L. S., Grant, W. F., Gessford, S. K., Hansen, A. B., Silverman, M. A., et al. (2006). Activity-dependent release of tissue plasminogen activator from the dendritic spines of hippocampal neurons revealed by live-cell imaging. J. Neurobiol. 66, 564-577. doi: 10.1002/neu.20250

Lockshin, R. A., and Zakeri, Z. (1994). Programmed cell death: early changes in metamorphosing cells. Biochem. Cell Biol. 72, 589-596. doi: 10.1139/ o94-078

Lodish, H. F. (1988). Transport of secretory and membrane glycoproteins from the rough endoplasmic reticulum to the Golgi. A rate-limiting step in protein maturation and secretion. J. Biol. Chem. 263, 2107-2110.

Lorek, A., Takei, Y., Cady, E. B., Wyatt, J. S., Penrice, J., Edwards, A. D., et al. (1994). Delayed ("secondary") cerebral energy failure after acute hypoxia-ischemia in the newborn piglet: continuous 48 -hour studies by phosphorus magnetic resonance spectroscopy. Pediatr. Res. 36, 699-706. doi: 10.1203/00006450199412000-00003

Loron, G., Olivier, P., See, H., Le Sache, N., Angulo, L., Biran, V., et al. (2011). Ciprofloxacin prevents myelination delay in neonatal rats subjected to $E$. coli sepsis. Ann. Neurol. 69, 341-351. doi: 10.1002/ana.22190

Lubics, A., Reglödi, D., Tamás, A., Kiss, P., Szalai, M., Szalontay, L., et al. (2005). Neurological reflexes and early motor behavior in rats subjected to neonatal hypoxic-ischemic injury. Behav. Brain Res. 157, 157-165. doi: 10.1016/j.bbr. 2004.06.019

Ma, J., Tong, Y., Yu, D., and Mao, M. (2012a). Tissue plasminogen activatorindependent roles of neuroserpin in the central nervous system. Neural Regen. Res. 7, 146-151. doi: 10.3969/j.issn.1673-5374.2012.02.012

Ma, J., Yu, D., Tong, Y., and Mao, M. (2012b). Effect of neuroserpin in a neonatal hypoxic-ischemic injury model ex vivo. Biol. Res. 45, 357-362. doi: 10.4067/ S0716-97602012000400005

Magnani, D., Hasenpusch-Theil, K., and Theil, T. (2013). Gli3 controls subplate formation and growth of cortical axons. Cereb. Cortex 23, 2542-2551. doi: 10.1093/cercor/bhs237

Malaeb, S. N., Davis, J. M., Pinz, I. M., Newman, J. L., Dammann, O., and Rios, M. (2014). Effect of sustained postnatal systemic inflammation on hippocampal volume and function in mice. Pediatr. Res. 76, 363-369. doi: 10.1038/pr. 2014.106

Malik, G. K., Trivedi, R., Gupta, R. K., Hasan, K. M., Hasan, M., Gupta, A., et al. (2006). Serial quantitative diffusion tensor MRI of the term neonates with hypoxic-ischemic encephalopathy (HIE). Neuropediatrics 37, 337-343. doi: 10.1055/s-2007-964869

Mallard, C., Davidson, J. O., Tan, S., Green, C. R., Bennet, L., Robertson, N. J., et al. (2013). Astrocytes and microglia in acute cerebral injury underlying cerebral palsy associated with preterm birth. Pediatr. Res. 75, 234-240. doi: 10.1038/pr. 2013.188

Mallard, C., Welin, A. K., Peebles, D., Hagberg, H., and Kjellmer, I. (2003). White matter injury following systemic endotoxemia or asphyxia in the fetal sheep. Neurochem. Res. 28, 215-223. doi: 10.1023/A:1022368915400

Mallard, E. C., Williams, C. E., Gunn, A. J., Gunning, M. I., and Gluckman, P. D. (1993). Frequent episodes of brief ischemia sensitize the fetal sheep brain to neuronal loss and induce striatal injury. Pediatr. Res. 33, 61-65. doi: 10.1203/ 00006450-199301000-00013

Marini, A. M., Jiang, X., Wu, X., Pan, H., Guo, Z., Mattson, M. P., et al. (2007). Preconditioning and neurotrophins: a model for brain adaptation to seizures, ischemia and other stressful stimuli. Amino Acids 32, 299-304. doi: 10.1007/ s00726-006-0414-y

Marin-Padilla, M. (1996). Developmental neuropathology and impact of perinatal brain damage. I: hemorrhagic lesions of neocortex. J. Neuropathol. Exp. Neurol. 55, 758-773. doi: 10.1097/00005072-199607000-00002

Marin-Padilla, M. (1997). Developmental neuropathology and impact of perinatal brain damage. II: white matter lesions of the neocortex. J. Neuropathol. Exp. Neurol. 56, 219-235. doi: 10.1097/00005072-199703000-00001

Marin-Padilla, M. (1999). Developmental neuropathology and impact of perinatal brain damage. III: gray matter lesions of the neocortex. J. Neuropathol. Exp. Neurol. 58, 407-429. doi: 10.1097/00005072-199905000-00001

Marques-Smith, A., Lyngholm, D., Kaufmann, A. K., Stacey, J. A., HoerderSuabedissen, A., Becker, E. B., et al. (2016). A transient translaminar GABAergic interneuron circuit connects thalamocortical recipient layers in neonatal somatosensory cortex. Neuron 89, 536-549. doi: 10.1016/j.neuron.2016.01.015

Marret, S., Mukendi, R., Gadisseux, J. F., Gressens, P., and Evrard, P. (1995). Effect of ibotenate on brain development: an excitotoxic mouse model of microgyria and posthypoxic-like lesions. J. Neuropathol. Exp. Neurol. 54, 358-370. doi: 10.1097/00005072-19950500000009

Martin, L. J., Brambrink, A., Koehler, R. C., and Traystman, R. J. (1997). Primary sensory and forebrain motor systems in the newborn brain are preferentially damaged by hypoxia-ischemia. J. Compar. Neurol. 377, 262-285. doi: 10.1002/ (SICI)1096-9861(19970113)377:2<262::AID-CNE8>3.0.CO;2-1

Martin, N., Bossenmeyer-Pourie, C., Koziel, V., Jazi, R., Audonnet, S., Vert, P., et al. (2012). Non-injurious neonatal hypoxia confers resistance to brain senescence in aged male rats. PLoS ONE 7:e48828. doi: 10.1371/journal.pone. 0048828 
Martin, R., Mozet, C., Martin, H., Welt, K., Engel, C., and Fitzl, G. (2011). The effect of Ginkgo biloba extract (EGb 761) on parameters of oxidative stress in different regions of aging rat brains after acute hypoxia. Aging Clin. Exp. Res. 23, 255-263. doi: 10.3275/7229

Martinez-Biarge, M., Diez-Sebastian, J., Kapellou, O., Gindner, D., Allsop, J. M., Rutherford, M. A., et al. (2011). Predicting motor outcome and death in term hypoxic-ischemic encephalopathy. Neurology 76, 2055-2061. doi: 10.1212/ WNL.0b013e31821f442d

McDonald, F. B., Dempsey, E. M., and O’Halloran, K. D. (2016). Early life exposure to chronic intermittent hypoxia primes increased susceptibility to hypoxiainduced weakness in rat sternohyoid muscle during adulthood. Front. Physiol. 7:69. doi: 10.3389/fphys.2016.00069

McDonald, J. W., Behrens, M. I., Chung, C., Bhattacharyya, T., and Choi, D. W. (1997). Susceptibility to apoptosis is enhanced in immature cortical neurons. Brain Res. 759, 228-232. doi: 10.1016/S0006-8993(97) 00248-5

McDonald, J. W., and Johnston, M. V. (1992). Neuroprotective synergism of 2-amino-3-phosphonoproprionate (D,L-AP3) and MK-801 against ibotenate induced brain injury. Neurosci. Lett. 145, 213-216. doi: 10.1016/0304-3940(92) 90025-3

McDonald, J. W., Roeser, N. F., Silverstein, F. S., and Johnston, M. V. (1989a). Quantitative assessment of neuroprotection against NMDA-induced brain injury. Exp. Neurol. 106, 289-296.

McDonald, J. W., Silverstein, F. S., Cardona, D., Hudson, C., Chen, R., and Johnston, M. V. (1990). Systemic administration of MK-801 protects against $\mathrm{N}$-methyl-D-aspartate- and quisqualate-mediated neurotoxicity in perinatal rats. Neuroscience 36, 589-599. doi: 10.1016/0306-4522(90)90002-L

McDonald, J. W., Silverstein, F. S., and Johnston, M. V. (1988). Neurotoxicity of N-methyl-D-aspartate is markedly enhanced in developing rat central nervous system. Brain Res. 459, 200-203. doi: 10.1016/0006-8993(88) 90306-X

McDonald, J. W., Silverstein, F. S., and Johnston, M. V. (1989b). Neuroprotective effects of MK-801, TCP, PCP and CPP against N-methyl-D-aspartate induced neurotoxicity in an in vivo perinatal rat model. Brain Res. 490, 33-40.

McDonald, J. W., Uckele, J., Silverstein, F. S., and Johnston, M. V. (1989c). HA-966 (1-hydroxy-3-aminopyrrolidone-2) selectively reduces $\mathrm{N}$-methyl-D-aspartate (n.d.)-mediated brain damage. Neurosci. Lett. 104, 167-170.

McKinstry, R. C., Miller, J. H., Snyder, A. Z., Mathur, A., Schefft, G. L., Almli, C. R., et al. (2002). A prospective, longitudinal diffusion tensor imaging study of brain injury in newborns. Neurology 59, 824-833. doi: 10.1212/WNL.59. 6.824

McLean, C., and Ferriero, D. (2004). Mechanisms of hypoxic-ischemic injury in the term infant. Semin. Perinatol. 28, 425-432. doi: 10.1053/j.semperi.2004.10.005

McPherson, R. J., and Juul, S. E. (2010). Erythropoietin for infants with hypoxicischemic encephalopathy. Curr. Opin. Pediatr. 22, 139-145. doi: 10.1097/MOP. 0b013e328336eb57

McQuillen, P. S., and Ferriero, D. M. (2004). Selective vulnerability in the developing central nervous system. Pediatr. Neurol. 30, 227-235. doi: 10.1016/ j.pediatrneurol.2003.10.001

McQuillen, P. S., and Ferriero, D. M. (2005). Perinatal subplate neuron injury: implications for cortical development and plasticity. Brain Pathol. 15, 250-260. doi: 10.1111/j.1750-3639.2005.tb00528.x

McQuillen, P. S., Sheldon, R. A., Shatz, C. J., and Ferriero, D. M. (2003). Selective vulnerability of subplate neurons after early neonatal hypoxiaischemia. J. Neurosci. 23, 3308-3315.

McRae, A., Gilland, E., Bona, E., and Hagberg, H. (1995). Microglia activation after neonatal hypoxic-ischemia. Dev. Brain Res. 84, 245-252. doi: 10.1016/01653806(94)00177-2

Meldrum, B. (1990). Protection against ischaemic neuronal damage by drugs acting on excitatory neurotransmission. Cerebrovasc. Brain Metab. Rev. 2, 27-57.

Ment, L. R., Bada, H. S., Barnes, P., Grant, P. E., Hirtz, D., Papile, L. A., et al. (2002). Practice parameter: neuroimaging of the neonate: report of the quality standards subcommittee of the american academy of neurology and the practice committee of the child neurology society. Neurology 58, 1726-1738. doi: 10.1212/WNL.58.12.1726

Ment, L. R., Duncan, C. C., and Ehrenkranz, R. A. (1984). Perinatal cerebral infarction. Ann. Neurol. 16, 559-568. doi: 10.1002/ana.410160506
Ment, L. R., Stewart, W. B., Ardito, T. A., and Madri, J. A. (1991). Beagle pup germinal matrix maturation studies. Stroke 22, 390-395. doi: 10.1161/01.STR. 22.3.390

Mercuri, E., Ricci, D., Cowan, F. M., Lessing, D., Frisone, M. F., Haataja, L., et al. (2000). Head growth in infants with hypoxic-ischemic encephalopathy: correlation with neonatal magnetic resonance imaging. Pediatrics 106(2 Pt 1), 235-243. doi: 10.1542/peds.106.2.235

Miguel, P. M., Schuch, C. P., Rojas, J. J., Carletti, J. V., Deckmann, I., Martinato, L. H. M., et al. (2015). Neonatal hypoxia-ischemia induces attention-deficit hyperactivity disorder-like behavior in rats. Behav. Neurosci. 129, 309-320. doi: $10.1037 /$ bne0000063

Mikati, M. A., El Hokayem, J. A., and El Sabban, M. E. (2007). Effects of a single dose of erythropoietin on subsequent seizure susceptibility in rats exposed to acute hypoxia at P10. Epilepsia 48, 175-181. doi: 10.1111/j.1528-1167.2006. 00900.x

Mikati, M. A., Zeinieh, M. P., Kurdi, R. M., Harb, S. A., El Hokayem, J. A., Daderian, R. H., et al. (2005). Long-term effects of acute and of chronic hypoxia on behavior and on hippocampal histology in the developing brain. Dev. Brain Res. 157, 98-102. doi: 10.1016/j.devbrainres.2005.03.007

Mikhailenko, V. A., Butkevich, I. P., Bagaeva, T. R., Makukhina, G. V., and Otellin, V. A. (2009). Short- and long-term influences of hypoxia during early postnatal period of development on behavioral and hormonal responses in rats. Neurosci. Lett. 464, 214-217. doi: 10.1016/j.neulet.2009.08.047

Miller, S. L., Wallace, E. M., and Walker, D. W. (2012). Antioxidant therapies: a potential role in perinatal medicine. Neuroendocrinology 96, 13-23. doi: $10.1159 / 000336378$

Miller, S. P., Ramaswamy, V., Michelson, D., Barkovich, A. J., Holshouser, B., Wycliffe, N., et al. (2005). Patterns of brain injury in term neonatal encephalopathy. J. Pediatr. 146, 453-460. doi: 10.1016/j.jpeds.2004.12.026

Miller, S. P., Weiss, J., Barnwell, A., Ferriero, D. M., Latal-Hajnal, B., FerrerRogers, A., et al. (2002). Seizure-associated brain injury in term newborns with perinatal asphyxia. Neurology 58, 542-548. doi: 10.1212/WNL.58.4.542

Miranda, E., and Lomas, D. (2006). Neuroserpin: a serpin to think about. Cell. Mol. Life Sci. 63, 709-722. doi: 10.1007/s00018-005-5077-4

Mishra, O. P., and Delivoria-Papadopoulos, M. (1989). Lipid peroxidation in developing fetal guinea pig brain during normoxia and hypoxia. Brain Res. Dev. Brain Res. 45, 129-135. doi: 10.1016/0165-3806(89)90014-X

Mishra, O. P., and Delivoria-Papadopoulos, M. (1999). Cellular mechanisms of hypoxic injury in the developing brain. Brain Res. Bull. 48, 233-238. doi: 10.1016/S0361-9230(98)00170-1

Mitha, A., Foix-L'Helias, L., Arnaud, C., Marret, S., Vieux, R., Aujard, Y., et al. (2013). Neonatal infection and 5-year neurodevelopmental outcome of very preterm infants. Pediatrics 132, e372-80. doi: 10.1542/peds.2012-3979

Mohsenifar, A., Lotfi, A. S., Ranjbar, B., Allameh, A., Zaker, F., Hasani, L., et al. (2007). A study of the oxidation-induced conformational and functional changes in neuroserpin. Iran. Biomed. J. 11, 41-46.

Molnár, Z., Adams, R., and Blakemore, C. (1998). Mechanisms underlying the early establishment of thalamocortical connections in the rat. J. Neurosci. 18, 5723-5745.

Moorcraft, J., Bolas, N. M., Ives, N. K., Ouwerkerk, R., Smyth, J., Rajagopalan, B., et al. (1991). Global and depth resolved phosphorus magnetic resonance spectroscopy to predict outcome after birth asphyxia. Arch. Dis. Child 66, 1119-1123. doi: 10.1136/adc.66.10_Spec_No.1119

Mortola, J. P. (1999). How newborn mammals cope with hypoxia. Respir. Physiol. 116, 95-103. doi: 10.1016/S0034-5687(99)00038-9

Mortola, J. P., and Naso, L. (1998). Thermogenesis in newborn rats after prenatal or postnatal hypoxia. J. Appl. Physiol. 85, 84-90.

Munuswamy-Ramanujam, G., Dai, E., Liu, L., Shnabel, M., Sun, Y. M., Bartee, M., et al. (2010). Neuroserpin, a thrombolytic serine protease inhibitor (serpin), blocks transplant vasculopathy with associated modification of T-helper cell subsets. Thromb. Haemost. 103, 545-555. doi: 10.1160/TH09-070441

Muramatsu, K., Fukuda, A., Togari, H., Wada, Y., and Nishino, H. (1997). Vulnerability to cerebral hypoxic-ischemic insult in neonatal but not in adult rats is in parallel with disruption of the blood-brain barrier. Stroke 28, 2281-2288; discussion 2288-2289. doi: 10.1161/01.str.28.11.2281

Murray, D. M., Bala, P., O'Connor, C. M., Ryan, C. A., Connolly, S., and Boylan, G. B. (2010). The predictive value of early neurological examination in neonatal 
hypoxic-ischaemic encephalopathy and neurodevelopmental outcome at 24 months. Dev. Med. Child Neurol. 52, e55-e59. doi: 10.1111/j.1469-8749.2009. 03550.x

Murray, D. M., Boylan, G. B., Ryan, C. A., and Connolly, S. (2009). Early EEG findings in hypoxic-ischemic encephalopathy predict outcomes at 2 years. Pediatrics 124, e459-e467. doi: 10.1542/peds.2008-2190

Murray, D. M., O’Connor, C. M., Ryan, C. A., Korotchikova, I., and Boylan, G. B. (2016). Early EEG grade and outcome at 5 years after mild neonatal hypoxic ischemic encephalopathy. Pediatrics 138, e20160659. doi: 10.1542/peds.20160659

Myers, M. (1975). "Investigation of skin flap necrosis," in Skin Flaps, eds W. C. Grabb and M. B. Myers (Boston, MA: Little, Brown and Company), 3.

Nagel, S., Papadakis, M., Pfleger, K., Grond-Ginsbach, C., Buchan, A., and Wagner, S. (2012). Microarray analysis of the global gene expression profile following hypothermia and transient focal cerebral ischemia. Neuroscience 208, 109-122. doi: 10.1016/j.neuroscience.2012.01.048

Nakajima, W., Ishida, A., Lange, M. S., Gabrielson, K. L., Wilson, M. A., Martin, L. J., et al. (2000). Apoptosis has a prolonged role in the neurodegeneration after hypoxic ischemia in the newborn rat. J. Neurosci. 20, 7994-8004.

Nakajima, W., Ishida, A., and Takada, G. (1997). Magnesium attenuates a striatal dopamine increase induced by anoxia in the neonatal rat brain: an in vivo microdialysis study. Pediatr. Res. 41, 809-814. doi: 10.1203/00006450199706000-00003

Nalivaeva, N. N., Fisk, L., Aviles, R. M. C., Plesneva, S. A., Zhuravin, I. A., and Turner, A. J. (2003). Effects of prenatal hypoxia on expression of amyloid precursor protein and metallopeptidases in the rat brain. Lett. Peptide Sci. 10, 455-462. doi: 10.1007/BF02442577

Nash, K. B., Bonifacio, S. L., Glass, H. C., Sullivan, J. E., Barkovich, A. J., Ferriero, D. M., et al. (2011). Video-EEG monitoring in newborns with hypoxic-ischemic encephalopathy treated with hypothermia. Neurology 76, 556-562. doi: 10.1212/ WNL.0b013e31820af91a

Navarova, J., Schmidtova, M., Ujhazy, E., Dubovicky, M., and Mach, M. (2006). Selected biochemical variables in a model of neonatal anoxia in rats. Neuro Endocrinol. Lett. 27(Suppl. 2), 78-81.

Neil, J., Miller, J., Mukherjee, P., and Huppi, P. S. (2002). Diffusion tensor imaging of normal and injured developing human brain - a technical review. NMR Biomed. 15, 543-552. doi: 10.1002/nbm.784

Ness, J. K., Romanko, M. J., Rothstein, R. P., Wood, T. L., and Levison, S. W. (2001). Perinatal hypoxia-ischemia induces apoptotic and excitotoxic death of periventricular white matter oligodendrocyte progenitors. Dev. Neurosci. 23, 203-208. doi: 10.1159/000046144

Neufeld, M. D., Frigon, C., Graham, A. S., and Mueller, B. A. (2005). Maternal infection and risk of cerebral palsy in term and preterm infants. J. Perinatol. 25, 108-113. doi: 10.1038/sj.jp.7211219

Nguyen, V., and McQuillen, P. S. (2010). AMPA and metabotropic excitoxicity explain subplate neuron vulnerability. Neurobiol. Dis. 37, 195-207. doi: 10.1016/ j.nbd.2009.10.002

Nicole, O., Docagne, F., Ali, C., Margaill, I., Carmeliet, P., MacKenzie, E. T., et al. (2001). The proteolytic activity of tissue-plasminogen activator enhances NMDA receptor-mediated signaling. Nat. Med. 7, 59-64. doi: 10.1038/83358

Nijboer, C. H., Groenendaal, F., Kavelaars, A., Hagberg, H. H., van Bel, F., and Heijnen, C. J. (2007). Gender-specific neuroprotection by 2 -iminobiotin after hypoxia-ischemia in the neonatal rat via a nitric oxide independent pathway. J. Cereb. Blood Flow Metab. 27, 282-292. doi: 10.1038/sj.jcbfm.9600342

Nijboer, C. H., van der Kooij, M. A., van Bel, F., Ohl, F., Heijnen, C. J., and Kavelaars, A. (2010). Inhibition of the JNK/AP-1 pathway reduces neuronal death and improves behavioral outcome after neonatal hypoxic-ischemic brain injury. Brain Behav. Immun. 24, 812-821. doi: 10.1016/j.bbi.2009.09.008

Nikolov, N. M., and Cunningham, A. J. (2003). Mild therapeutic hypothermia to improve the neurologic outcome after cardiac arrest. Surv. Anesthesiol. 47, 219-220. doi: 10.1097/01.sa.0000087691.31092.12

Nobuta, H., Ghiani, C. A., Paez, P. M., Spreuer, V., Dong, H., Korsak, R. A., et al. (2012). STAT3-mediated astrogliosis protects myelin development in neonatal brain injury. Ann. Neurol. 72, 750-765. doi: 10.1002/ana.23670

Noh, M. R., Kim, S. K., Sun, W., Park, S. K., Choi, H. C., Lim, J. H., et al. (2006). Neuroprotective effect of topiramate on hypoxic ischemic brain injury in neonatal rats. Exp. Neurol. 201, 470-478. doi: 10.1016/j.expneurol.2006.04.038
Northington, F. J., Chavez-Valdez, R., and Martin, L. J. (2011). Neuronal cell death in neonatal hypoxia-ischemia. Ann. Neurol. 69, 743-758. doi: 10.1002/ ana.22419

Northington, F. J., Ferriero, D. M., Graham, E. M., Traystman, R. J., and Martin, L. J. (2001). Early neurodegeneration after hypoxia-ischemia in neonatal rat is necrosis while delayed neuronal death is apoptosis. Neurobiol. Dis. 8, 207-219. doi: $10.1006 /$ nbdi.2000.0371

Northington, F. J., Graham, E. M., and Martin, L. J. (2005). Apoptosis in perinatal hypoxic-ischemic brain injury: how important is it and should it be inhibited? Brain Res. Rev. 50, 244-257. doi: 10.1016/j.brainresrev.2005.07.003

Northington, F. J., Zelaya, M. E., O’Riordan, D. P., Blomgren, K., Flock, D. L., Hagberg, H., et al. (2007). Failure to complete apoptosis following neonatal hypoxia-ischemia manifests as "continuum" phenotype of cell death and occurs with multiple manifestations of mitochondrial dysfunction in rodent forebrain. Neuroscience 149, 822-833. doi: 10.1016/j.neuroscience.2007.06.060

Novikoff, A. B. (1976). The endoplasmic reticulum: a cytochemist's view (a review). Proc. Natl. Acad. Sci. U.S.A. 73, 2781-2787. doi: 10.1073/pnas.73.8.2781

O’Brien, J. S., and Sampson, E. L. (1965). Myelin Membrane: a molecular abnormality. Science 150, 1613-1614. doi: 10.1126/science.150.3703.1613

O'Connell, B., Moritz, K., Walker, D., and Dickinson, H. (2013). Treatment of pregnant spiny mice at mid gestation with a synthetic glucocorticoid has sex-dependent effects on placental glycogen stores. Placenta 34, 932-940. doi: 10.1016/j.placenta.2013.06.310

Oeschger, F. M., Wang, W. Z., Lee, S., Garcia-Moreno, F., Goffinet, A. M., Arbones, M. L., et al. (2012). Gene expression analysis of the embryonic subplate. Cereb. Cortex 22, 1343-1359. doi: 10.1093/cercor/bhr197

Oguni, H., Sugama, M., and Osawa, M. (2008). Symptomatic parieto-occipital epilepsy as sequela of perinatal asphyxia. Pediatr. Neurol. 38, 345-352. doi: 10.1016/j.pediatrneurol.2007.10.016

Okiyoneda, T., Harada, K., Takeya, M., Yamahira, K., Wada, I., Shuto, T., et al. (2004). Delta F508 CFTR pool in the endoplasmic reticulum is increased by calnexin overexpression. Mol. Biol. Cell 15, 563-574. doi: 10.1091/mbc.E03-060379

Okusa, C., Oeschger, F., Ginet, V., Wang, W. Z., Hoerder-Suabedissen, A., Matsuyama, T., et al. (2014). Subplate in a rat model of preterm hypoxiaischemia. Ann. Clin. Transl. Neurol. 1, 679-691. doi: 10.1002/acn3.97

Omouendze, P. L., Henry, V. J., Porte, B., Dupré, N., Carmeliet, P., Gonzalez, B. J., et al. (2013). Hypoxia-ischemia or excitotoxin-induced tissue plasminogen activator-dependent gelatinase activation in mice neonate brain microvessels. PLoS ONE 8:e71263. doi: 10.1371/journal.pone.0071263

Osterwalder, T., Cinelli, P., Baici, A., Pennella, A., Krueger, S. R., Schrimpf, S. P., et al. (1998). The axonally secreted serine proteinase inhibitor, neuroserpin, inhibits plasminogen activators and plasmin but not thrombin. J. Biol. Chem. 273, 2312-2321. doi: 10.1074/jbc.273.4.2312

Osterwalder, T., Contartese, J., Stoeckli, E. T., Kuhn, T. B., and Sonderegger, P. (1996). Neuroserpin, an axonally secreted serine protease inhibitor. EMBO J. $15,2944-2953$.

Otoya, R. E., Seltzer, A. M., and Donoso, A. O. (1997). Acute and long-lasting effects of neonatal hypoxia on ( )-3-[125 I] MK-801 binding to NMDA brain receptors. Exp. Neurol. 148, 92-99. doi: 10.1006/exnr.1997.6612

Ozer, E. A., Yilmaz, O., Akhisaroglu, M., Tuna, B., Bakiler, A. R., and Ozer, E. (2002). Heat shock protein 70 expression in neonatal rats after hypoxic stress. J. Matern Fetal Neonatal Med. 12, 112-117. doi: 10.1080/jmf.12.2.112.117

Palmer, C., Vannucci, R. C., and Towfighi, J. (1990). Reduction of perinatal hypoxic-ischemic brain damage with allopurinol. Pediatr. Res. 27(4 Pt 1), 332-336. doi: 10.1203/00006450-199004000-00003

Pang, Y., Rodts-Palenik, S., Cai, Z., Bennett, W. A., and Rhodes, P. G. (2005). Suppression of glial activation is involved in the protection of IL-10 on maternal E. coli induced neonatal white matter injury. Brain Res. Dev. Brain Res. 157, 141-149. doi: 10.1016/j.devbrainres.2005.03.015

Park, D., Shin, K., Choi, E., Choi, Y., Jang, J., Kim, J., et al. (2015). Protective effects of $\mathrm{N}$-acetyl-1-cysteine in human oligodendrocyte progenitor cells and restoration of motor function in neonatal rats with hypoxic-ischemic encephalopathy. Evid. Based Complement. Alternat. Med. 2015:764251. doi: 10.1155/2015/764251

Park, W. S., Sung, S. I., Ahn, S. Y., Yoo, H. S., Sung, D. K., Im, G. H., et al. (2015). Hypothermia augments neuroprotective activity of mesenchymal stem 
cells for neonatal hypoxic-ischemic encephalopathy. PLoS ONE 10:e0120893. doi: 10.1371/journal.pone. 0120893

Parolini, O., Alviano, F., Bergwerf, I., Boraschi, D., De Bari, C., De Waele, P., et al. (2010). Toward cell therapy using placenta-derived cells: disease mechanisms, cell biology, preclinical studies, and regulatory aspects at the round table. Stem Cells Dev. 19, 143-154. doi: 10.1089/scd.2009.0404

Partanen, E., Kujala, T., Naatanen, R., Liitola, A., Sambeth, A., and Huotilainen, M. (2013). Learning-induced neural plasticity of speech processing before birth. Proc. Natl. Acad. Sci. U.S.A. 110, 15145-15150. doi: 10.1073/pnas.1302159110

Pauliah, S. S., Shankaran, S., Wade, A., Cady, E. B., and Thayyil, S. (2013). Therapeutic hypothermia for neonatal encephalopathy in low- and middleincome countries: a systematic review and meta-analysis. PLOS ONE 8:e58834. doi: 10.1371/journal.pone.0058834

Paulose, C. S., Chathu, F., Khan, S. R., and Krishnakumar, A. (2008). Neuroprotective role of Bacopa monnieri extract in epilepsy and effect of glucose supplementation during hypoxia: glutamate receptor gene expression. Neurochem. Res. 33, 1663-1671. doi: 10.1007/s11064-007-9513-8

Pazaiti, A., Soubasi, V., Spandou, E., Karkavelas, G., Georgiou, T., Karalis, P., et al. (2009). Evaluation of long-lasting sensorimotor consequences following neonatal hypoxic-ischemic brain injury in rats: the neuroprotective role of MgSO4. Neonatology 95, 33-40. doi: 10.1159/000151753

Pazos, M., Cinquina, V., Gomez, A., Layunta, R., Santos, M., Fernández-Ruiz, J., et al. (2012). Cannabidiol administration after hypoxia-ischemia to newborn rats reduces long-term brain injury and restores neurobehavioral function. Neuropharmacology 63, 776-783. doi: 10.1016/j.neuropharm.2012.05.034

Pedraza, M., Hoerder-Suabedissen, A., Albert-Maestro, M. A., Molnár, Z., and De Carlos, J. A. (2014). Extracortical origin of some murine subplate cell populations. Proc. Natl. Acad. Sci. U.S.A. 111, 8613-8618. doi: 10.1073/pnas. 1323816111

Peebles, D. M., Miller, S., Newman, J. P., Scott, R., and Hanson, M. A. (2003). The effect of systemic administration of lipopolysaccharide on cerebral haemodynamics and oxygenation in the 0.65 gestation ovine fetus in utero. BJOG 110, 735-743. doi: 10.1111/j.1471-0528.2003.02152.x

Pelham, H. R. (1989). Heat shock and the sorting of luminal ER proteins. EMBO J. 8, 3171-3176.

Pellitteri, R., Catania, M. V., Bonaccorso, C. M., Ranno, E., Dell'Albani, P., and Zaccheo, D. (2014). Viability of olfactory ensheathing cells after hypoxia and serum deprivation: Implication for therapeutic transplantation. J. Neurosci. Res. 92, 1757-1766. doi: 10.1002/jnr.23442

Peng, Z., Li, J., Li, Y., Yang, X., Feng, S., Han, S., et al. (2013). Downregulation of miR-181b in mouse brain following ischemic stroke induces neuroprotection against ischemic injury through targeting heat shock protein A5 and ubiquitin carboxyl-terminal hydrolase isozyme L1. J. Neurosci. Res. 91, 1349-1362. doi: 10.1002/jnr.23255

Penrice, J., Lorek, A., Cady, E. B., Amess, P. N., Wylezinska, M., Cooper, C. E., et al. (1997). Proton magnetic resonance spectroscopy of the brain during acute hypoxia-ischemia and delayed cerebral energy failure in the newborn piglet. Pediatr. Res. 41, 795-802. doi: 10.1203/00006450-199706000-00001

Pereira, L. O., Arteni, N. S., Petersen, R. C., da Rocha, A. P., Achaval, M., and Netto, C. A. (2007). Effects of daily environmental enrichment on memory deficits and brain injury following neonatal hypoxia-ischemia in the rat. Neurobiol. Learn. Mem. 87, 101-108. doi: 10.1016/j.nlm.2006.07.003

Perera, P. N. D., Hu, Q., Tang, J., Li, L., Barnhart, M., Doycheva, D. M., et al. (2014). Delayed remote ischemic postconditioning improves long term sensory motor deficits in a neonatal hypoxic ischemic rat model. PLoS ONE 9:e90258. doi: 10.1371 /journal.pone. 0090258

Perlman, J. M. (1997). Intrapartum hypoxic-ischemic cerebral injury and subsequent cerebral palsy: medicolegal issues. Pediatrics 99, 851-859. doi: 10.1542 /peds.99.6.851

Perlman, J. M. (2006). Summary proceedings from the neurology group on hypoxic-ischemic encephalopathy. Pediatrics 117(Suppl. 1), S28-S33. doi: 10.1542/peds.2005-0620E

Perlman, J. M., and Risser, R. (1993). Severe fetal acidemia: neonatal neurologic features and short-term outcome. Pediatr. Neurol. 9, 277-282. doi: 10.1016/ 0887-8994(93)90063-I

Perrin, R. G., Rutka, J. T., Drake, J. M., Meltzer, H., Hellman, J., Jay, V., et al. (1997). Management and outcomes of posterior fossa subdural hematomas in neonates. Neurosurgery 40, 1190-1199; discussion 1199-1200. doi: 10.1097/ 00006123-199706000-00016

Petersson, K. H., Pinar, H., Stopa, E. G., Faris, R. A., Sadowska, G. B., Hanumara, R. C., et al. (2002). White matter injury after cerebral ischemia in ovine fetuses. Pediatr. Res. 51, 768-776. doi: 10.1203/00006450-200206000-00019

Pfeffer, S. R., and Rothman, J. E. (1987). Biosynthetic protein transport and sorting by the endoplasmic reticulum and Golgi. Annu. Rev. Biochem. 56, 829-852. doi: 10.1146/annurev.bi.56.070187.004145

Placencia, F. X., Kong, L., and Weisman, L. E. (2009). Treatment of methicillin-resistant Staphylococcus aureus in neonatal mice: lysostaphin versus vancomycin. Pediatr. Res. 65, 420-424. doi: 10.1203/PDR.0b013e3181994a53

Poggi, S. H., Park, J., Toso, L., Abebe, D., Roberson, R., Woodard, J. E., et al. (2005). No phenotype associated with established lipopolysaccharide model for cerebral palsy. Am. J. Obstet. Gynecol. 192, 727-733. doi: 10.1016/j.ajog.2004.12.053

Pogledic, I., Kostovic, I., Fallet-Bianco, C., Adle-Biassette, H., Gressens, P., and Verney, C. (2014). Involvement of the subplate zone in preterm infants with periventricular white matter injury. Brain Pathol. 24, 128-141. doi: 10.1111/bpa. 12096

Portera-Cailliau, C., Price, D. L., and Martin, L. J. (1997a). Excitotoxic neuronal death in the immature brain is an apoptosis-necrosis morphological continuum. J. Comp. Neurol. 378, 70-87. doi: 10.1002/(sici)10969861(19970203)378:1<10::aid-cne4>3.0.co;2-n

Portera-Cailliau, C., Price, D. L., and Martin, L. J. (1997b). Non-NMDA and NMDA receptor-mediated excitotoxic neuronal deaths in adult brain are morphologically distinct: further evidence for an apoptosis-necrosis continuum. J. Comp. Neurol. 378, 88-104.

Pourie, G., Blaise, S., Trabalon, M., Nedelec, E., Gueant, J. L., and Daval, J. L. (2006). Mild, non-lesioning transient hypoxia in the newborn rat induces delayed brain neurogenesis associated with improved memory scores. Neuroscience 140 , 1369-1379. doi: 10.1016/j.neuroscience.2006.02.083

Price, D. J., Aslam, S., Tasker, L., and Gillies, K. (1997). Fates of the earliest generated cells in the developing murine neocortex. J. Comp. Neurol. 377, 414-422. doi: 10.1002/(SICI)1096-9861(19970120)377:3<414::AID-CNE8>3.0. $\mathrm{CO} ; 2-5$

Pryds, O., Greisen, G., Lou, H., and Friis-Hansen, B. (1990). Vasoparalysis associated with brain damage in asphyxiated term infants. J. Pediatr. 117(1 Pt 1), 119-125. doi: 10.1016/s0022-3476(05)72459-8

Pu, Y., Garg, A., Corby, R., Gao, J. H., Zeng, C. M., Pu, Y., et al. (2008). A positive correlation between alpha-glutamate and glutamine on brain $1 \mathrm{H}-\mathrm{MR}$ spectroscopy and neonatal seizures in moderate and severe hypoxic-ischemic encephalopathy. AJNR Am. J. Neuroradiol. 29, 216. doi: 10.3174/ajnr.A0798

Pulera, M. R., Adams, L. M., Liu, H., Santos, D. G., Nishimura, R. N., Yang, F., et al. (1998). Apoptosis in a neonatal rat model of cerebral hypoxia-ischemia. Stroke 29, 2622-2630. doi: 10.1161/01.STR.29.12.2622

Puyal, J., Vaslin, A., Mottier, V., and Clarke, P. G. (2009). Postischemic treatment of neonatal cerebral ischemia should target autophagy. Ann. Neurol. 66, 378-389. doi: 10.1002/ana.21714

Qian, Z., Gilbert, M. E., Colicos, M. A., Kandel, E. R., and Kuhl, D. (1993). Tissue-plasminogen activator is induced as an immediate-early gene during seizure, kindling and long-term potentiation. Nature 361, 453-457. doi: 10.1038/361453a0

Rabi, Y., Rabi, D., and Yee, W. (2007). Room air resuscitation of the depressed newborn: a systematic review and meta-analysis. Resuscitation 72, 353-363. doi: 10.1016/j.resuscitation.2006.06.134

Rakhade, S. N., and Jensen, F. E. (2009). Epileptogenesis in the immature brain: emerging mechanisms. Nat. Rev. Neurol. 5, 380-391. doi: 10.1038/nrneurol. 2009.80

Rakhade, S. N., Klein, P. M., Huynh, T., Hilario-Gomez, C., Kosaras, B., Rotenberg, A., et al. (2011). Development of later life spontaneous seizures in a rodent model of hypoxia-induced neonatal seizures. Epilepsia 52, 753-765. doi: 10.1111/j.1528-1167.2011.02992.x

Rastogi, R. N., Prichard, J. S., and Lowden, J. A. (1968). Elevation of phosphorus levels in serum and decreased rain content of gangliosides in rats following neonatal asphyxia. Pediatr. Res. 2, 125-130. doi: 10.1203/00006450-19680300000008

Raveendran, A. T., and Skaria, P. C. (2013). Learning and cognitive deficits in hypoxic neonatal rats intensified by BAX mediated apoptosis: protective role 
of glucose, oxygen, and epinephrine. Int. J. Neurosci. 123, 80-88. doi: 10.3109/ 00207454.2012.731457

Reddy, K., Mallard, C., Guan, J., Marks, K., Bennet, L., Gunning, M., et al. (1998). Maturational change in the cortical response to hypoperfusion injury in the fetal sheep. Pediatr. Res. 43, 674-682. doi: 10.1203/00006450-199805000-00017

Redline, R. W., and O'Riordan, M. A. (2000). Placental lesions associated with cerebral palsy and neurologic impairment following term birth. Arch. Pathol. Lab. Med. 124, 1785-1791.

Rennie, J. M., Chorley, G., Boylan, G. B., Pressler, R., Nguyen, Y., and Hooper, R. (2004). Non-expert use of the cerebral function monitor for neonatal seizure detection. Arch. Dis. Child. Fetal Neonatal Ed. 89, F37-F40. doi: 10.1136/fn.89. 1.f37

Represa, A., Tremblay, E., and Ben-Ari, Y. (1989). Transient increase of NMDAbinding sites in human hippocampus during development. Neurosci. Lett. 99, 61-66. doi: 10.1016/0304-3940(89)90265-6

Ricagno, S., Caccia, S., Sorrentino, G., Antonini, G., and Bolognesi, M. (2009). Human neuroserpin: structure and time-dependent inhibition. J. Mol. Biol. 388, 109-121. doi: 10.1016/j.jmb.2009.02.056

Ricagno, S., Pezzullo, M., Barbiroli, A., Manno, M., Levantino, M., Santangelo, M. G., et al. (2010). Two latent and two hyperstable polymeric forms of human neuroserpin. Biophys. J. 99, 3402-3411. doi: 10.1016/j.bpj.2010. 09.021

Rice, J. E., Vannucci, R. C., and Brierley, J. B. (1981). The influence of immaturity on hypoxic-ischemic brain damage in the rat. Ann. Neurol. 9, 131-141. doi: 10.1002/ana.410090206

Richardson, B., Korkola, S., Asano, H., Challis, J., Polk, D., and Fraser, M. (1996). Regional blood flow and the endocrine response to sustained hypoxemia in the preterm ovine fetus. Pediatr. Res. 40, 337-343. doi: 10.1203/00006450199608000-00024

Richardson, B. S., and Bocking, A. D. (1998). Metabolic and circulatory adaptations to chronic hypoxia in the fetus. Comp. Biochem. Physiol. A Mol. Integr. Physiol. 119, 717-723. doi: 10.1016/S1095-6433(98)01010-1

Richardson, B. S., Carmichael, L., Homan, J., Johnston, L., and Gagnon, R. (1996). Fetal cerebral, circulatory, and metabolic responses during heart rate decelerations with umbilical cord compression. Am. J. Obstet. Gynecol. 175(4 Pt 1), 929-936. doi: 10.1016/S0002-9378(96)80027-5

Richer, L. P., Shevell, M. I., and Miller, S. P. (2001). Diagnostic profile of neonatal hypotonia: an 11-year study. Pediatr. Neurol. 25, 32-37. doi: 10.1016/S08878994(01)00277-6

Richetto, J., Calabrese, F., Meyer, U., and Riva, M. A. (2013). Prenatal versus postnatal maternal factors in the development of infection-induced working memory impairments in mice. Brain Behav. Immun. 33, 190-200. doi: 10.1016/ j.bbi.2013.07.006

Riikonen, R. S., Kero, P. O., and Simell, O. G. (1992). Excitatory amino acids in cerebrospinal fluid in neonatal asphysia. Pediatr. Neurol. 8, 37-40. doi: 10.1016/ 0887-8994(92)90050-9

Rijken, D., Wijngaards, G., and Welbergen, J. (1980). Relationship between tissue plasminogen activator and the activators in blood and vascular wall. Thromb. Res. 18, 815-830. doi: 10.1016/0049-3848(80)90204-2

Rijken, D., Wijngaards, G., Zaal-de Jong, M., and Welbergen, J. (1979). Purification and partial characterization of plasminogen activator from human uterine tissue. Biochim. Biophys. Acta 580, 140-153. doi: 10.1016/0005-2795(79) 90205-8

Robertson, C., and Finer, N. (1985). Term infants with hypoxic-ischemic encephalopathy: outcome at 3.5 years. Dev. Med. Child Neurol. 27, 473-484. doi: 10.1111/j.1469-8749.1985.tb04571.x

Robertson, C., Finer, N., and Grace, M. (1989). School performance of survivors of neonatal encephalopathy associated with birth asphyxia at term. J. Pediatr. 114, 753-760. doi: 10.1016/S0022-3476(89)80132-5

Robertson, J. D., Enoksson, M., Suomela, M., Zhivotovsky, B., and Orrenius, S. (2002). Caspase-2 acts upstream of mitochondria to promote cytochrome c release during etoposide-induced apoptosis. J. Biol. Chem. 277, 29803-29809. doi: 10.1074/jbc.M204185200

Robertson, N. J., Cowan, F. M., Cox, I. J., and Edwards, A. D. (2002). Brain alkaline intracellular pH after neonatal encephalopathy. Ann. Neurol. 52, 732-742. doi: 10.1002/ana.10365

Robertson, N. J., Cox, I. J., Cowan, F. M., Counsell, S. J., Azzopardi, D., and Edwards, A. D. (1999). Cerebral intracellular lactic alkalosis persisting months after neonatal encephalopathy measured by magnetic resonance spectroscopy. Pediatr. Res. 46, 287-296. doi: 10.1203/00006450-19990900000007

Robertson, N. J., and Iwata, O. (2007). Bench to bedside strategies for optimizing neuroprotection following perinatal hypoxia-ischaemia in high and low resource settings. Early Hum. Dev. 83, 801-811. doi: 10.1016/j.earlhumdev. 2007.09.015

Robinson, S., Li, Q., Dechant, A., and Cohen, M. L. (2006). Neonatal loss of gamma-aminobutyric acid pathway expression after human perinatal brain injury. J. Neurosurg. 104 6(Suppl.), 396-408.

Rocha-Ferreira, E., and Hristova, M. (2015). Antimicrobial peptides and complement in neonatal hypoxia-ischemia induced brain damage. Front. Immunol. 6:56. doi: 10.3389/fimmu.2015.00056

Rodewald, A. K., Onderdonk, A. B., Warren, H. B., and Kasper, D. L. (1992). Neonatal mouse model of group B streptococcal infection. J. Infect. Dis. 166, 635-639. doi: 10.1093/infdis/166.3.635

Rodriguez-Alvarez, N., Jimenez-Mateos, E. M., Dunleavy, M., Waddington, J. L., Boylan, G. B., and Henshall, D. C. (2015). Effects of hypoxia-induced neonatal seizures on acute hippocampal injury and later-life seizure susceptibility and anxiety-related behavior in mice. Neurobiol. Dis. 83, 100-114. doi: 10.1016/j. nbd.2015.08.023

Rodríguez-González, R., Agulla, J., Pérez-Mato, M., Sobrino, T., and Castillo, J. (2011a). Neuroprotective effect of neuroserpin in rat primary cortical cultures after oxygen and glucose deprivation and tPA. Neurochem. Int. 58, 337-343. doi: 10.1016/j.neuint.2010.12.006

Rodríguez-González, R., Millán, M., Sobrino, T., Miranda, E., Brea, D., de la Ossa, N. P., et al. (2011b). The natural tissue plasminogen activator inhibitor neuroserpin and acute ischaemic stroke outcome. Thromb. Haemost. 105, 421-429. doi: 10.1160/TH10-09-0621

Rodríguez-González, R., Sobrino, T., Rodríguez-Yáñez, M., Millán, M., Brea, D., Miranda, E., et al. (2011c). Association between neuroserpin and molecular markers of brain damage in patients with acute ischemic stroke. J. Transl. Med. 9:58. doi: 10.1186/1479-5876-9-58

Rodts-Palenik, S., Wyatt-Ashmead, J., Pang, Y., Thigpen, B., Cai, Z., Rhodes, P., et al. (2004). Maternal infection-induced white matter injury is reduced by treatment with interleukin-10. Am. J. Obstet. Gynecol. 191, 1387-1392. doi: 10.1016/j.ajog.2004.06.093

Rogalska, J., and Caputa, M. (2010). Neonatal asphyxia under hyperthermic conditions alters HPA axis function in juvenile rats. Neurosci. Lett. 472, 68-72. doi: 10.1016/j.neulet.2010.01.060

Rogalska, J., Caputa, M., Wentowska, K., and Nowakowska, A. (2004). Stressinduced behaviour in juvenile rats: effects of neonatal asphyxia, body temperature and chelation of iron. Behav. Brain Res. 154, 321-329. doi: 10.1016/ j.bbr.2004.02.020

Rogalska, J., Danielisova, V., and Caputa, M. (2006). Effect of neonatal body temperature on postanoxic, potentially neurotoxic iron accumulation in the rat brain. Neurosci. Lett. 393, 249-254. doi: 10.1016/j.neulet.2005.09.085

Rogalska, J., Kang, P., Wotherspoon, W., Macleod, M. R., and Lai, M. (2009). Effect of hyperthermia and anoxia on glucocorticoid and mineralocorticoid receptor expression in neonatal rat hippocampus. Neurosci. Lett. 450, 196-200. doi: 10.1016/j.neulet.2008.11.033

Rognlien, A. G. W., Wollen, E. J., Atneosen-Åsegg, M., and Saugstad, O. D. (2014). Increased expression of inflammatory genes in the neonatal mouse brain after hyperoxic reoxygenation. Pediatr. Res. 77, 326-333. doi: 10.1038/pr. 2014.193

Roohey, T., Raju, T. N., and Moustogiannis, A. N. (1997). Animal models for the study of perinatal hypoxic-ischemic encephalopathy: a critical analysis. Early Hum. Dev. 47, 115-146. doi: 10.1016/S0378-3782(96)01773-2

Rorke, L. B. (1992). Anatomical features of the developing brain implicated in pathogenesis of hypoxic-ischemic injury. Brain Pathol. 2, 211-221. doi: 10.1111/ j.1750-3639.1992.tb00694.x

Roth, S. C., Edwards, A. D., Cady, E. B., Delpy, D. T., Wyatt, J. S., Azzopardi, D., et al. (1992). Relation between cerebral oxidative metabolism following birth asphyxia, and neurodevelopmental outcome and brain growth at one year. Dev. Med. Child Neurol. 34, 285-295. doi: 10.1111/j.1469-8749.1992. tb11432.x

Rotstein, M., Bassan, H., Kariv, N., Speiser, Z., Harel, S., and Gozes, I. (2006). $\mathrm{NAP}$ enhances neurodevelopment of newborn apolipoprotein E-deficient mice 
subjected to hypoxia. J. Pharmacol. Exp. Ther. 319, 332-339. doi: 10.1124/jpet. 106.106898

Rousset, C. I., Chalon, S., Cantagrel, S., Bodard, S., Andres, C., Gressens, P., et al. (2006). Maternal exposure to LPS induces hypomyelination in the internal capsule and programmed cell death in the deep gray matter in newborn rats. Pediatr. Res. 59, 428-433. doi: 10.1203/01.pdr.0000199905.08848.55

Rousset, C. I., Kassem, J., Aubert, A., Planchenault, D., Gressens, P., Chalon, S., et al. (2013). Maternal exposure to lipopolysaccharide leads to transient motor dysfunction in neonatal rats. Dev. Neurosci. 35, 172-181. doi: 10.1159/ 000346579

Ruiz, C. C. U., Rosado-de-Castro, P. H., Mendez-Otero, R., and Pimentel-Coelho, P. M. (2017). "Mesenchymal stromal cell therapy for neonatal hypoxic-ischemic encephalopathy," in Neurological Regeneration, ed. P. Van Pham (Berlin: Springer), 105-120.

Ruiz, S., Diep, D., Gore, A., Panopoulos, A. D., Montserrat, N., Plongthongkum, N., et al. (2012). Identification of a specific reprogramming-associated epigenetic signature in human induced pluripotent stem cells. Proc. Natl. Acad. Sci. U.S.A. 109, 16196-16201. doi: 10.1073/pnas.1202352109

Ruth, V. J., and Raivio, K. O. (1988). Perinatal brain damage: predictive value of metabolic acidosis and the Apgar score. BMJ 297, 24-27. doi: 10.1136/bmj.297. 6640.24

Rutherford, M., Counsell, S., Allsop, J., Boardman, J., Kapellou, O., Larkman, D., et al. (2004). Diffusion-weighted magnetic resonance imaging in term perinatal brain injury: a comparison with site of lesion and time from birth. Pediatrics 114, 1004-1014. doi: 10.1542/peds.2004-0222

Rutherford, M. A., Pennock, J. M., Counsell, S. J., Mercuri, E., Cowan, F. M., Dubowitz, L. M., et al. (1998). Abnormal magnetic resonance signal in the internal capsule predicts poor neurodevelopmental outcome in infants with hypoxic-ischemic encephalopathy. Pediatrics $102(2$ Pt 1), 323-328. doi: $10.1542 /$ peds.102.2.323

Saadani-Makki, F., Kannan, S., Lu, X., Janisse, J., Dawe, E., Edwin, S., et al. (2008). Intrauterine administration of endotoxin leads to motor deficits in a rabbit model: a link between prenatal infection and cerebral palsy. Am. J. Obstet. Gynecol. 199, 651.e1-651.e7. doi: 10.1016/j.ajog.2008.06.090

Sabir, H., Osredkar, D., Maes, E., Wood, T., and Thoresen, M. (2016). Xenon combined with therapeutic hypothermia is not neuroprotective after severe hypoxia-ischemia in neonatal rats. PLOS ONE 11:e0156759. doi: 10.1371/ journal.pone.0156759

Sakurada, O., Kennedy, C., Jehle, J., Brown, J. D., Carbin, G. L., and Sokoloff, L. (1978). Measurement of local cerebral blood flow with iodo [14C] antipyrine. Am. J. Physiol. 234, H59-H66.

Salhab, W. A., Perlman, J. M., Silver, L., and Broyles, R. S. (2004a). Necrotizing enterocolitis and neurodevelopmental outcome in extremely low birth weight infants $<1000$ g. J. Perinatol. 24, 534-540.

Salhab, W. A., Wyckoff, M. H., Laptook, A. R., and Perlman, J. M. (2004b). Initial hypoglycemia and neonatal brain injury in term infants with severe fetal acidemia. Pediatrics 114, 361-366.

Samaiya, P. K., and Krishnamurthy, S. (2015). Characterization of mitochondrial bioenergetics in neonatal anoxic model of rats. J. Bioenerg. Biomembr. 47, 217-222. doi: 10.1007/s10863-015-9603-2

Sampath, D., Shmueli, D., White, A. M., and Raol, Y. H. (2015). Flupirtine effectively prevents development of acute neonatal seizures in an animal model of global hypoxia. Neurosci. Lett. 607, 46-51. doi: 10.1016/j.neulet.2015. 09.005

Sanches, E., Arteni, N., Nicola, F., Boisserand, L., Willborn, S., and Netto, C. (2013). Early hypoxia-ischemia causes hemisphere and sex-dependent cognitive impairment and histological damage. Neuroscience 237, 208-215. doi: 10.1016/ j.neuroscience.2013.01.066

Sanches, E. F., Arteni, N. S., Spindler, C., Moysés, F., Siqueira, I. R., Perry, M. L., et al. (2012). Effects of pre-and postnatal protein malnutrition in hypoxic-ischemic rats. Brain Res. 1438, 85-92. doi: 10.1016/j.brainres.2011. 12.024

Santiago, A. R., Baptista, F. I., Santos, P. F., Cristovao, G., Ambrosio, A. F., Cunha, R. A., et al. (2014). Role of microglia adenosine $\mathrm{A}(2 \mathrm{~A})$ receptors in retinal and brain neurodegenerative diseases. Mediators Inflamm. 2014:465694. doi: $10.1155 / 2014 / 465694$

Sato, Y., Hayakawa, M., Iwata, O., Okumura, A., Kato, T., Hayakawa, F., et al. (2008). Delayed neurological signs following isolated parasagittal injury in asphyxia at term. Eur. J. Paediatr. Neurol. Soc. 12, 359-365. doi: 10.1016/j.ejpn. 2007.10.003

Saunders, N. R., Dreifuss, J. J., Dziegielewska, K. M., Johansson, P. A., Habgood, M. D., Mollgard, K., et al. (2014). The rights and wrongs of blood-brain barrier permeability studies: a walk through 100 years of history. Front. Neurosci. 8:404. doi: $10.3389 /$ fnins.2014.00404

Saunders, N. R., Habgood, M. D., and Dziegielewska, K. M. (1999). Barrier mechanisms in the brain, II. Immature brain. Clin. Exp. Pharmacol. Physiol. 26, 85-91. doi: 10.1046/j.1440-1681.1999.02987.x

Saunders, N. R., Liddelow, S. A., and Dziegielewska, K. M. (2012). Barrier mechanisms in the developing brain. Front. Pharmacol. 3:46. doi: 10.3389/ fphar.2012.00046

Savman, K., Blennow, M., Gustafson, K., Tarkowski, E., and Hagberg, H. (1998). Cytokine response in cerebrospinal fluid after birth asphyxia. Pediatr. Res. 43, 746-751. doi: 10.1203/00006450-199806000-00006

Schanne, F. A., Kane, A. B., Young, E. E., and Farber, J. L. (1979). Calcium dependence of toxic cell death: a final common pathway. Science 206, 700-702. doi: 10.1126/science. 386513

Scheepens, A., Wassink, G., Piersma, M. J., Van de Berg, W. D., and Blanco, C. E. (2003). A delayed increase in hippocampal proliferation following global asphyxia in the neonatal rat. Brain Res. Dev. Brain Res. 142, 67-76. doi: 10.1016/ S0165-3806(03)00032-4

Schrimpf, S. P., Bleiker, A. J., Brecevic, L., Kozlov, S. V., Berger, P., Osterwalder, T., et al. (1997). Human neuroserpin (PI12): cDNA cloning and chromosomal localization to 3q26. Genomics 40, 55-62. doi: 10.1006/geno.1996.4514

Schroder, M., and Kaufman, R. J. (2005). ER stress and the unfolded protein response. Mutat. Res. 569, 29-63. doi: 10.1016/j.mrfmmm.2004.06.056

Schulze, C., and Firth, J. A. (1992). Interendothelial junctions during blood-brain barrier development in the rat: morphological changes at the level of individual tight junctional contacts. Brain Res. Dev. Brain Res. 69, 85-95. doi: 10.1016/ 0165-3806(92)90125-G

Seidler, F. J., and Slotkin, T. A. (1990). Effects of acute hypoxia on neonatal rat brain: regionally selective, long-term alterations in catecholamine levels and turnover. Brain Res. Bull. 24, 157-161. doi: 10.1016/0361-9230(90)90200-J

Semple, B. D., Blomgren, K., Gimlin, K., Ferriero, D. M., and Noble-Haeusslein, L. J. (2013). Brain development in rodents and humans: identifying benchmarks of maturation and vulnerability to injury across species. Progress Neurobiol. 106, 1-16. doi: 10.1016/j.pneurobio.2013.04.001

Shah, D. K., Lavery, S., Doyle, L. W., Wong, C., McDougall, P., and Inder, T. E. (2006). Use of 2-channel bedside electroencephalogram monitoring in term-born encephalopathic infants related to cerebral injury defined by magnetic resonance imaging. Pediatrics 118, 47-55. doi: 10.1542/peds.20051294

Shah, P. S. (2010). Hypothermia: a systematic review and meta-analysis of clinical trials. Semin. Fetal Neonatal Med. 15, 238-246. doi: 10.1016/j.siny.2010.02.003

Shah, P. S., Beyene, J., To, T., Ohlsson, A., and Perlman, M. (2006). Postasphyxial hypoxic-ischemic encephalopathy in neonates: outcome prediction rule within 4 hours of birth. Arch. Pediatr. Adolesc. Med. 160, 729-736. doi: 10.1001/ archpedi.160.7.729

Shah, P. S., Ohlsson, A., and Perlman, M. (2007). Hypothermia to treat neonatal hypoxic ischemic encephalopathy: systematic review. Arch. Pediatr. Adolesc. Med. 161, 951-958. doi: 10.1001/archpedi.161.10.951

Shalak, L., and Perlman, J. M. (2004). Hypoxic-ischemic brain injury in the term infant-current concepts. Early Hum. Dev. 80, 125-141. doi: 10.1016/j. earlhumdev.2004.06.003

Shankaran, S., Laptook, A., Wright, L. L., Ehrenkranz, R. A., Donovan, E. F., Fanaroff, A. A., et al. (2002). Whole-body hypothermia for neonatal encephalopathy: animal observations as a basis for a randomized, controlled pilot study in term infants. Pediatrics 110, 377-385. doi: 10.1542/peds.110.2.377

Shankaran, S., Laptook, A. R., Ehrenkranz, R. A., Tyson, J. E., McDonald, S. A., Donovan, E. F., et al. (2005). Whole-body hypothermia for neonates with hypoxic-ischemic encephalopathy. N. Engl. J. Med. 353, 1574-1584. doi: 10.1056/NEJMcps050929

Shankaran, S., Pappas, A., McDonald, S. A., Vohr, B. R., Hintz, S. R., Yolton, K., et al. (2012). Childhood outcomes after hypothermia for neonatal encephalopathy. N. Engl. J. Med. 366, 2085-2092. doi: 10.1056/NEJMoa1112066

Shankaran, S., Woldt, E., Koepke, T., Bedard, M. P., and Nandyal, R. (1991). Acute neonatal morbidity and long-term central nervous system sequelae of perinatal 
asphyxia in term infants. Early Hum. Dev. 25, 135-148. doi: 10.1016/03783782(91)90191-5

Sharma, R. (2014). Prevention of Frey syndrome with superficial temporal fascia interpositioning: a retrospective study. Int. J. Oral Maxillofac. Surg. 43, 413-417. doi: 10.1016/j.ijom.2013.12.001

Sheldon, R. A., Sedik, C., and Ferriero, D. M. (1998). Strain-related brain injury in neonatal mice subjected to hypoxia-ischemia. Brain Res. 810, 114-122. doi: 10.1016/S0006-8993(98)00892-0

Shellhaas, R. A., Soaita, A. I., and Clancy, R. R. (2007). Sensitivity of amplitudeintegrated electroencephalography for neonatal seizure detection. Pediatrics 120, 770-777. doi: 10.1542/peds.2007-0514

Shi, L., Smith, S. E., Malkova, N., Tse, D., Su, Y., and Patterson, P. H. (2009). Activation of the maternal immune system alters cerebellar development in the offspring. Brain Behav. Immun. 23, 116-123. doi: 10.1016/j.bbi.2008.07.012

Shimomura, C., and Ohta, H. (1988). Behavioral abnormalities and seizure susceptibility in rat after neonatal anoxia. Brain Dev. 10, 160-163. doi: 10.1016/ S0387-7604(88)80020-2

Sidhu, R. S., Tuor, U. I., and Del Bigio, M. R. (1997). Nuclear condensation and fragmentation following cerebral hypoxia-ischemia occurs more frequently in immature than older rats. Neurosci. Lett. 223, 129-132. doi: 10.1016/S03043940(97)13426-7

Simpson, E. A., Murray, L., Paukner, A., and Ferrari, P. F. (2014). The mirror neuron system as revealed through neonatal imitation: presence from birth, predictive power and evidence of plasticity. Philos. Trans. R. Soc. Lond. B Biol. Sci. 369:20130289. doi: 10.1098/rstb.2013.0289

Sinclair, D. B., Campbell, M., Byrne, P., Prasertsom, W., and Robertson, C. M. (1999). EEG and long-term outcome of term infants with neonatal hypoxicischemic encephalopathy. Clin. Neurophysiol. 110, 655-659. doi: 10.1016/ S1388-2457(99)00010-3

Singh, D., Kumar, P., Majumdar, S., and Narang, A. (2004). Effect of phenobarbital on free radicals in neonates with hypoxic ischemic encephalopathy-a randomized controlled trial. J. Perinat. Med. 32, 278-281. doi: 10.1515/JPM. 2004.052

Slotkin, T., Lappi, S., McCook, E., Lorber, B., and Seidler, F. (1995). Loss of neonatal hypoxia tolerance after prenatal nicotine exposure: implications for sudden infant death syndrome. Brain Res. Bull. 38, 69-75. doi: 10.1016/0361-9230(95) 00073-N

Slotkin, T. A., Cowdery, T. S., Orband, L., Pachman, S., and Whitmore, W. L. (1986). Effects of neonatal hypoxia on brain development in the rat: immediate and long-term biochemical alterations in discrete regions. Brain Res. 374, 63-74. doi: 10.1016/0006-8993(86)90395-1

Smith, P. L., Hagberg, H., Naylor, A. S., and Mallard, C. (2014). Neonatal peripheral immune challenge activates microglia and inhibits neurogenesis in the developing murine hippocampus. Dev. Neurosci. 36, 119-131. doi: 10.1159/ 000359950

Soares, D. P., and Law, M. (2009). Magnetic resonance spectroscopy of the brain: review of metabolites and clinical applications. Clin. Radiol. 64, 12-21. doi: 10.1016/j.crad.2008.07.002

Sokoloff, L., Reivich, M., Kennedy, C., Des Rosiers, M., Patlak, C. S., Pettigrew, K. E. A., et al. (1977). The [14C] deoxyglucose method for the measurement of local cerebral glucose utilization: theory, procedure, and normal values in the conscious and anesthetized albino rat1. J. Neurochem. 28, 897-916. doi: 10.1111/j.1471-4159.1977.tb10649.x

Soul, J. S., Robertson, R. L., Tzika, A. A., du Plessis, A. J., and Volpe, J. J. (2001). Time course of changes in diffusion-weighted magnetic resonance imaging in a case of neonatal encephalopathy with defined onset and duration of hypoxicischemic insult. Pediatrics 108, 1211-1214. doi: 10.1542/peds.108.5.1211

Speiser, Z., Katzir, O., Rehavi, M., Zabarski, T., and Cohen, S. (1998). Sparing by rasagiline (TVP-1012) of cholinergic functions and behavior in the postnatal anoxia rat. Pharmacol. Biochem. Behav. 60, 387-393. doi: 10.1016/S00913057(97)00603-5

Speiser, Z., Uziel, J., Defrin-Assa, R., Gitter, S., and Urca, G. (1991). Different behavioral deficits are induced by anoxia/hypoxia in neonatal and senescent rats: blockade by MK-801. Behav. Brain Res. 42, 181-186. doi: 10.1016/S01664328(05)80009-9

Spraggins, Y., Seidler, F. J., and Slotkin, T. A. (1994). Cocaine exacerbates hypoxia-lnduced cell damage in the developing brain: effects on ornithine decarboxylase activity and protein synthesis. Neonatology 66, 254-266. doi: $10.1159 / 000244115$

Srinivasakumar, P., Zempel, J., Wallendorf, M., Lawrence, R., Inder, T., and Mathur, A. (2013). Therapeutic hypothermia in neonatal hypoxic ischemic encephalopathy: electrographic seizures and magnetic resonance imaging evidence of injury. J. Pediatr. 163, 465-470. doi: 10.1016/j.jpeds.2013. 01.041

Staley, K. J., Soldo, B. L., and Proctor, W. R. (1995). Ionic mechanisms of neuronal excitation by inhibitory GABAA receptors. Science 269, 977-981. doi: 10.1126/ science.7638623

Starkov, A. A., Chinopoulos, C., and Fiskum, G. (2004). Mitochondrial calcium and oxidative stress as mediators of ischemic brain injury. Cell Calcium 36, 257-264. doi: 10.1016/j.ceca.2004.02.012

Steinman, K. J., Gorno-Tempini, M. L., Glidden, D. V., Kramer, J. H., Miller, S. P., Barkovich, A. J., et al. (2009). Neonatal watershed brain injury on magnetic resonance imaging correlates with verbal IQ at 4 years. Pediatrics 123, 1025-1030. doi: 10.1542/peds.2008-1203

Stewart, P. A., and Hayakawa, K. (1994). Early ultrastructural changes in bloodbrain barrier vessels of the rat embryo. Brain Res. Dev. Brain Res. 78, 25-34. doi: 10.1016/0165-3806(94)90005-1

Stiller, R., von Mering, R., Konig, V., Huch, A., and Huch, R. (2002). How well does reflectance pulse oximetry reflect intrapartum fetal acidosis? Am. J. Obst. Gynecol. 186, 1351-1357. doi: 10.1067/mob.2002.122411

Stoll, B. J., Hansen, N. I., Adams-Chapman, I., Fanaroff, A. A., Hintz, S. R., Vohr, B., et al. (2004). Neurodevelopmental and growth impairment among extremely low-birth-weight infants with neonatal infection. JAMA 292, 2357-2365. doi: 10.1001/jama.292.19.2357

Stolp, H. B., Liddelow, S. A., and Saunders, N. R. (2016). Editorial: ontogeny and phylogeny of brain barrier mechanisms. Front. Neurosci. 10:41. doi: 10.3389/ fnins.2016.00041

Stonestreet, B. S., Burgess, G. H., and Cserr, H. F. (1992). Blood-brain barrier integrity and brain water and electrolytes during hypoxia/hypercapnia and hypotension in newborn piglets. Brain Res. 590, 263-270. doi: 10.1016/00068993(92)91104-M

Stridh, L., Mottahedin, A., Johansson, M. E., Valdez, R. C., Northington, F., Wang, X., et al. (2013). Toll-like receptor-3 activation increases the vulnerability of the neonatal brain to hypoxia-ischemia. J. Neurosci. 33, 12041-12051. doi: 10.1523/JNEUROSCI.0673-13.2013

Stritt, C., Stern, S., Harting, K., Manke, T., Sinske, D., Schwarz, H., et al. (2009). Paracrine control of oligodendrocyte differentiation by SRF-directed neuronal gene expression. Nat. Neurosci. 12, 418-427. doi: 10.1038/nn. 2280

Stroemer, R. P., and Rothwell, N. J. (1998). Exacerbation of ischemic brain damage by localized striatal injection of interleukin-1beta in the rat. J. Cereb. Blood Flow Metab. 18, 833-839. doi: 10.1097/00004647-199808000-00003

Strunk, T., Hartel, C., Temming, P., Matzke, N., Zimmer, J., and Schultz, C. (2008). Erythropoietin inhibits cytokine production of neonatal and adult leukocytes. Acta Paediatr. 97, 16-20. doi: 10.1111/j.1651-2227.2007. 00560.x

Strunk, T., Inder, T., Wang, X., Burgner, D., Mallard, C., and Levy, O. (2014). Infection-induced inflammation and cerebral injury in preterm infants. Lancet Infect. Dis. 14, 751-762. doi: 10.1016/S1473-3099(14)70710-8

Suarez-Sola, M. L., Gonzalez-Delgado, F. J., Pueyo-Morlans, M., Medina-Bolivar, O. C., Hernandez-Acosta, N. C., Gonzalez-Gomez, M., et al. (2009). Neurons in the white matter of the adult human neocortex. Front. Neuroanat. 3:7. doi: 10.3389/neuro.05.007.2009

Svedin, P., Hagberg, H., Savman, K., Zhu, C., and Mallard, C. (2007). Matrix metalloproteinase-9 gene knock-out protects the immature brain after cerebral hypoxia-ischemia. J. Neurosci. 27, 1511-1518. doi: 10.1523/JNEUROSCI.439106.2007

Svedin, P., Kjellmer, I., Welin, A. K., Blad, S., and Mallard, C. (2005). Maturational effects of lipopolysaccharide on white-matter injury in fetal sheep. J. Child Neurol. 20, 960-964. doi: 10.1177/08830738050200120501

Tagin, M. A., Woolcott, C. G., Vincer, M. J., Whyte, R. K., and Stinson, D. A. (2012). Hypothermia for neonatal hypoxic ischemic encephalopathy: an updated systematic review and meta-analysis. Arch. Pediatr. Adolesc. Med. 166, 558-566. doi: 10.1001/archpediatrics.2011.1772 
Tahraoui, S. L., Marret, S., Bodenant, C., Leroux, P., Dommergues, M. A., Evrard, P., et al. (2001). Central role of microglia in neonatal excitotoxic lesions of the murine periventricular white matter. Brain Pathol. 11, 56-71. doi: 10.1111/j.1750-3639.2001.tb00381.x

Tajiri, N., Kaneko, Y., Shinozuka, K., Ishikawa, H., Yankee, E., McGrogan, M., et al. (2013). Stem cell recruitment of newly formed host cells via a successful seduction? Filling the gap between neurogenic niche and injured brain site. PLoS ONE 8:e74857. doi: 10.1371/journal.pone.0074857

Takada, S., dos Santos Haemmerle, C., Motta-Teixeira, L., Machado-Nils, A., Lee, V., Takase, L., et al. (2015). Neonatal anoxia in rats: hippocampal cellular and subcellular changes related to cell death and spatial memory. Neuroscience 284, 247-259. doi: 10.1016/j.neuroscience.2014.08.054

Takada, S. H., Motta-Teixeira, L. C., Machado-Nils, A. V., Lee, V. Y., Sampaio, C. A., Polli, R. S., et al. (2016). Impact of neonatal anoxia on adult rat hippocampal volume, neurogenesis and behavior. Behav. Brain Res. 296, 331-338. doi: 10.1016/j.bbr.2015.08.039

Takada, T., Takata, K., and Ashihara, E. (2016). Inhibition of monocarboxylate transporter 1 suppresses the proliferation of glioblastoma stem cells. J. Physiol. Sci. 66, 387-396. doi: 10.1007/s12576-016-0435-6

Takahashi, S., Tanaka, H., and Oki, J. (1999). Development of spinal motoneurons in rats after a neonatal hypoxic insult. Pediatr. Neurol. 21, 715-720. doi: 10.1016/S0887-8994(99)00080-6

Takao, K., and Miyakawa, T. (2015). Genomic responses in mouse models greatly mimic human inflammatory diseases. Proc. Natl. Acad. Sci. U.S.A. 112, 1167-1172. doi: 10.1073/pnas.1401965111

Takeoka, M., Soman, T. B., Yoshii, A., Caviness, V. S. Jr., Gonzalez, R. G., Grant, P. E., et al. (2002). Diffusion-weighted images in neonatal cerebral hypoxicischemic injury. Pediatr. Neurol. 26, 274-281. doi: 10.1016/S0887-8994(01) 00403-9

Talos, D. M., Fishman, R. E., Park, H., Folkerth, R. D., Follett, P. L., Volpe, J. J., et al. (2006). Developmental regulation of alpha-amino-3-hydroxy-5methyl-4-isoxazole-propionic acid receptor subunit expression in forebrain and relationship to regional susceptibility to hypoxic/ischemic injury. I. Rodent cerebral white matter and cortex. J. Comp. Neurol. 497, 42-60. doi: 10.1002/ cne. 20972

Tanaka, H., Takahashi, S., Miyamoto, A., Oki, J., Cho, K., and Okuno, A. (1995). Effects of neonatal hypoxia on brainstem cholinergic neuronspedunculopontine nucleus and laterodorsal tegmental nucleus. Brain Dev. 17, 264-270. doi: 10.1016/0387-7604(95)00043-B

Tang, Y., Pacary, E., Freret, T., Divoux, D., Petit, E., Schumann-Bard, P., et al. (2006). Effect of hypoxic preconditioning on brain genomic response before and following ischemia in the adult mouse: identification of potential neuroprotective candidates for stroke. Neurobiol. Dis. 21, 18-28. doi: 10.1016/j. nbd.2005.06.002

Tao, F., Lu, S. D., Zhang, L. M., Huang, Y. L., and Sun, F. Y. (2001). Role of excitatory amino acid transporter 1 in neonatal rat neuronal damage induced by hypoxia-ischemia. Neuroscience 102, 503-513. doi: 10.1016/S0306-4522(00) 00485-1

Teesalu, T., Kulla, A., Simisker, A., Sirén, V., Lawrence, D. A., Asser, T., et al. (2004). Tissue plasminogen activator and neuroserpin are widely expressed in the human central nervous system. Thromb. Haemost. 92, 358-368. doi: $10.1160 /$ th02-12-0310

Thompson, C., Puterman, A., Linley, L., Hann, F., Elst, C. V. D., Molteno, C., et al. (1997). The value of a scoring system for hypoxic ischaemic encephalopathy in predicting neurodevelopmental outcome. Acta Paediatr. 86, 757-761. doi: 10.1111/j.1651-2227.1997.tb08581.x

Thompson, D. K., Warfield, S. K., Carlin, J. B., Pavlovic, M., Wang, H. X., Bear, M., et al. (2007). Perinatal risk factors altering regional brain structure in the preterm infant. Brain 130(Pt 3), 667-677. doi: 10.1093/brain/awl277

Thoresen, M., Hobbs, C. E., Wood, T., Chakkarapani, E., and Dingley, J. (2009). Cooling combined with immediate or delayed xenon inhalation provides equivalent long-term neuroprotection after neonatal hypoxiaischemia. J. Cereb. Blood Flow Metab. 29, 707-714. doi: 10.1038/jcbfm. 2008.163

Ting, P., Yamaguchi, S., Bacher, J. D., Killens, R. H., and Myers, R. E. (1983). Hypoxic-ischemic cerebral necrosis in midgestational sheep fetuses: physiopathologic correlations. Exp. Neurol. 80, 227-245. doi: 10.1016/00144886(83)90019-5
Tjärnlund-Wolf, A., Olsson, S., Jood, K., Blomstrand, C., and Jern, C. (2011). No evidence for an association between genetic variation at the SERPINI1 locus and ischemic stroke. J. Neurol. 258, 1885. doi: 10.1007/s00415-011-6022-0

Toet, M. C., Hellstrom-Westas, L., Groenendaal, F., Eken, P., and de Vries, L. S. (1999). Amplitude integrated EEG 3 and 6 hours after birth in full term neonates with hypoxic-ischaemic encephalopathy. Arch. Dis. Child. Fetal Neonatal Ed. 81, F19-F23. doi: 10.1136/fn.81.1.f19

Toet, M. C., van der Meij, W., de Vries, L. S., Uiterwaal, C. S., and van Huffelen, K. C. (2002). Comparison between simultaneously recorded amplitude integrated electroencephalogram (cerebral function monitor) and standard electroencephalogram in neonates. Pediatrics 109, 772-779. doi: 10.1542/peds. 109.5.772

Tolner, E. A., Hochman, D. W., Hassinen, P., Otahal, J., Gaily, E., Haglund, M. M., et al. (2011). Five percent $\mathrm{CO}(2)$ is a potent, fast-acting inhalation anticonvulsant. Epilepsia 52, 104-114. doi: 10.1111/j.1528-1167.2010. 02731.x

Tomimatsu, T., Fukuda, H., Endoh, M., Mu, J., Watanabe, N., Kohzuki, M., et al. (2002). Effects of neonatal hypoxic-ischemic brain injury on skilled motor tasks and brainstem function in adult rats. Brain Res. 926, 108-117. doi: 10.1016/ S0006-8993(01)03311-X

Toso, L., Poggi, S., Park, J., Einat, H., Roberson, R., Dunlap, V., et al. (2005). Inflammatory-mediated model of cerebral palsy with developmental sequelae. Am. J. Obstet. Gynecol. 193(3 Pt 2), 933-941. doi: 10.1016/j.ajog.2005. 05.072

Towfighi, J., Yager, J., Housman, C., and Vannucci, R. (1991). Neuropathology of remote hypoxic-ischemic damage in the immature rat. Acta Neuropathol. 81, 578-587. doi: 10.1007/BF00310141

Towfighi, J., Zec, N., Yager, J., Housman, C., and Vannucci, R. C. (1995). Temporal evolution of neuropathologic changes in an immature rat model of cerebral hypoxia: a light microscopic study. Acta Neuropathol. 90, 375-386. doi: 10.1007/ BF00315011

Tran, T. V., and Weisman, L. E. (2004). Dexamethasone effects on group B streptococcal infection in newborn rats. Pediatr. Infect. Dis. J. 23, 47-52. doi: 10.1097/01.inf.0000105107.76541.ee

Tremblay, E., Roisin, M. P., Represa, A., Charriaut-Marlangue, C., and Ben-Ari, Y. (1988). Transient increased density of NMDA binding sites in the developing rat hippocampus. Brain Res. 461, 393-396. doi: 10.1016/0006-8993(88) 90275-2

Triulzi, F., Parazzini, C., and Righini, A. (2006). Patterns of damage in the mature neonatal brain. Pediatr. Radiol. 36, 608-620. doi: 10.1007/s00247-006-0203-5

Trommer, B. L., Groothuis, D. R., and Pasternak, J. F. (1987). Quantitative analysis of cerebral vessels in the newborn puppy: the structure of germinal matrix vessels may predispose to hemorrhage. Pediatr. Res. 22, 23-28. doi: 10.1203/ 00006450-198707000-00007

Tu, Y. F., Tsai, Y. S., Wang, L. W., Wu, H. C., Huang, C. C., and Ho, C. J. (2011). Overweight worsens apoptosis, neuroinflammation and blood-brain barrier damage after hypoxic ischemia in neonatal brain through JNK hyperactivation. J. Neuroinflammation 8:40. doi: 10.1186/1742-2094-8-40

Tuor, U., Chumas, P., and Del Bigio, M. (1995). Prevention of hypoxic-ischemic damage with dexamethasone is dependent on age and not influenced by fasting. Exp. Neurol. 132, 116-122. doi: 10.1016/0014-4886(95)90065-9

Tuor, U. I., and Grewal, D. (1994). Autoregulation of cerebral blood flow: influence of local brain development and postnatal age. Am. J. Physiol. 267(6 Pt 2), H2220-H2228.

Uehara, T., Tabuchi, M., and Mori, E. (1999). Risk factors for silent cerebral infarcts in subcortical white matter and basal ganglia. Stroke 30, 378-382. doi: 10.1161/ 01.STR.30.2.378

Ujhazy, E., Schmidtova, M., Dubovicky, M., Navarova, J., Brucknerova, I., and Mach, M. (2006). Neurobehavioural changes in rats after neonatal anoxia: effect of antioxidant stobadine pretreatment. Neuro Endocrinol. Lett. 27(Suppl. 2), 82-85.

Valiente, M., Obenauf, A. C., Jin, X., Chen, Q., Zhang, X. H., Lee, D. J., et al. (2014). Serpins promote cancer cell survival and vascular co-option in brain metastasis. Cell 156, 1002-1016. doi: 10.1016/j.cell.2014.01.040

van der Worp, H. B., Sena, E. S., Donnan, G. A., Howells, D. W., and Macleod, M. R. (2007). Hypothermia in animal models of acute ischaemic stroke: a systematic review and meta-analysis. Brain 130(Pt 12), 3063-3074. doi: 10.1093/brain/ awm 083 
van Laerhoven, H., de Haan, T. R., Offringa, M., Post, B., and van der Lee, J. H. (2013). Prognostic tests in term neonates with hypoxic-ischemic encephalopathy: a systematic review. Pediatrics 131, 88-98. doi: 10.1542/peds. 2012-1297

Vandenberg, R. J., and Ryan, R. M. (2013). Mechanisms of glutamate transport. Physiol. Rev. 93, 1621-1657. doi: 10.1152/physrev.00007.2013

Vannucci, R., Connor, J., Mauger, D., Palmer, C., Smith, M., Towfighi, J., et al. (1999). Rat model of perinatal hypoxic-ischemic brain damage. J. Neurosci. Res. 55, 158-163. doi: 10.1002/(SICI)1097-4547(19990115)55:2<158::AID-JNR3>3. $0 . \mathrm{CO} ; 2-1$

Vannucci, R. C., Brucklacher, R. M., and Vannucci, S. J. (2005). Glycolysis and perinatal hypoxic-ischemic brain damage. Dev. Neurosci. 27, 185-190. doi: 10.1159/000085991

Vannucci, R. C., Christensen, M. A., and Stein, D. T. (1989). Regional cerebral glucose utilization in the immature rat: effect of hypoxia-ischemia. Pediatr. Res. 26, 208-214. doi: 10.1203/00006450-198909000-00011

Vannucci, R. C., Christensen, M. A., and Yager, J. Y. (1993). Nature, time-course, and extent of cerebral edema in perinatal hypoxic-ischemic brain damage. Pediatr. Neurol. 9, 29-34. doi: 10.1016/0887-8994(93)90006-X

Vannucci, R. C., and Duffy, T. E. (1976). Carbohydrate metabolism in fetal and neonatal rat brain during anoxia and recovery. Am. J. Physiol. 230, 1269-1275.

Vannucci, R. C., Lyons, D. T., and Vasta, F. (1988). Regional cerebral blood flow during hypoxia-ischemia in immature rats. Stroke 19, 245-250. doi: 10.1161/01. STR.19.2.245

Vannucci, R. C., and Vannucci, S. J. (2005). Perinatal hypoxic-ischemic brain damage: evolution of an animal model. Dev. Neurosci. 27, 81-86. doi: 10.1159/ 000085978

Vannucci, R. C., and Yager, J. Y. (1992). Glucose, lactic acid, and perinatal hypoxicischemic brain damage. Pediatr. Neurol. 8, 3-12. doi: 10.1016/0887-8994(92) 90045-Z

Vannucci, S. J., and Hagberg, H. (2004). Hypoxia-ischemia in the immature brain. J. Exp. Biol. 207(Pt 18), 3149-3154. doi: 10.1242/jeb.01064

Vannucci, S. J., and Vannucci, R. C. (1980). Glycogen metabolism in neonatal rat brain during anoxia and recovery. J. Neurochem. 34, 1100-1105. doi: 10.1111/j. 1471-4159.1980.tb09946.x

Vargas-Origel, A., Espinosa-Garcia, J. O., Muniz-Quezada, E., Vargas-Nieto, M. A., and Aguilar-Garcia, G. (2004). Prevention of hypoxic-ischemic encephalopathy with high-dose, early phenobarbital therapy. Gac. Med. Mex. 140, 147-153.

Venerosi, A., Cutuli, D., Chiarotti, F., and Calamandrei, G. (2006). C-section birth per se or followed by acute global asphyxia altered emotional behaviour in neonate and adult rats. Behav. Brain Res. 168, 56-63. doi: 10.1016/j.bbr.2005. 10.010

Vento, M., Asensi, M., Sastre, J., Garcia-Sala, F., Pallardo, F. V., and Vina, J. (2001a). Resuscitation with room air instead of $100 \%$ oxygen prevents oxidative stress in moderately asphyxiated term neonates. Pediatrics 107, 642-647.

Vento, M., Asensi, M., Sastre, J., Garcia-Sala, F., and Vina, J. (2001b). Six years of experience with the use of room air for the resuscitation of asphyxiated newly born term infants. Biol. Neonate 79, 261-267.

Verma, P. K., Panerai, R. B., Rennie, J. M., and Evans, D. H. (2000). Grading of cerebral autoregulation in preterm and term neonates. Pediatr. Neurol. 23, 236-242. doi: 10.1016/S0887-8994(00)00184-3

Vermeulen, R. J., Fetter, W. P., Hendrikx, L., Van Schie, P. E., van der Knaap, M. S., and Barkhof, F. (2003). Diffusion-weighted MRI in severe neonatal hypoxic ischaemia: the white cerebrum. Neuropediatrics 34, 72-76. doi: 10.1055/s-200339599

Vincer, M. J., Allen, A. C., Joseph, K. S., Stinson, D. A., Scott, H., and Wood, E. (2006). Increasing prevalence of cerebral palsy among very preterm infants: a population-based study. Pediatrics 118, e1621-e1626. doi: 10.1542/peds.20061522

Vohr, B. R., Wright, L. L., Dusick, A. M., Mele, L., Verter, J., Steichen, J. J., et al. (2000). Neurodevelopmental and functional outcomes of extremely low birth weight infants in the National Institute of Child Health and Human Development Neonatal Research Network, 1993-1994. Pediatrics 105, 1216-1226. doi: 10.1542/peds.105.6.1216

Volpe, A. R., Petrone, M. E., De Vizio, W., Davies, R. M., and Proskin, H. M. (1996). A review of plaque, gingivitis, calculus and caries clinical efficacy studies with a fluoride dentifrice containing triclosan and PVM/MA copolymer. J. Clin. Den. 7(Suppl.), S1-S14.
Volpe, J. (ed.). (1995). "Hypoxic-ischemic encephalopathy: neuropathology and pathogenesis," in Neurology of the Newborn, (London: W B Saunders), 279-313.

Volpe, J. (2001). Hypoxic-Ischemic Encephalopathy in Neurology of the Newborn. Philadelphia, PA: WB Saunders.

Volpe, J. J. (1977). Neonatal seizures. Clin. Perinatol. 4, 43-63.

Volpe, J. J. (1989). Intraventricular hemorrhage in the premature infant-current concepts. Part I. Ann. Neurol. 25, 3-11. doi: 10.1002/ana.410250103

Volpe, J. J. (2008). Neurology of the Newborn. Philadelphia, PA: Elsevier Health Sciences.

Volpe, J. J. (2009). The encephalopathy of prematurity-brain injury and impaired brain development inextricably intertwined. Semin. Pediatr. Neurol. 16, 167-178. doi: 10.1016/j.spen.2009.09.005

Volpe, J. J. (2012). Neonatal encephalopathy: an inadequate term for hypoxic-ischemic encephalopathy. Ann. Neurol. 72, 156-166. doi: 10.1002/ana.23647

Waddell, J., Hanscom, M., Shalon Edwards, N., McKenna, M. C., and McCarthy, M. M. (2016). Sex differences in cell genesis, hippocampal volume and behavioral outcomes in a rat model of neonatal HI. Exp. Neurol. 275(Pt 2), 285-295. doi: 10.1016/j.expneurol.2015.09.003

Walsh, B. H., Murray, D. M., and Boylan, G. B. (2011). The use of conventional EEG for the assessment of hypoxic ischaemic encephalopathy in the newborn: a review. Clin. Neurophysiol. 122, 1284-1294. doi: 10.1016/j.clinph.2011.03.032

Wang, C. T., Lin, H. J., Cheng, B. C., Lin, M. T., and Chang, C. P. (2015). Attenuating systemic inflammatory markers in simulated highaltitude exposure by heat shock protein 70-mediated hypobaric hypoxia preconditioning in rats. J. Formos. Med. Assoc. 114, 328-338. doi: 10.1016/j. jfma.2012.11.015

Wang, L., Goldstein, F. C., Veledar, E., Levey, A. I., Lah, J. J., Meltzer, C. C., et al. (2009). Alterations in cortical thickness and white matter integrity in mild cognitive impairment measured by whole-brain cortical thickness mapping and diffusion tensor imaging. Am. J. Neuroradiol. 30, 893-899. doi: 10.3174/ajnr. A1484

Wang, L. S., Zhou, J., Shao, X. M., and Tang, X. C. (2002). Huperzine A attenuates cognitive deficits and brain injury in neonatal rats after hypoxia-ischemia. Brain Res. 949, 162-170. doi: 10.1016/S0006-8993(02)02977-3

Wang, S., Zhang, X. Q., Song, C. G., Xiao, T., Zhao, M., Zhu, G., et al. (2015). In vivo effects of bumetanide at brain concentrations incompatible with NKCC1 inhibition on newborn DGC structure and spontaneous EEG seizures following hypoxia-induced neonatal seizures. Neurosci. 286, 203-215. doi: 10.1016/j. neuroscience.2014.11.031

Wang, X., Hagberg, H., Nie, C., Zhu, C., Ikeda, T., and Mallard, C. (2007a). Dual role of intrauterine immune challenge on neonatal and adult brain vulnerability to hypoxia-ischemia. J. Neuropathol. Exp. Neurol. 66, 552-561.

Wang, X., Hagberg, H., Zhu, C., Jacobsson, B., and Mallard, C. (2007b). Effects of intrauterine inflammation on the developing mouse brain. Brain Res. 1144, 180-185. doi: 10.1016/j.brainres.2007.01.083

Wang, X., Rousset, C. I., Hagberg, H., and Mallard, C. (2006). Lipopolysaccharideinduced inflammation and perinatal brain injury. Semin. Fetal Neonatal Med. 11, 343-353. doi: 10.1016/j.siny.2006.04.002

Wang, X., Zhu, C., Qiu, L., Hagberg, H., Sandberg, M., and Blomgren, K. (2003). Activation of ERK1/2 after neonatal rat cerebral hypoxia-ischaemia. J. Neurochem. 86, 351-362. doi: 10.1046/j.1471-4159.2003.01838.x

Wannier-Morino, P., Rager, G., Sonderegger, P., and Grabs, D. (2003). Expression of neuroserpin in the visual cortex of the mouse during the developmental critical period. Eur. J. Neurosci. 17, 1853-1860. doi: 10.1046/j.1460-9568.2003. 02628.x

Ward, P., Counsell, S., Allsop, J., Cowan, F., Shen, Y., Edwards, D., et al. (2006). Reduced fractional anisotropy on diffusion tensor magnetic resonance imaging after hypoxic-ischemic encephalopathy. Pediatrics 117, e619-e630. doi: 10.1542/peds.2005-0545

Wasterlain, C. G. (1979). Does anoxemia play a role in the effects of neonatal seizures on brain growth? An experimental study in the rat. Eur. Neurol. 18, 222-229. doi: 10.1159/000115080

Watanabe, S., Fukuda, T., and Ueko, S. (1980). Changes in electroencephalogram of the rat following olfactory bulbectomy. Tohoku J. Exp. Med. 130, 41-48. doi: 10.1620/tjem.130.41

Weeke, L. C., Boylan, G. B., Pressler, R. M., Hallberg, B., Blennow, M., Toet, M. C., et al. (2016). Role of EEG background activity, seizure burden and 
MRI in predicting neurodevelopmental outcome in full-term infants with hypoxic-ischaemic encephalopathy in the era of therapeutic hypothermia. Eur. J. Paediatr. Neurol. 20, 855-864. doi: 10.1016/j.ejpn.2016.06.003

Welsh, F. A., O'Connor, M. J., Marcy, V. R., Spatacco, A. J., and Johns, R. L. (1982). Factors limiting regeneration of ATP following temporary ischemia in cat brain. Stroke 13, 234-242. doi: 10.1161/01.STR.13.2.234

Westphal, O. (1965). Bacterial lipopolysaccharide-extraction with phenol water and further application of procedure. Methods Carbohydr. Chem. 1, 83-91.

White, A. R., and Cappai, R. (2003). Neurotoxicity from glutathione depletion is dependent on extracellular trace copper. J. Neurosci. Res. 71, 889-897. doi: 10.1002/jnr.10537

Wigglesworth, J. S., and Pape, K. E. (1978). An integrated model for haemorrhagic and ischaemic lesions in the newborn brain. Early Hum. Dev. 2, 179-199. doi: 10.1016/0378-3782(78)90010-5

Williams, C. E., Gunn, A. J., Mallard, C., and Gluckman, P. D. (1992). Outcome after ischemia in the developing sheep brain: an electroencephalographic and histological study. Ann. Neurol. 31, 14-21. doi: 10.1002/ana.410310104

Wilson-Costello, D., Friedman, H., Minich, N., Siner, B., Taylor, G., Schluchter, M., et al. (2007). Improved neurodevelopmental outcomes for extremely low birth weight infants in 2000-2002. Pediatrics 119, 37-45. doi: 10.1542/peds.2006-1416

Woo, T. U., Beale, J. M., and Finlay, B. L. (1991). Dual fate of subplate neurons in a rodent. Cereb. Cortex 1, 433-443. doi: 10.1093/cercor/1.5.433

Wood, P. L. (1995). Microglia as a unique cellular target in the treatment of stroke: potential neurotoxic mediators produced by activated microglia. Neurol. Res. 17, 242-248. doi: 10.1080/01616412.1995.11740321

Wu, J., Echeverry, R., Guzman, J., and Yepes, M. (2010). Neuroserpin protects neurons from ischemia-induced plasmin-mediated cell death independently of tissue-type plasminogen activator inhibition. Am. J. Pathol. 177, 2576-2584. doi: 10.2353/ajpath.2010.100466

Wu, J., and Kaufman, R. J. (2006). From acute ER stress to physiological roles of the Unfolded Protein Response. Cell Death Differ. 13, 374-384. doi: 10.1038/sj. cdd. 4401840

Wyatt, J. S., Edwards, A. D., Azzopardi, D., and Reynolds, E. O. (1989). Magnetic resonance and near infrared spectroscopy for investigation of perinatal hypoxic-ischaemic brain injury. Arch. Dis. Child. 64, 953-963. doi: 10.1136/adc. 64.7_Spec_No.953

Xiong, M., Li, J., Ma, S., Yang, Y., and Zhou, W. (2013). Effects of hypothermia on oligodendrocyte precursor cell proliferation, differentiation and maturation following hypoxia ischemia in vivo and in vitro. Exp. Neurol. 247, 720-729. doi: 10.1016/j.expneurol.2013.03.015

Yager, J., Towfighi, J., and Vannucci, R. (1993). Influence of mild hypothermia on hypoxic-ischemic brain damage in the immature rat. Pediatr. Res. 34, 525-529. doi: 10.1203/00006450-199310000-00029

Yager, J. Y., and Ashwal, S. (2009). Animal models of perinatal hypoxic-ischemic brain damage. Pediatr. Neurol. 40, 156-167. doi: 10.1016/j.pediatrneurol.2008. 10.025

Yager, J. Y., Brucklacher, R. M., and Vannucci, R. C. (1991). Cerebral oxidative metabolism and redox state during hypoxia-ischemia and early recovery in immature rats. Am. J. Physiol. 261(4 Pt 2), H1102-H1108.

Yager, J. Y., Brucklacher, R. M., and Vannucci, R. C. (1996). Paradoxical mitochondrial oxidation in perinatal hypoxic-ischemic brain damage. Brain Res. 712, 230-238. doi: 10.1016/0006-8993(95)01423-3

Yager, J. Y., Heitjan, D. F., Towfighi, J., and Vannucci, R. C. (1992). Effect of insulin-induced and fasting hypoglycemia on perinatal hypoxic-ischemic brain damage. Pediatr. Res. 31, 138-142. doi: 10.1203/00006450-19920200000009

Yamamoto, H., Inaba, S., Nishiura, Y., Kishi, F., and Kawakami, Y. (1985). Acute inhalation of cigarette smoke augments hypoxic chemosensitivity in humans. $J$. Appl. Physiol. 58, 717-723.

Yamamoto, H., and Kato, T. (1986). The effect of neonatal anoxia on brain cholecystokinin-8-like immunoreactivity and monoamine levels of mature rats. Brain Res. 391, 285-288. doi: 10.1016/0165-3806(86)90294-4

Yamamoto, K., Yamamoto, Y., Fujimiya, T., and Okae, M. (1986). Effects of ethanol on the blood gas and acid-base state in hypoxic rats. Jpn. J. Legal Med. 40, 357-360.

Yang, D., and Kuan, C. (2015). Anti-tissue Plasminogen Activator (tPA) as an Effective Therapy of Neonatal Hypoxia-Ischemia with and without
Inflammation. CNS Neurosci. Ther. 21, 367-373. doi: 10.1111/cns. 12365

Yang, D., Li, S. Y., Yeung, C. M., Chang, R. C. C., So, K. F., Wong, D., et al. (2012). Lycium barbarum extracts protect the brain from blood-brain barrier disruption and cerebral edema in experimental stroke. PLoS ONE 7:e33596. doi: 10.1371/journal.pone.0033596

Yang, D., Sun, Y. Y., Lin, X., Baumann, J. M., Warnock, M., Lawrence, D. A., et al. (2013a). Taming neonatal hypoxic-ischemic brain injury by intranasal delivery of plasminogen activator inhibitor-1. Stroke 44, 2623-2627. doi: 10.1161/STROKEAHA.113.001233

Yang, D., Sun, Y. Y., Nemkul, N., Baumann, J. M., Shereen, A., Dunn, R. S., et al. (2013b). Plasminogen activator inhibitor-1 mitigates brain injury in a rat model of infection-sensitized neonatal hypoxia-ischemia. Cereb. Cortex 23, 1218-1229. doi: 10.1093/cercor/bhs115

Yao, L., Kan, E. M., Kaur, C., Dheen, S. T., Hao, A., Lu, J., et al. (2013). Notch-1 signaling regulates microglia activation via NF-kappaB pathway after hypoxic exposure in vivo and in vitro. PLoS ONE 8:e78439. doi: 10.1371/journal.pone. 0078439

Yazaki, M., Liepnieks, J. J., Murrell, J. R., Takao, M., Guenther, B., Piccardo, P., et al. (2001). Biochemical characterization of a neuroserpin variant associated with hereditary dementia. Am. J. Pathol. 158, 227-233. doi: 10.1016/S0002-9440(10) 63961-2

Yepes, M. (2015). Tissue-type plasminogen activator is a neuroprotectant in the central nervous system. Front. Cell. Neurosci. 9:304. doi: 10.3389/fncel.2015. 00304

Yepes, M., and Lawrence, D. A. (2004a). Neuroserpin: a selective inhibitor of tissuetype plasminogen activator in the central nervous system. Thromb. Haemost. 91, 457-464. doi: 10.1160/th03-12-0766

Yepes, M., and Lawrence, D. A. (2004b). New functions for an old enzyme: nonhemostatic roles for tissue-type plasminogen activator in the central nervous system. Exp. Biol. Med. 229, 1097-1104.

Yepes, M., and Lawrence, D. A. (2004c). Tissue-type plasminogen activator and neuroserpin: a well-balanced act in the nervous system? Trends Cardiovasc. Med. 14, 173-180.

Yepes, M., Sandkvist, M., Coleman, T. A., Moore, E., Wu, J. Y., Mitola, D., et al. (2002). Regulation of seizure spreading by neuroserpin and tissuetype plasminogen activator is plasminogen-independent. J. Clin. Invest. 109, 1571-1578. doi: 10.1172/JCI0214308

Yepes, M., Sandkvist, M., Wong, M. K., Coleman, T. A., Smith, E., Cohan, S. L., et al. (2000). Neuroserpin reduces cerebral infarct volume and protects neurons from ischemia-induced apoptosis. Blood 96, 569-576.

Yoon, B. H., Kim, C. J., Romero, R., Jun, J. K., Park, K. H., Choi, S. T., et al. (1997). Experimentally induced intrauterine infection causes fetal brain white matter lesions in rabbits. Am. J. Obstet. Gynecol. 177, 797-802. doi: 10.1016/S00029378(97)70271-0

You, Y., and Kaur, C. (2000). Expression of induced nitric oxide synthase in amoeboid microglia in postnatal rats following an exposure to hypoxia. Neurosci. Lett. 279, 101-104. doi: 10.1016/S0304-3940(99) 00967-2

Yuan, T. M., Yu, H. M., Gu, W. Z., and Li, J. P. (2005). White matter damage and chemokine induction in developing rat brain after intrauterine infection. J. Perinatal Med. 33, 415-422. doi: 10.1515/JPM.2005.074

Zanelli, S., Goodkin, H. P., Kowalski, S., and Kapur, J. (2014). Impact of transient acute hypoxia on the developing mouse EEG. Neurobiol. Dis. 68, 37-46. doi: 10.1016/j.nbd.2014.03.005

Zeinieh, M. P., Talhouk, R. S., El-Sabban, M. E., and Mikati, M. A. (2010). Differential expression of hippocampal connexins after acute hypoxia in the developing brain. Brain Dev. 32, 810-817. doi: 10.1016/j.braindev.2009. 11.003

Zeinstra, E., Fock, J. M., Begeer, J. H., van Weerden, T. W., Maurits, N. M., and Zweens, M. J. (2001). The prognostic value of serial EEG recordings following acute neonatal asphyxia in full-term infants. Eur. J. Paediatr. Neurol. 5, 155-160. doi: 10.1053/ejpn.2001.0496

Zhang, C. P., Zhu, L. L., Zhao, T., Zhao, H., Huang, X., Ma, X., et al. (2006). Characteristics of neural stem cells expanded in lowered oxygen and the potential role of hypoxia-inducible factor-1Alpha. Neurosignals 15, 259-265. doi: $10.1159 / 000103385$ 
Zhang, Q., Ding, Y., Yao, Y., Yu, Y., Yang, L., and Cui, H. (2013). Creating rat model for hypoxic brain damage in neonates by oxygen deprivation. PLoS ONE 8:e83589. doi: 10.1371/journal.pone.0083589

Zhang, Q., Yuan, L., Liu, D., Wang, J., Wang, S., Zhang, Q., et al. (2014). Hydrogen sulfide attenuates hypoxia-induced neurotoxicity through inhibiting microglial activation. Pharmacol. Res. 84, 32-44. doi: 10.1016/j.phrs.2014. 04.009

Zhang, X., Zhang, Q., Li, W., Nie, D., Chen, W., Xu, C., et al. (2014). Therapeutic effect of human umbilical cord mesenchymal stem cells on neonatal rat hypoxic-ischemic encephalopathy. J. Neurosci. Res. 92, 35-45. doi: 10.1002/jnr. 23304

Zhang, Y., He, K., Wang, F., Li, X., and Liu, D. (2015). Notch-1 signaling regulates astrocytic proliferation and activation after hypoxia exposure. Neurosci. Lett. 603, 12-18. doi: 10.1016/j.neulet.2015.07.009

Zhang, Z., Zhang, L., Yepes, M., Jiang, Q., Li, Q., Arniego, P., et al. (2002). Adjuvant treatment with neuroserpin increases the therapeutic window for tissue-type plasminogen activator administration in a rat model of embolic stroke. Circulation 106, 740-745. doi: 10.1161/01.CIR.0000023942.10 849.41

Zhao, B. Q., Tejima, E., and Lo, E. H. (2007). Neurovascular proteases in brain injury, hemorrhage and remodeling after stroke. Stroke 38(Suppl. 2), 748-752. doi: 10.1161/01.STR.0000253500.32979.d1

Zheng, T., and Weiss, M. D. (2013). Neonatal transplant in hypoxic injury. Methods Mol. Biol. 1059, 147-156. doi: 10.1007/978-1-62703-574-3_13

Zheng, X. R., Zhang, S. S., Yin, F., Tang, J. L., Yang, Y. J., Wang, X., et al. (2012). Neuroprotection of VEGF-expression neural stem cells in neonatal cerebral palsy rats. Behav. Brain Res. 230, 108-115. doi: 10.1016/j.bbr.2012 01.026

Zhou, C., Lippman, J. J., Sun, H., and Jensen, F. E. (2011). Hypoxia-induced neonatal seizures diminish silent synapses and long-term potentiation in hippocampal CA1 neurons. J. Neurosci. 31, 18211-18222. doi: 10.1523/ JNEUROSCI.4838-11.2011

Zhu, C., Kang, W., Xu, F., Cheng, X., Zhang, Z., Jia, L., et al. (2009). Erythropoietin improved neurologic outcomes in newborns with hypoxicischemic encephalopathy. Pediatrics 124, e218-e226. doi: 10.1542/peds.20083553

Zhu, C., Xu, F., Wang, X., Shibata, M., Uchiyama, Y., Blomgren, K., et al. (2006). Different apoptotic mechanisms are activated in male and female brains after neonatal hypoxia-ischaemia. J. Neurochem. 96, 1016-1027. doi: 10.1111/j.14714159.2005.03639.x

Conflict of Interest Statement: The authors declare that the research was conducted in the absence of any commercial or financial relationships that could be construed as a potential conflict of interest.

Copyright (C) 2017 Millar, Shi, Hoerder-Suabedissen and Molnár. This is an openaccess article distributed under the terms of the Creative Commons Attribution License (CC BY). The use, distribution or reproduction in other forums is permitted, provided the original author(s) or licensor are credited and that the original publication in this journal is cited, in accordance with accepted academic practice. No use, distribution or reproduction is permitted which does not comply with these terms. 